University of San Diego

Digital USD

2010

\title{
An Investigation into Digital Media: Characteristics of Learning Objects which K-12 Teachers Determine Meet their Instructional Needs
}

Patricia Ann Guthrie EdD

University of San Diego

Follow this and additional works at: https://digital.sandiego.edu/dissertations

Part of the Leadership Studies Commons

\section{Digital USD Citation}

Guthrie, Patricia Ann EdD, "An Investigation into Digital Media: Characteristics of Learning Objects which K-12 Teachers Determine Meet their Instructional Needs" (2010). Dissertations. 898.

https://digital.sandiego.edu/dissertations/898

This Dissertation: Open Access is brought to you for free and open access by the Theses and Dissertations at Digital USD. It has been accepted for inclusion in Dissertations by an authorized administrator of Digital USD. For more information, please contact digital@sandiego.edu. 


\title{
AN INVESTIGATION INTO DIGITAL MEDIA: CHARACTERISTICS OF \\ LEARNING OBJECTS WHICH K-12 TEACHERS DETERMINE MEET THEIR INSTRUCTIONAL NEEDS
}

\author{
by \\ Patricia Ann Guthrie \\ A Dissertation Submitted to the Faculty of \\ San Diego State University and the University of San Diego \\ in Partial Fulfillment \\ of the Requirements for the Degree \\ Doctor of Education
}

Dissertation Committee:

Bernard J. Dodge, Ph.D., San Diego State University

Douglas Fisher, Ph.D., San Diego State University Viviana Alexandrowicz, Ph.D., University of San Diego

Spring 2010 
Copyright (C) 2010

by

Patricia Ann Guthrie

All Rights Reserved 


\section{DEDICATION}

To my mom, who was always so proud of my accomplishments and my dad, who would have been. To my son, who is. 
You must be the change you want to see in the world.

-Mahatma Gandhi 


\title{
ABSTRACT OF THE DISSERTATION
}

\author{
An Investigation into Digital Media: Characteristics of Learning \\ Objects which K-12 Teachers Determine Meet Their Instructional \\ Needs \\ by \\ Patricia Ann Guthrie \\ Doctor of Education
}

San Diego State University and the University of San Diego, 2010

In recent years, learning objects have emerged as an instructional tool for teachers. Digital libraries and collections provide teachers with free or fee-base access to a variety of learning objects from photos and famous speeches to Flash animations and interactive Java Applets. Learning objects offer opportunities for students to interact with digital media in ways that can bring concepts and ideas to life. Students can visualize what changes in matter might look like and practice math skills like multiplying decimals. They can even receive instant feedback and interact with tutorials as many times as needed.

The purpose of this mixed methods study is to examine how K-12 teachers determine the characteristics of learning objects that meet their instructional needs. Capturing snapshots of what characteristics of learning objects that successful K-12 teachers select may lead to a clearer picture that could advance the use of learning objects in the classroom. By incorporating learning objects into their instructional practices, teachers can enhance their instruction as well as demonstrate to media savvy students how to use readily available learning objects to express and communicate what they've learned.

In order to identify the characteristics of learning objects that teachers deem useful, a small sample of K-12 teachers experienced in using learning objects were interviewed using the Repertory Grid Technique. This technique is used to elicit personal constructs. In this study, a representative group of learning objects were examined to elicit constructs or characteristics about learning objects with regard to instructional use. The resulting learning object characteristics were analyzed to determine if the characteristics deemed useful by teachers are aligned to the characteristics that learning object designers use. 


\section{TABLE OF CONTENTS}

PAGE

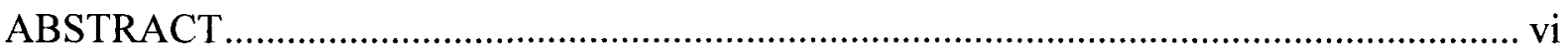

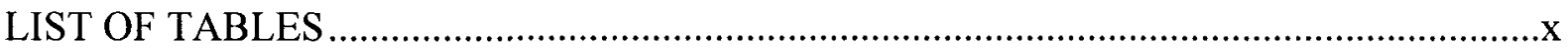

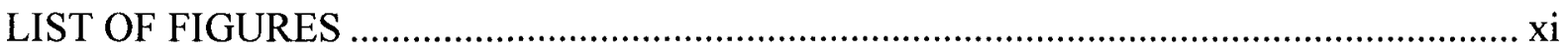

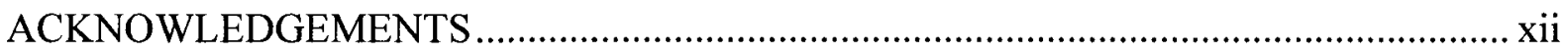

CHAPTER

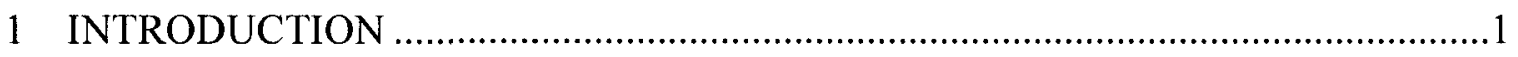

Background to the Study .................................................................................

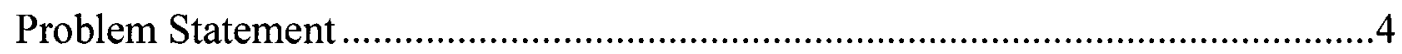

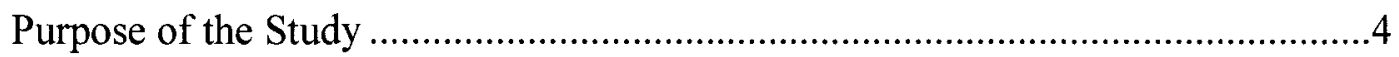

Research Questions ........................................................................................

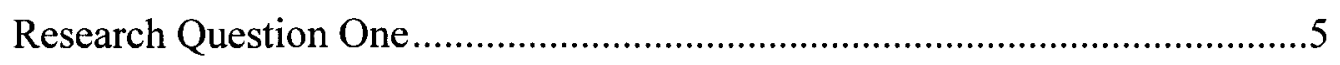

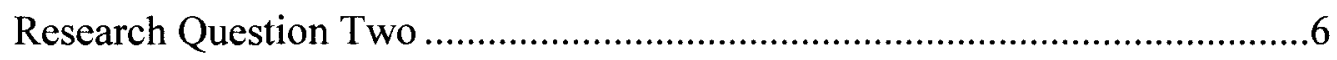

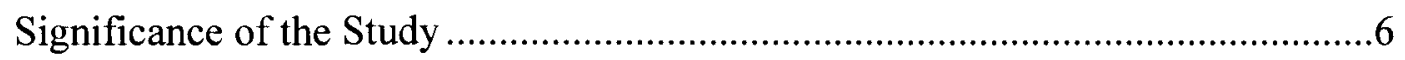

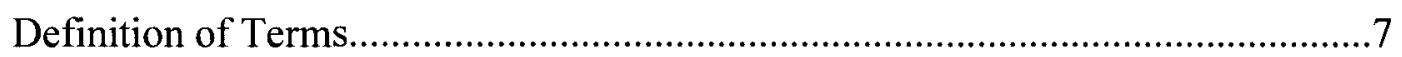

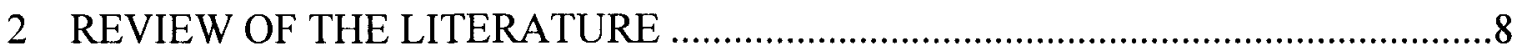

TEACHER THINKING, DECISION MAKING, AND PLANNING .....................8

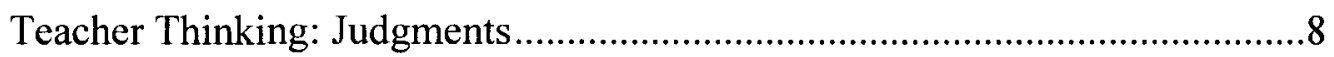

Teacher Decision Making and Planning ........................................................10

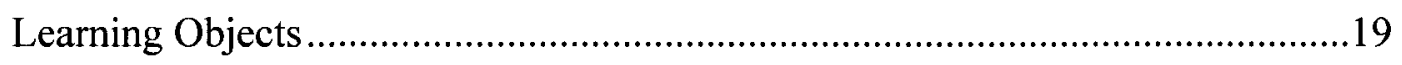

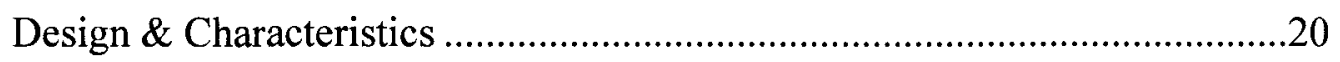

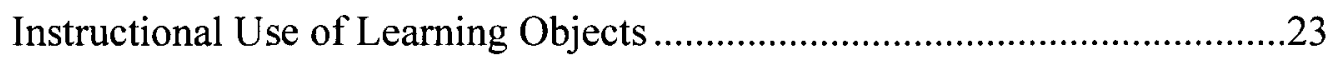


Lessons from Children's Programming Studies ……………..............................25

Personal Construct Theory and the Repertory Grid Technique...............................26

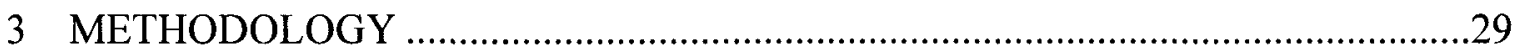

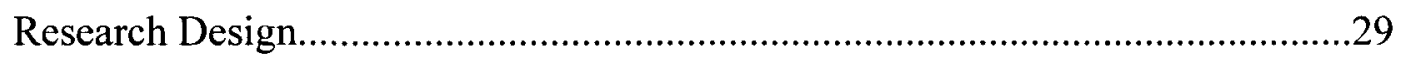

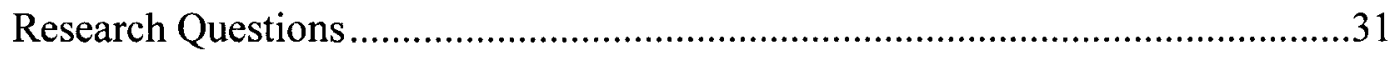

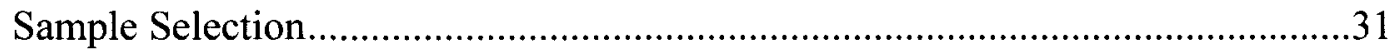

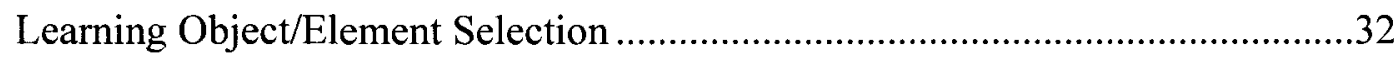

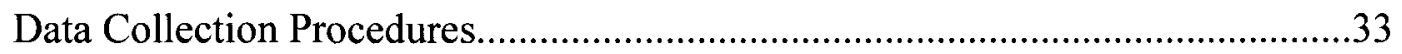

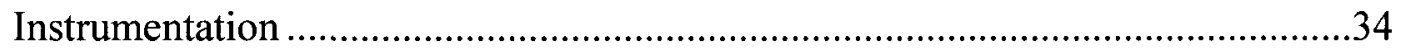

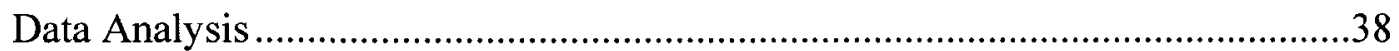

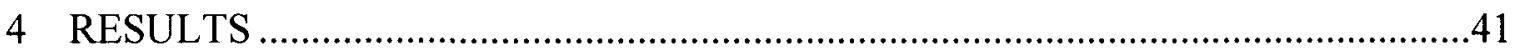

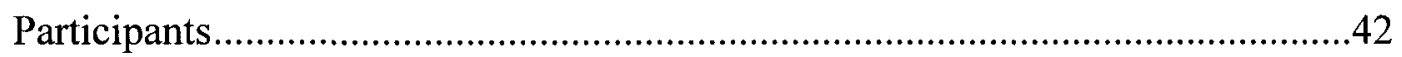

Data Analysis Procedures and Findings ...............................................................4

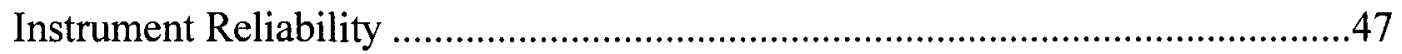

Research Question One Results ....................................................................49

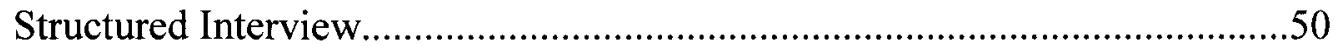

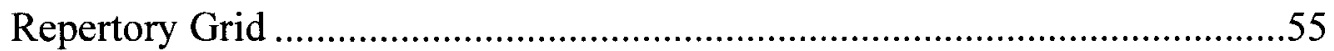

FOCUS (Hierarchical) Cluster Analysis....................................................56

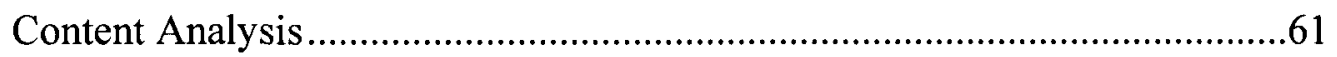

Summary of Research Question One Results .........................................................68

Research Question Two Results .........................................................................78

Summary of Research Question Two Results ........................................................85

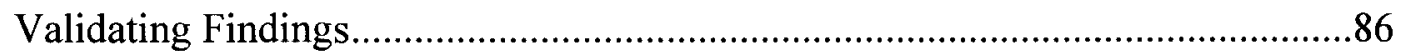

5 DISCUSSION

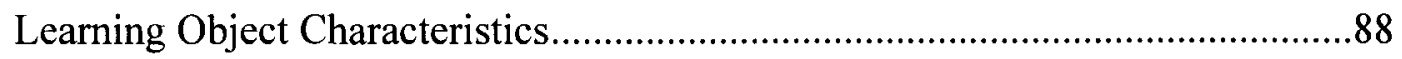




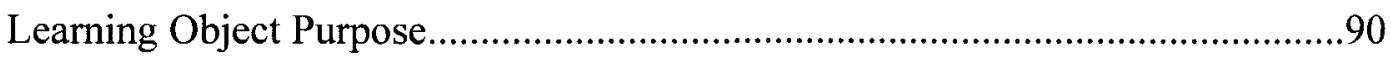

Learning Objects For Specific Students ............................................................ 91

Learning Object Design Characteristics ............................................................93

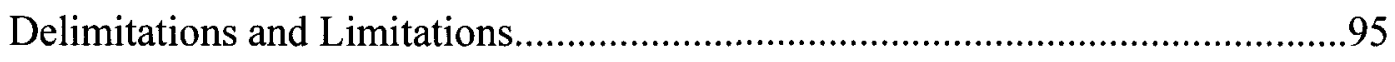

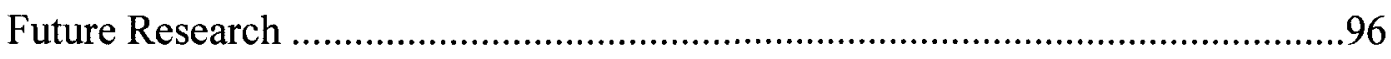

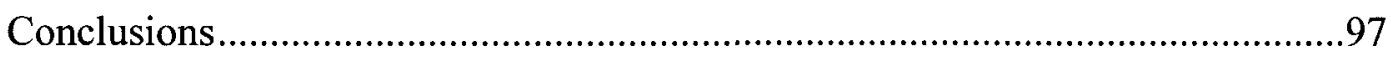

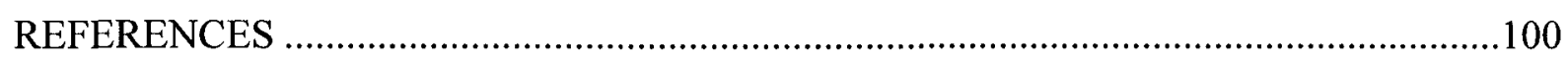
APPENDICES

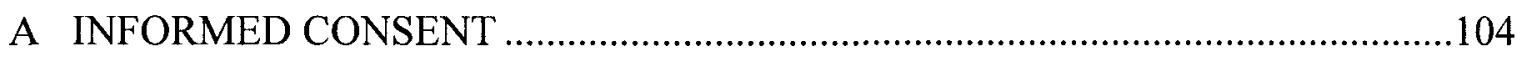

B LEARNING OBJECT QUICK REFERENCE ........................................................108

C REPERTORY GRID INSTRUMENT AND STRUCTURED INTERVIEW............111

D SUMMARY OF FOCUS CLUSTER CONSTRUCT CORRELATIONS OF

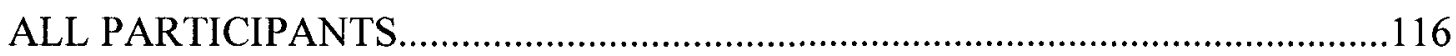

E CATEGORIES OF CONSTRUCTS OR LEARNING OBJECT

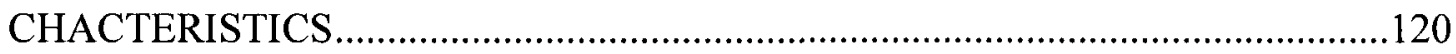

F LEARNING OBJECT INSTRUMENT ..............................................................129 


\section{LIST OF TABLES}

PAGE

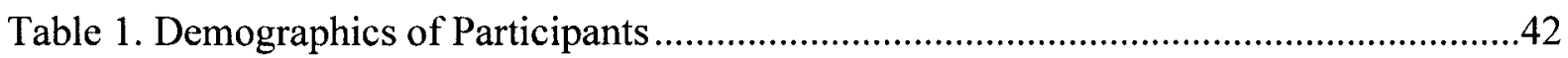

Table 2. Content Analysis - Percentage of Agreement ………………....................................48

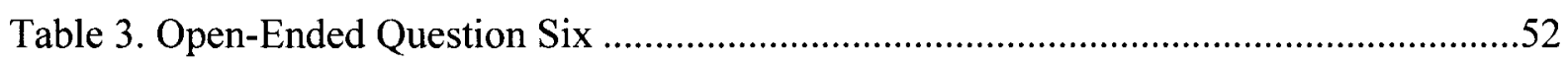

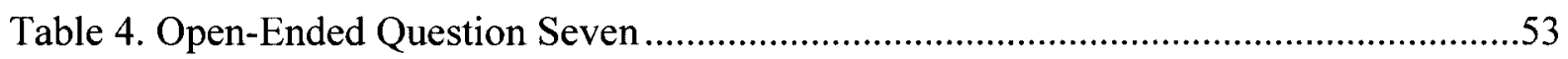

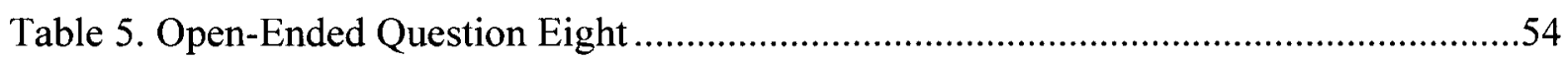

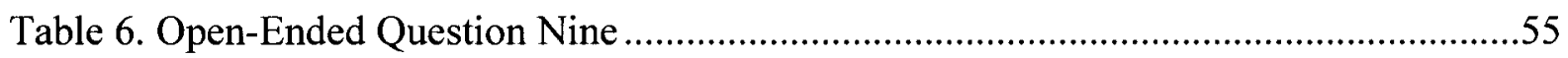

Table 7. Summary of FOCUS Cluster Construct Correlations of All Participants .................60

Table 8. Thinking \& Learning Category Sort .........................................................................6

Table 9. Thinking \& Learning Category............................................................................66

Table 10. Learning Object Design Category …………........................................................68

Table 11. Thinking \& Learning Category with Specific Students: ELL, LP, LD, \& GATE

Table 12. Learning Object Design Category with Specific Students: ELL, LP, LD, \& GATE

Table 12. Learning Object Design Category with Specific Students: ELL, LP, LD, \& GATE (continued)

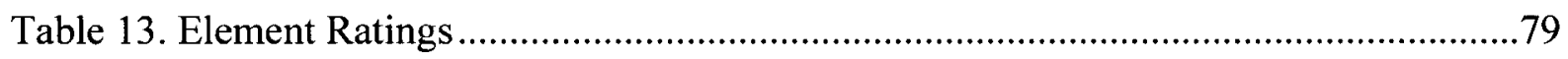

Table 14. Comparison of LORI and Teacher Defined Learning Object Characteristics..........81

Table 15. Categories of Learning Object Characteristics .......................................................90 


\section{LIST OF FIGURES}

PAGE

Figure 1. Shavelson \& Stern Decision Model.

Figure 2. Adapted Shavelson \& Sterns' Decision Model (Changes in the model are italicized).

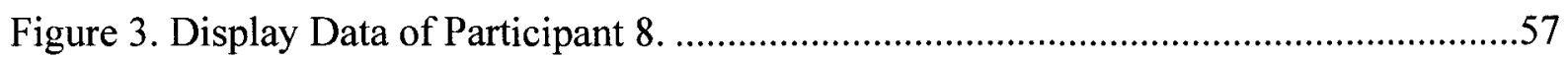

Figure 4. FOCUS V-branch Dendrogram of Participant 002 ..........................................59 


\section{ACKNOWLEDGEMENTS}

To my son, who has always believed in me and encouraged me. Love and hugs to my family: Alyssa, Karie, Sean, Souk, Jake, Remee, and Jakob, with whom I am most blessed. Thanks to my pals - my Lunch Buddies, who have always supported my efforts and have been my biggest cheerleaders. Thanks to my participants who generously donated their time and expertise. Many thanks to so many people that I work with who have encouraged me and teased me endlessly. A very special thank you to Doug, who taught me so much about qualitative statistics and encouraged me in my journey. Thank you, Viviana, for collaborating about teaching. Lastly, thank you, Bernie, for your patience, inspiration, belief in me, and never-ending support. You are a role model of always pushing the envelope and trying to figure out ways to support and interest teachers and ultimately, students, in the learning journey. I admire you and appreciate the visionary that you are. 


\section{CHAPTER 1}

\section{INTRODUCTION}

\section{BACKGROUND TO THE STUdY}

Teachers today face the necessity of customizing learning opportunities in order to address the needs of their students. This goal may seem overwhelming at times but could be made more doable if teachers use digital media or learning objects in their instructional practice. What separates most digital media from learning objects is their purpose. Learning objects are digital media used to support learning (Wiley, 2002). However, digital media can include digital photos of a vacation or an animated Flash advertisement, both of which are not used to support learning. Unlike print resources such as books, textbooks, and magazines, learning objects can be customized and reused or repurposed. The customizable and reusable aspects of learning objects are what make them attractive to teachers as they can be customized to meet the learning needs of different students. For example, a digital video clip of a wagon train can be used in a first grade classroom to demonstrate a mode of transportation from long ago, thus addressing a First Grade California History-Social Studies Standard. This same clip can also be used in a fifth grade classroom to demonstrate how people traveled west along the Oregon Trail. In this case, the fifth grade teacher is using the learning object to develop his students' background knowledge of the Westward Movement, a Fifth Grade California History-Social Studies standard. The level of sophistication of the fifth grade learning object may even include a "voice over" of the teacher narrating pertinent information in the video clip. Such examples illustrate how teachers may effectively use 
learning objects to customize instruction and learning opportunities for their students.

Besides being customizable and reusable, another advantage of using learning objects in instruction is their availability. They are readily available on the Internet through digital libraries (free and fee-based) and educational collaborations between universities and K-12 schools. While access to the Internet was once an obstacle as schools did not have the infrastructure, it no longer presents a barrier. $99 \%$ of all public schools have Internet access (Kleiner \& Lewis, 2003). With Internet access, schools can subscribe to commercial digital libraries which house learning objects that teachers may access and use freely for instructional purposes. In addition, teachers can share learning objects that they and their students have created, thereby sharing the wealth. By sharing their learning objects, teachers can help prevent the reinventing of the wheel, a common complaint among teachers who find themselves reproducing instructional materials that others have created. Teacher or student created learning objects may also be uploaded to a school's intranet or to a digital library. Alternatively, teachers can upload or post their learning objects to one of many educational services such as the Multimedia Educational Resource for Learning and Online Teaching (MERLOT) or to the National Science Digital Library (NSDL), a National Science Foundation project. Membership in both initiatives is free and members may freely upload or download learning objects.

The use of learning objects in instruction needs to be grounded in instructional design theory (Wiley, 2002). Using learning objects in instruction does not guarantee that learning occurs, just as using a book in the classroom doesn't guarantee literacy. It is the student interaction with the learning object or book that promotes learning. Instructional theory, as Reigeluth (1999) states, “... describes a variety of methods of instruction (different ways of 
facilitating human learning and development) and when to use--and not use--each of those methods." According to Wiley (2002), the successful use of learning objects is grounded in decisions of instructional sequencing. Sequencing, in instructional design terms, defines how learning objects are combined to make instructional sense. By using sound instructional design strategies, teachers can use learning objects in intentional ways to help meet the learning needs of their students.

Today's students, the "Net Generation" - learners born in the 1980s or later, have grown up with a variety of technology. According to Oblinger and Oblinger (2005), Net Gen learners, youth aged 13 to 17 years, spend an average of 3.1 hours a day watching TV and 3.5 hours using digital media such as the computer, video games, and the Internet (p.13). Roberts, Foehr, and Rideout (2005) report that children, in the 8-18 year-old range, spend over one-quarter of their day using media, making this generation the "media" generation (p.60). Whether we call children in this similar age range the Net Generation or the Media Generation, it is clear that these learners interact and communicate using technologies that many teachers did not use when they were learners or when they were in teacher preparation programs. By incorporating learning objects into their instructional practices, teachers may enhance their instruction as well as demonstrate to media savvy students how to use readily available learning objects to express and communicate what they've learned.

Like all instructional materials, learning objects must meet educational objectives that lead toward students passing state standards. As learning objects are so numerous, it is challenging to determine which learning object best meets a given set of instructional goals. It is critical for teachers to be discerning when selecting appropriate learning objects. Determining the characteristics of learning objects that may enhance learning experiences for 
specific students is important because some learning objects, just like some reading material, may be over a student's head or not challenging enough, or simply "too dry" to engage the student. So what makes one learning object more desirable or useful than another? What decisions do teachers make when deciding to use learning objects? This study focuses on the characteristics of learning objects that K-12 teachers use to determine how to meet their instructional purposes.

\section{Problem Statement}

Current discussion and research on learning objects have involved defining related terms, management issues such as size (granularity) or labeling (metadata), and how learning objects are used in various applications and industries. However, little research has been conducted regarding the instructional decisions that teachers make when determining which learning objects they use and how they will use it. Yet, innovative teachers are using learning objects in their instruction as teaching tools and leading their students to use them in constructing and communicating new understandings. With this in mind, several questions surface, such as how do experienced K-12 teachers determine what learning object should be used, how it should be used, and when it is appropriate to use? What characteristics of learning objects do they perceive as lending themselves to greater usability or reusability? Are there are different characteristics of learning objects more appropriate for specific groups of learners or are learning objects selected based on their fit for all learners?

\section{Purpose OF THE STUdY}

The purpose of this mixed methods study is to examine the phenomenon of how experienced K-12 teachers determine which learning objects meet their instructional 
purposes. Teachers experienced in using learning objects in their instruction have skills and instructional strategies that other teachers can acquire. In order to identify the characteristics of learning objects that teachers deem useful, a small sample of eight K-12 teachers experienced in using learning objects were interviewed using the Repertory Grid Technique. This technique is used to elicit personal constructs. George Kelly, a clinical psychologist, first put forth personal construct theory in 1955 (Stewart, 2005). Kelly believed that a person's experiences and observations helped to formulate his constructs, his perceptions and beliefs about the world. In this study, a representative sample of learning objects were examined to elicit constructs or characteristics teachers have about learning objects with regard to instructional usage. The resulting learning object profile was examined by the sample teachers to determine if it reflected the characteristics they'd deemed useful for their instructional purposes. In order to ascertain the quality of the representative group of learning objects, three expert learning object designers rated them on a scale used to measure the quality of learning objects. Lastly, the characteristics of the learning objects elicited from the sample teachers were analyzed to see how they correlated to key characteristics identified by learning object designers.

\section{RESEARCH QUESTIONS}

This study examined the following research questions:

\section{Research Question One}

RQ1: What are the important characteristics of learning objects that K-12 teachers determine useful for their instructional purposes?

RQIa. Do teachers discern that the purpose of some characteristics of learning 
objects are more appropriate for:

- conceptual development;

- skill development; and/or

- content information?

RQ1b. Do K-12 teachers use specific characteristics of learning objects for specific learners?

\section{Research Question Two}

RQ2: How well do the characteristics of learning objects that teachers determine useful relate to traditional design characteristics of learning objects, i.e. reusability, granularity, adaptability, interoperability, accessibility, and discoverability?

\section{Significance OF THE STUdy}

As learning objects are a relatively new development, the research on what characteristics successful teachers use to determine the usefulness of learning objects is limited. This study will add to this body of research. Analyzing the instructional decisions experienced K-12 teachers make, regarding learning object usage, can assist other teachers in productively accessing, using, reusing, and creating learning objects to design lessons enhanced by technology to better meet their student's instructional needs. By definition, a learning object's purpose is to advance or facilitate student learning. Therefore, it is pertinent to determine the characteristics of learning objects that teachers experienced in their usage find the most useful in their lessons. Capturing snapshots of the kinds of decisions that experienced K-12 teachers make may lead to recommendations that advance the effective use of learning objects in schools. 


\section{DEFINITION OF TERMS}

Learning Objects: Digital media whose purpose is to support learning.

Accessibility: The ability of a learning object to be accessed - online and/or downloadable is the usual means.

Adaptability: The ability of learning objects to be adapted or tailored to meet specific learner or situational needs is an attractive characteristic for teachers.

Discoverability: The ability of a learning object to be easily located, i.e. such as on search engines.

Granularity: In terms of learning objects, granularity refers to its size. The more granular a learning object is, the smaller it is, and the less tied to a specific learning context.

Interoperability: The ability of a learning object to be used on multiple systems, commonly called the "plug and play" feature.

Metadata: The descriptors about a learning object such as the type of learning object it is, i.e. online, QuickTime movie, interactive capabilities, etc... This is similar to the keyword features of search engines.

Reusable/Repurposed: A characteristic of learning objects is their ability to be used in different contexts and for different purposes. For example, teachers of different grade levels or subject matter may use the same learning object in different contexts. A painting might be used demonstrate a specific type of artistic style in an art class while the same painting might be used as an example of the way people lived in a particular period of time in a history-social science class. 


\section{CHAPTER 2}

\section{REVIEW OF THE LITERATURE}

\section{Teacher Thinking, Decision Making, and Planning}

Throughout the 1970s and early 1980s, researchers investigated teacher thinking, decision making, and planning. While many researchers focused on a single aspect of teaching such as teacher decision making, the studies as a whole reflect the complex nature of the profession. Teacher planning cannot be investigated without studying the decisions or thinking that teachers do while planning. For that reason, a review of the research includes a discussion of these three aspects of teaching.

\section{Teacher Thinking: Judgments}

Teachers make judgments about their students and what they believe to be effective teaching. Clark and Yinger (1977), in a review of research on teacher thinking, suggested that teacher judgment plays an important part in predicting the achievement and affective outcomes of students. Judgments are made regarding students: what they know, what their behavior indicates, what their academic abilities are, and what they need to achieve.

Teachers also make judgments about what is "effective teaching". Anderson (1977) studied high school teachers to determine what characteristics were most important in determining effective teaching. The characteristics of effective teaching were, “... interest in individual students, content knowledge, and clarity of explanations" (Clark \& Yinger, p. 286). Instructional judgments include what to teach, what materials are appropriate for their 
lessons, and what strategies would be most effective.

In another study, Clark, Wildfong, and Yinger (1978) researched what features of language arts teaching activities would teachers find useful (as cited in Clark \& Yinger, p. 289). Fourteen experienced elementary teachers rated 26 language arts activities on their attractiveness in using the activity in their classroom. Each teacher listed the features of the activities that they rated as highly attractive. Then two researchers categorized the features independently and compared the results. The resulting categories fell into four headings that activities relate to: students, subject matter, teacher, and learning environment. The judgments that teachers most frequently mentioned were those relating to student behavior. Activities were most often accepted or rejected based on teacher judgment of whether it motivated and encouraged student involvement. The third and fourth most frequently mentioned categories were whether or not the activity influenced student cognitive and affective outcomes, respectively. Overall, the highest rated activities were those rated high in student motivation and involvement, low in difficulty, and high in teacher's perceptions of effective teaching (p. 290).

In a final study on teacher judgment, ten elementary teachers in one school were asked to sort their students into two or more categories at five different times during the school year (p. 291). Then teachers described the different categories that they sorted their students into. Teachers most frequently sorted their students in terms of their personality and degree of involvement. At the end of the year, teachers accurately predicted reading achievement in their students, but were less accurate in determining whether students were making good progress.

In summary, there are few studies about teacher judgment and the results are not 
consistent. Some results contradicted those of other studies. Many studies focused on preservice teachers in their research as opposed to in-service teachers. Using preservice teachers may affect the outcomes of these studies, as experience is a critical component of teacher judgment. However, overall, the studies do indicate that teachers make judgments about their students and about what makes "good teaching." Student behavior ranks high in factors that teachers make judgments about and consider when planning, in particularly student motivation and involvement.

\section{Teacher Decision Making and Planning}

Teacher planning includes the decisions made before, during, and after instruction. Planning involves decisions that teachers make about learners, materials, and when instruction takes place. There are different models of planning such as the rational model (Tyler, 1950), the Madeline Hunter model (Hunter, 1985), and Backward Design (Wiggins \& McTighe, 1998). In the research on teacher planning, researchers have sought answers to how teachers think and the kinds of instructional decisions they make.

Some common findings have emerged in the research on teacher planning. Teachers tend to focus on three aspects during planning: content (subject matter and materials), student focus (ability), and activities (Borko, Shavelson, \& Stern, 1981; Borko \& Cadwell, 1982; Clark \& Yinger, 1977; McCutcheon, 1980; Peterson, Marx, \& Clark, 1978; Shavelson \& Stern, 1981; Yinger, 1980). These findings were contrary to the "rational model" of teacher planning first suggested by Tyler (1950), which puts objectives at the forefront of instructional planning followed by activity selection, activity organization, and lastly, evaluation (Clark \& Yinger, 1977). In fact, researchers found that rather than being the first 
step in planning, objectives were not particularly important in teacher planning or at least not one of the top considerations in teacher planning. In a study of twelve elementary teachers, McCutcheon (1980) reported that teachers tended to make note of objectives in their planbooks only if their principal required it. Otherwise it was deemed redundant as the objectives are noted in the teachers' manuals. Additionally, from teachers' perspectives, planbooks serve as a reminder, a place to list planned activities, which might include notations of page numbers from a text or a concept jotted down, but nothing explained in detail.

A more formalized version of Tyler's rational model, the Madeline Hunter Model became widely adopted in the 1980s and 1990s in teacher education. Hunter's perspective of her model was one "... that increases the probability of learning by (1) identifying professional decisions teachers must make; (2) supplying research-based cause-effect relationships to support those decisions; and (3) encouraging the teacher to use data emerging from students and classroom situations to augment or correct those decisions" (Hunter, 1985, p. 57). This method focuses instruction on Mastery Learning and consists of seven steps: the anticipatory set (setting the stage for the learner), objectives/standards, teaching and modeling, guided practice, check for understanding, independent practice, and closure. In a study of 33 K-12 teachers, Brown (1990) identified five factors that influence instructional planning: teachers' personal beliefs, maintaining student attention, meeting lesson goals, facilitating student learning, and effective transitioning between activities. Unlike previous studies in which teachers planned using activities and content to drive their planning, teachers in Brown's study had been trained in the Madeline Hunter Model of instruction. Brown noted that while teachers in the study did not begin their planning with objectives, 
they did use objectives at some point during their planning. These findings were consistent with those of Zahorik's (1975) study of 194 K-12 teachers and Chen's (2000) study of five social studies junior high teachers in Taiwan.

In the mid-to-late 1990s, state departments of education across the United States began to adopt content standards and instructional planning shifted to include a focus on standards. School districts adopted state standards and curriculum designers began to design curriculum to meet this new instructional focus. Wiggins and McTighe (1998) developed an approach to curriculum instruction for teachers called backward design. This method of planning is an ends-means method of planning containing components of Tyler's rational planning and Hunter's Seven Steps, but differing in significant ways. According to backward design, curriculum and learning experiences should be "a means to an end." The means are the learning activities and experiences, teaching methods, and assessments. The "means" support the "ends" which are the standards, goals, and objectives (p. 13). Backward design begins with the goals and objectives followed by assessments that are developed to meet these objectives. The designer/teacher then creates various lessons and activities needed for students to accomplish the objectives. Along the way, teachers may adapt or modify the lessons as needed. Fitzharris (2005) suggests curriculum design provides teachers an opportunity to see the bigger picture - to tailor curriculum to meet students' needs as they review curriculum, goals, objectives, standards, activities, and other resources.

One kind of planning of unique interest that emerged in the studies is the idea of teacher mental planning. Mental planning comprises the times during which the teacher plans by rehearsing content and reflecting on students and their performance as well as the teacher's own performance (Glatthorn, 1993; McCutcheon, 1980; Parker \& Gehrke, 1986). 
This mental planning occurs consciously and unconsciously at various times during the instructional day and even during off-times for teachers - after school, weekends, and even summer vacations! McCutcheon states, "Mental planning is probably the part of teaching that has the potential for being the most professional activity of teaching, for it gives teachers the opportunity to relate theoretical knowledge to particular cases" (p. 8). However, McCutcheon noted that mental planning was rarely used in this way. Instead, teachers use mental planning to anticipate problems, rehearse lessons from start to finish including what the students and teacher will do, and review the material needed for the lesson. In a study of teachers in Taiwan, Chen (2000) found the teachers used mental planning much more frequently than they did written plans. It was determined that one reason for this was the lack of need to write down detailed plans as teachers lectured more frequently than they used activities, unlike their American counterparts.

Clark and Yinger (1977) describe two different kinds of planning or phases of teaching: the preactive phase and the interactive phase. Planning is one of the activities that teachers do during the preactive phase of teaching. The preactive phase of teaching are those moments during teaching where the teacher is not directly interacting with students, such as grading, setting up equipment and materials, interacting with colleagues, and planning. Further, Yinger (1980) states that of the many things that teachers do, "... planning is probably the most important" (p. 108).

The thinking and decisions that occur during teaching are called interactive decision making (Clark \&Yinger, 1977; Marland, 1986; Peterson, Marx, \& Clark, 1978). In implementing lessons, teachers continually make decisions to adapt and adjust their plans based on student needs and interruptions to schedules. In a study of six volunteer teachers, 
Marland describes three different models of interactive thinking: customized response, opportunity seeking, and problem avoidance. Customized responses are tailored responses to student cues (body language or behavior), questions, and needs while problem avoidance reflects a teacher's perception or anticipation of a problem such as student inattention, offsubject or silly responses, and other student behaviors. Opportunity seeking refers to a teacher's application of a principle that the teacher holds, such as eliminating "no, that's not correct" from his responses to students. At the center of each of these models is the "thinking on your feet" aspect of teaching - how a teacher thinks and responds in his teaching with students. Interactive decision making while not specifically part of teacher planning is instead reflective of teacher planning using a teacher's experience, anticipation of student needs and behaviors, and goals or principles (Marland, 1986).

In another study on teacher thinking and planning, McAlpine, Weston, Berthiaume, and Fairbank-Roch (2006) studied two university instructors as they planned from pre-course to post-course. They identified two types of goals and four domains of knowledge that teachers implemented at varying levels during their courses. The two types of goals were teaching goals - what the instructor intended in his instruction and learning goals - what the instructor intended learners to gain from instruction. In addition, McAlpine et al. categorized instructors' knowledge into four different categories:

- pedagogical knowledge - knowledge of teaching strategies and methods;

- content knowledge - specific knowledge within a subject area;

- pedagogical content knowledge - knowledge of teaching strategies specific to a particular content area; and

- learner knowledge - knowledge and understanding of learners in general and within specific content. 
In this study, $86 \%$ of the statements instructors made were about teacher goals compared $14 \%$ that were learner goal statements. The goal statements were "... more concrete and specific in the first three interviews and more tentative and conditional in the post-course interview" (p. 139). Of the four domains of knowledge, statements about pedagogical knowledge were made most frequently (58\%), and content knowledge was mentioned the least $(7 \%)$. Instructors in the study used all knowledge domains at varying levels of complexity throughout the planning and plan implementation phases of the study.

Instructional planning, that is planning for teaching specific lessons or units of study, require a teacher to:

- Be a competent subject matter expert (content knowledge);

- Use and discern appropriate content materials - sometimes required by the school and sometimes a matter of teacher choice (pedagogical knowledge and pedagogical content knowledge);

- Understand learning theory with regards to his students (learner knowledge); and

- Use local school, district, and state content requirements.

McCutcheon (1980) found that very few teachers used curriculum materials that were not provided. Teachers relied on textbooks mandated by their school or district for reading and math, but used an eclectic variety of materials for science and social studies. This difference was attributed to the lack of time available (only 30 minutes) for science and social studies while extended periods were allotted to language arts and mathematics. Teachers felt this limited the opportunities for extended critical thinking and concept development in these subjects. While teachers used prescribed textbooks, it was found that teachers adapted the materials to meet their teaching style and student needs. Some influences on planning include: limited teacher education; teacher isolation; mandated and 
inadequate materials; and administrative practices and policies. Administrative practices and policies that influence planning are classroom interruptions; mandated time per subjects and class size, which affect both schedule/time considerations; and student achievement programs related to promotion, retention, and adapting materials to meet student needs.

The final model of teacher decision making to be discussed is Shavelson and Stern (1981). They developed a framework for the process that teachers use for instructional planning. Teacher planning as viewed through this model consists of student information, content and materials, instructional tasks, school constraints, time and management, and teacher judgments, all of which result in pedagogical decisions. This model, aptly named a Decision Model, appears to account for many of the factors that Shavelson et al. and other researchers attribute to pedagogical judgments and decisions that teachers make when planning. As seen in Figure 1, Shavelson \& Stern's Decision Model lacks a focus on goals, objectives, or standards as in Backward design, but contains influencing factors from Brown's study such as teacher beliefs (Individual Differences between Teachers), maintaining student attention (Teachers' Attributions of Probable causes of Student Behavior), and facilitating student learning and effective transitioning between activities (Teachers' Use of Heuristics). In addition, the model includes specificity about the judgments that teachers make about their students such as their ability, what motivates them, and their behavior as well as judgments about the content they teach. Judgments about content include what level and pace is appropriate for their students and which standards they should focus on. Finally, the Decision Model includes Institutional Constraints that McCutcheon's study also identified as the administrative practices and policies that influence teacher planning. 


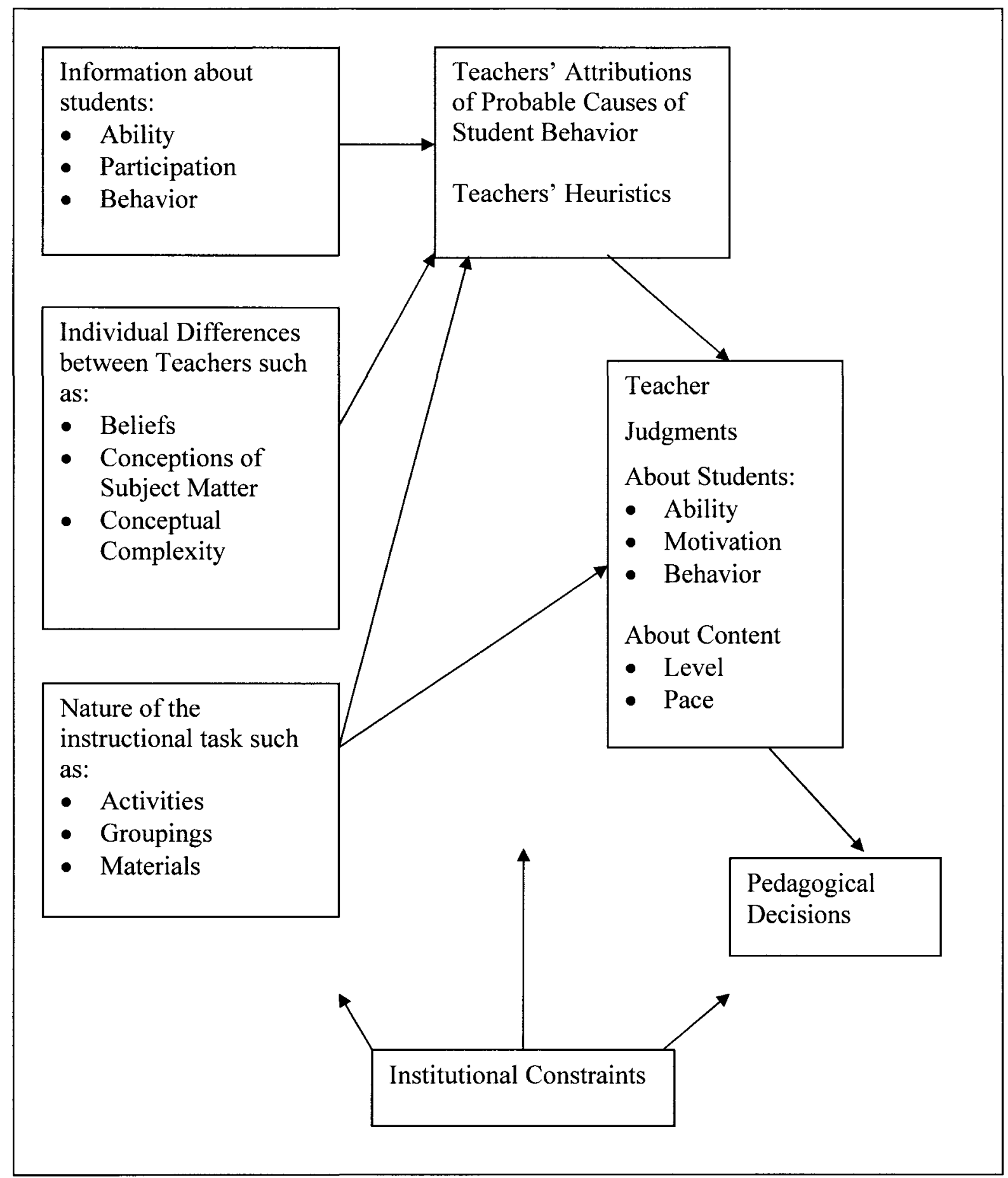

Figure 1. Shavelson \& Stern Decision Model.

Source: Shavelson, R. J. \& Stern, P. (1981). Research on teachers' pedagogical thoughts, judgments, decisions, and behavior. Review of Educational Research, 51(4), p. 472. 
Given the current focus on state standards, goals, and objectives, an adaption to the model, as shown in Figure 2, would include these elements and more closely resemble current teacher decision making.

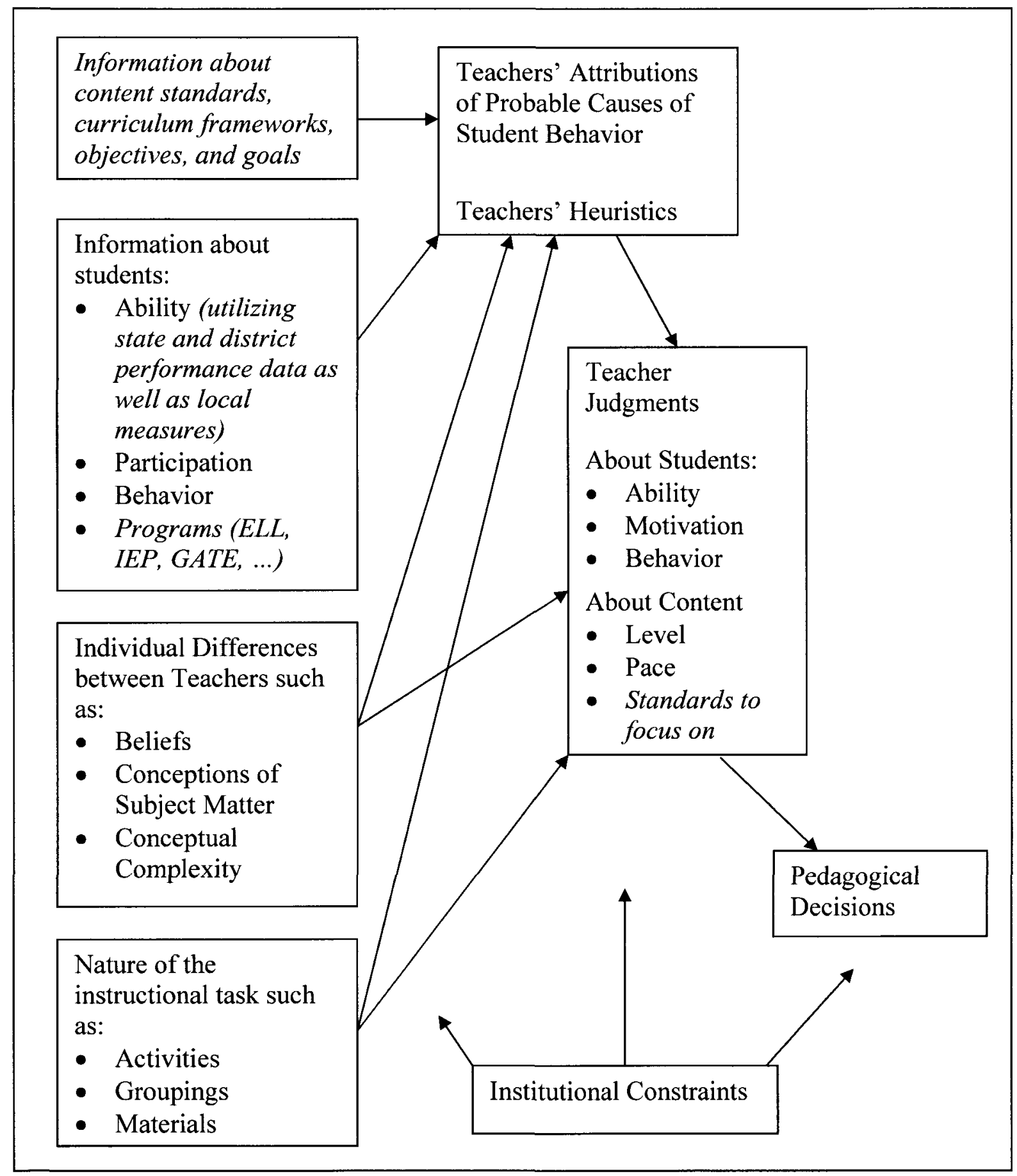

Figure 2. Adapted Shavelson \& Sterns' Decision Model (Changes in the model are italicized). 
Additional elements to the model include new ways information about students are categorized such as the inclusion in programs like English Language Learners (ELL), Individual Educational Plans (IEP), the Gifted and Talented Education (GATE), etc... With the state and national focus on student performance on standardized tests, schools have become adept at collecting and using student data to establish baselines and to measure student progress. These data can include student performance on state and local tests as well progress in the specialized programs mentioned previously. While data on student performance were collected in schools when Shavelson and Stern created their model, this information was not readily accessible, uniformly collected, or analyzed by teachers for use in their instructional planning. Current conditions in data collection and analysis have provided teachers with more readily available information regarding student progress. In addition, student performance data is more closely aligned to state standards, as are curriculum materials. The adapted model in Figure 2 includes these additional factors that teachers might use in their decision making and instructional planning. Clearly, teacher planning entails decisions and judgments that teachers must make. It can be seen as comprising layers of complexity requiring multiple lenses such as: what are the needs of the learners; what specific content goals, standards, and objectives are to be taught - state, district, and school level; what materials and resources are available or needed; how to implement instruction; when to schedule; and how to evaluate its success.

\section{LEARNING OBJECTS}

Research and interest in the possibilities that learning objects may provide to the learning community have increased over the last ten years. A Google search on 'learning 
objects' returns over $23,000,000$ results while Yahoo returns over $68,600,000$ results. Although some of the results may be duplicated in each search engine, the sheer number provides some indication of the interest in learning objects. Definitions of learning objects vary to some degree. The Institute of Electrical and Electronics Engineers (IEEE) Learning Technology Standards Committee (LTSC) defines learning objects as, “... any entity, digital or non-digital, which can be used, or reused or referenced during technology supported learning" (IEEE LTSC, 2006). Wiley (2002) defines a learning object as any digital resource that can be reused to support learning (p. 7). Wiley's streamlined and narrower definition serves two specific purposes. One, it defines learning objects as being digital and two, it defines learning objects as being purposeful - they support learning. Still another definition for learning objects categorizes them as first-order and second-order learning objects. Allert, Richter, and Nejdl (2004) define learning objects created with a specific learning objective as first-order while second-order learning objects employ strategies. For example, textbooks, lectures, and educational films are first-order learning objects whose purpose is presenting information while resources with scaffolds, scripts, and strategies such as problem solving and decision making are second-order as their purpose is fostering knowledge creation (p. 705). For the purposes of this study, Wiley's definition of learning objects is used because of its simplicity and conciseness.

\section{Design \& Characteristics}

Learning objects have many characteristics that help to facilitate their use in supporting learning. Reusability and repurposing are two terms related to learning objects that are often used synonymously. Reusability is the ability of a learning object to be used 
again and in multiple ways, while repurposing is using a learning object for different purposes. For this study, as in many studies, they are used interchangeably. Other characteristics of learning objects include granularity, adaptability, interoperability, accessibility, and discoverability. Granularity refers to the size of a learning object as it relates to context. The more granular a learning object is, the less grounded it is in specific learning contexts. Wiley et al. (2000) refers to this as a paradox because what makes learning objects so attractive to educators is its contextual nature - how grounded within the context of some learning idea or concept it is. Yet, the more contextual a learning object is, the less useful it is in other contexts. In other words, smaller learning objects have more granularity as they are less tied to one specific learning context therefore they are more usable or reusable in many learning contexts. Take the example given earlier about how a wagon train image or video clip might be used to demonstrate transportation of long ago for kindergartners while also being used to demonstrate how settlers traveled west in the $1800 \mathrm{~s}$ during the westward movement of early America. If the wagon train image or video clip is tied so specifically to one grade level objective, then it would be less usable to other grade levels. However, if it is loosely described then it can be reused in many learning contexts such as transportation of long ago, the movement of settlers west, life along the wagon trail, and uses of the wheel over time. In this study, the learning objects had very specific learning contexts in mathematics and were therefore, less granular in nature.

Other characteristics of learning objects are its interoperability and discoverability. Interoperability refers to its ability to run properly on multiple systems - its "plug and play" capacity (Reusable Learning, 2007). In addition, interoperability can mean how easily the learning object can be adapted or modified for a new context. Discoverability is the ability of 
the learning object to be readily located. An example of discoverability is the frequent use of search engines in finding information on the Internet. In a finding from public television studies, teachers identified that it was important to be able to readily locate and access media (Nugent, 2005). In this study, the learning objects were selected by the researcher, therefore, the learning object characteristic of discoverability was not measured. However, the learning objects are freely available online. Reusability, interoperability, and discoverability are all characteristics of learning objects that are easily embedded in metadata.

Metadata or "data about data" provide descriptions about learning objects (Wiley, 2002). Metadata can be likened to the storage of bibliographic information provided in the typical MARC (MAchine-Readable Cataloguing) record found in library collections (The British Library, n.d.). Unlike traditional library collections where books, records, artwork, etc... are physical objects that can be checked out or borrowed, digital media can be downloaded or streamed. In addition, learning objects have characteristics such as their reusability that provide an opportunity for more in-depth descriptions than would typically be provided in a MARC record. Quite a bit of discussion has revolved around the creation of metadata standards for learning objects. IEEE Learning Technology Standards Committee created the Learning Object Metadata Working Group to formulate standards focused on "... the minimal set of attributes needed to allow these Learning Objects to be managed, located, and evaluated" (IEEE LTSC, 2006). Typical attributes would include the type of learning object, author, owner, format, and distribution terms. In addition, metadata could include pedagogical attributes such as grade level and teaching style. Like the traditional MARC format standard, learning object metadata standards would allow additional fields to be added at the local level. Ultimately, the purpose of providing metadata standards is to create a 
means by which learning objects are accessible to end users - making the "invisible", visible.

\section{Instructional Use of Learning Objects}

Educators and educational institutions around the world are developing learning objects for classroom use. The Tasmanian Department of Education (DoE) is one such example, providing descriptions of what learning objects are, the advantages of using them in instruction, guidelines for their use in the classroom, and lastly, access to over 2000 learning objects (Tasmanian School Education Division, 2007).

According to the Tasmanian DoE Guidelines, learning objects can be used to:

- introduce a new concept or idea

- give students practice with something they are learning

- give students a new experience of a familiar idea

- pose problems for students to solve

- provide a backup resource

- give students practice at something they are having difficulty with

- provide students with a variety of experiences in a learning sequence

- assess student knowledge and/or understanding.

The Learning Federation (TLF), an initiative of the federal governments of Australia and New Zealand, developed over 4000 items of online curriculum content and created an infrastructure to support the initiative for all schools in their territories. Interactive learning objects were created for six curriculum priority areas: Science; Mathematics and numeracy; Literacy for students at risk; Studies of Australia; Languages other than English (Chinese, Japanese and Indonesian); and Innovation, enterprise and creativity. In a study of some of 
the mathematics and numeracy learning objects, teachers from six primary Catholic schools in Melbourne reported their students' experiences as enriching and exciting (Gronn, Clarke, \& Lewis, 2006). Students enjoyed the pictures and how the learning object showed right and wrong answers as well as how to correct wrong answers. From an instructional planning perspective, teachers shared that it was important for teachers to use the learning objects so that they understood their complexity, to be able to match the learning objects' difficulty level to the learner, and to structure other activities to ensure learning. Learning experiences entailed not only the use of learning objects, but also hands-on activities, students' metacognitive reflections, and whole class discussions.

In the United States, there are several university initiated collections of online learning materials such as Multimedia Educational Resource for Learning and Online Teaching (MERLOT) and Wisconsin Online Resource Center (Wisc-Online). MERLOT's collection is authored by a diverse community of university and K-12 faculty while WiscOnline's digital learning objects are created primarily by faculty from the Wisconsin Technical College System. Like the initiatives in Australia and New Zealand, these collections provide teachers with learning objects for use in their classrooms. The National Science Foundation funds Teachers' Domain (Digital Media for the Classroom and Professional Development), a collection that utilizes media from NOVA, Frontline, American Experience, and other public broadcasting partners. Educators can use, reuse, and create learning objects and post them to the site. The site is organized so that teachers can readily see which learning objects they can they can download and which ones they can modify. With so many free and/or low fee resources available, like those from MERLOT and Teachers' Domain, teachers can easily customize instruction for their students. 


\section{Lessons from Children's Programming Studies}

Studies from Children's Programming can provide useful directions for the creation and use of learning objects. In a study from the Children's Television Workshop, Mielke (1983) found that production techniques in Sesame Street such as humor, pacing, and crossmodal reinforcement were useful in capturing and directing children's attention (as cited in Sammur, 1990, p. 84). In a study of Sesame Street, Reeves (1970) found that animated cartoons, children performers, and animals held high attention for children while dialogue among adults held little (as cited in Sammur, p. 84). In Chen's (1984) study of 3-2-1 Contact, animations and high visual action held high interest for children (as cited in Sammur, p. 88). Lastly, in a study by Calvert and Kotler (2003), various educational shows from children's television were analyzed for their effect on second-to-sixth grade children's viewing experiences and the lessons they perceived from prosocial and academic programs. Of the favorite shows that children selected, they all shared “... common qualities of being prosocial, of dealing with realistic issues that children face, and of having humorous content imbedded in them" (p. 288). In addition, these programs were cartoons. Academic programs fell somewhere in the middle of children's selections of their favorite to least favorite programs.

Studies from interactive technologies used in children's television have provided designers with parameters to develop interfaces that assist in making various technologies more usable for children - usability issues specific to children. In short, interfaces must be simple, transparent, and intuitive. Strommen, a researcher at the Children's Workshop, found children's ability to navigate through and understand various screen environments were much more effective when icons depicted their function (Strommen \& Revelle, 1990, p.71). 
For example, children readily understood they could exit through the door icon. In addition, icons needed to have a large enough hot spot or interactive button or children would overshoot it. In still other studies, it was found that children frequently held down a key, which caused key repeat. To solve this problem, designers disabled the auto-repeat capability on the keyboard (p. 74). Lastly, studies of children's television and their related software found that children tended to ignore long streams of directions, dialogue, or information. Optimal segments of instruction appear to be no more than 20 seconds long. Clearly, lessons learned from children's television have been beneficial and influential in how we design and use computers, software, and other technologies for use with children.

\section{Personal Construct Theory and THE Repertory GRID TECHNIQUE}

George Kelly, psychologist, developed Personal Construct Theory through his work as director of Ohio State University's clinical program in the 1940s and 50s and published his two volume work in 1955 (Kelly, 1955). Kelly believed that people were like scientists, that they observed, experienced, and anticipated the world around them through their own lens, creating their own constructs. These personal constructs are guided by a person's experiences, perceptions, behaviors, anticipations, and observations (Stewart, 2005). When

one is faced with an experience that is unlike past experiences, then one's constructs are reconstructed. Therefore, one's personal constructs evolve as new experiences and observations occur. In addition, constructs have a dichotomous nature, that is, they are bipolar (Boeree, 2006). For example, if you perceive something as good then it may also be perceived as bad. Like a pole, constructs have opposite ends. This is easily seen when attending a movie and listening to people as you exit the theater. Some people liked the 
movie, others loved it, while still others hated it.

Constructs are personal - every individual has his own set of constructs. This was important to Kelly as he believed it was essential for researchers working with people to make sure their observations were not influenced by their own personal constructs. This influence of a researcher's personal constructs on his research observations is called observer bias. Kelly developed the Repertory Grid Technique to enable the researcher to elicit constructs from an interviewee through a series of questions, without the influence of observer bias. The grid technique prevents observer bias as constructs come from the interviewee not the interviewer. This questioning technique is called construct elicitation. A further questioning technique called laddering enables the interviewer to elicit constructs from the interviewee that are closer to the purpose of the research.

The Repertory Grid Technique (RGT) has been used in several studies in its original form as a one-to-one interview and it has been adapted and used with small groups and whole class discussions. According to Fransella, Bell, and Bannister (2004), "Repertory grid technique is merely a method that can provide useful information on some occasions with some clients." (p. 93) Fransella discusses first using the RGT in her work with a client in a clinical context because it was a "new tool for measuring what a person thinks and feels about aspects of their life" (p.146). However, she found it to be a successful tool to document how the client was able to deduce over time his thoughts on his actions and why he did what he did, which were contrary to his psychiatrist's point of view. Fransella further found that the pole of constructs in which you place yourself has the most meaning for you. That is, in the case of this study, if you look at three learning objects and determine that two are interactive and the third is not, and rate the importance of interactivity in learning objects as 
high, then you have indicated that the construct interactivity in learning objects is important to you. The value of using RGT as an instrument relies on its roots in personal construct theory; the underlying assumptions stem from the ideas that constructs are unique and personal to the individual.

In this study, the technique was used in one-to-one interviews with teachers experienced in using learning objects in their instruction. The purpose of using the Repertory Grid Technique in this study is that it provided a way to generate constructs about the phenomenon of teacher-designed instruction using learning objects - why certain learning objects are selected or not, what characteristics teachers look for, how decisions are made, in what contexts are learning objects used, etc... without observer bias. As stated previously, teaching is a complex process and teachers internalize their personal constructs about their teaching, their students, and what works with their students in their situation. Getting inside a teacher's head in order to glean what he sees and thinks of when looking at and selecting learning objects is hard to capture. However, the RGT provided a way to collect these constructs and compare them across individuals to get into the "thinking processes" and "personal constructs" that teachers using learning objects have developed through their experiences. 


\section{CHAPTER 3}

\section{METHODOLOGY}

The purpose of this mixed methods study was to investigate the phenomenon of how teachers identify learning objects that meet the instructional needs of students in their classroom. This study provides an extensive description of the characteristics of digital learning objects that teachers identify as useful in meeting the instructional needs of their students and ultimately, successful usage in their classroom. As a result of this study, an instrument was developed to assist inexperienced and experienced teachers alike in the selection of useful learning objects for the classroom. Lastly, this study compared the learning object characteristics that these teachers identified to those identified by experts in the field of learning object design to see if there were any correlations.

A description of the research design, the participants in the study, data collection procedures, and the research questions follow.

\section{RESEARCH DESIGN}

Teachers were interviewed individually and the interviews were conducted in three phases. The first phase of the interview used the Repertory Grid Technique. The Repertory Grid Technique (RGT) has its foundation in George Kelly's Personal Construct Theory (1955). This technique provides a means to examine one's constructs - a person's ideas and beliefs around a certain topic. One of the highlights of the RGT research method is that it enables the interviewer to capture the interviewee's constructs without observer bias (Stewart, 2005). Observer bias comes from the personal views and experience which a 
researcher may unconsciously bring to his observations. In this study, RGT was used to examine the characteristics (constructs) of learning objects (elements) that teachers determine meet their instructional purposes. The second phase of the study was a structured interview with open-ended questions conducted at the end of the RGT portion of the interview. The purpose of the structured interview was to collect demographic information, descriptions of the planning and decision making process of the teachers, and any additional information or comments the teachers wanted to add to clarify or elaborate on their responses. The last phase of the study was a follow-up interview for member checking and to clarify one of the findings in the data.

One of the goals of this study was to determine if teachers experienced in using learning objects in their classroom use the same criteria for determining their usefulness as learning object designers. In order to do this, the learning objects were rated by three learning object experts using the Learning Object Review Instrument (LORI). This rating was used to determine to what degree the learning objects selected by the researcher met criteria used by learning object designers. It was then compared to the rating of each learning object by teachers to see if there were any correlations in the element ratings by the teachers. It is important to note that while the LORI provided a constant rating system of specific dimensions of quality of the learning objects' characteristics, each teacher had his own constructs or dimensions of quality by which he rated each element. The mean of the means was used to determine a rating for each element by the teachers. This rating was then compared to the mean of the ratings the elements received from the experts. The dimensions of quality outlined in the LORI were then compared to the categories of characteristics that teachers determined useful in their classrooms. Lastly, the data was triangulated and member 
checking was used to verify participant responses.

\section{RESEARCH QUESTIONS}

$\boldsymbol{R Q 1}$. What are the important characteristics of learning objects that $\mathrm{K}-12$ teachers determine useful for their instructional purposes?

RQIa. Do teachers discern that some characteristics of learning objects are more appropriate for:

- conceptual development;

- $\quad$ skill development; and/or

- content information?

$\boldsymbol{R Q 1 b}$. Do K-12 teachers use specific characteristics of learning objects for specific learners?

$\boldsymbol{R Q 2}$. How well do the characteristics of learning objects that teachers determine useful relate to traditional design characteristics of learning objects, i.e. reusability, granularity, adaptability, interoperability, accessibility, and discoverability?

\section{SAMPle SELECTION}

The study began with a purposive sampling of K-12 teachers in online communities of practice. However, due to the limitation of available qualified participants, the study was opened to include practicing teachers recognized for their use of technology in the classroom by their peers, district mentors, or other technology resource personnel. The informed consent statement is available in Appendix A. Participants were included if they were K-12 teachers who teach math and use, reuse, and/or create learning objects such as Flash animations, Java interactive applets, PowerPoint, etc... for their classrooms. In order to 
provide a homogeneous set of elements in the study, mathematical content was used - largely due to the large number of readily available learning objects as well as importance given to the subject in instruction and professional development in the U.S. in recent years. Participants who do not currently teach mathematics, but have taught math in the last three years and use learning objects in their classroom were included. The criteria of having taught mathematics within the last three years was used to ensure that the teacher was up-to-date with current teaching methods for mathematics and would be able to effectively rate a learning object on its ability to meet his instructional needs. Participants who do not use mathematics or learning objects in their classrooms were excluded from the study.

Participating teachers were asked to spend approximately one and a half to two hours to complete the repertory grid and open-ended questions at their workplace. Creswell (1998) suggests a purposeful sampling of up to ten people for a phenomenology study, due to the intensive interview process. Stewart (2005) suggests the Repertory Grid Technique does not usually generate any new constructs beyond 20 interviews. Logistically constrained by the long individual interviews required in this study, the sample included eight teachers who met the criteria and volunteered to participate in the study.

\section{LEARNing ObJect/Element Selection}

The learning objects (elements) were chosen based on four rules suggested by Stewart (2005): 1) each element was discrete (separate standalone learning objects); 2) elements were homogenous (each learning object involved activities in the mathematics content arena); 3) no element was a subset of another, (e.g., teaching multiplication and then teaching multiplication to make brownies); and 4) the learning objects were not evaluative. Lastly, 
learning objects were selected to include a range of features found in all learning objects, i.e. interactivity; video; sound; game formats; choices for learners; teacher features including standards and assessments; and a variety of presentational designs. This is not an exhaustive list.

\section{Data Collection Procedures}

The data collection took place intermittently over the course of two years. Invitations to prospective participants were issued. Once participants were identified, interviews were scheduled according to the availability of the participant. All participants' anonymity was protected, as each participant was assigned a number, from 001 to 008 , in the order of his interview based on his availability. The interview protocol consisted of the repertory grid and the structured interview with open-ended questions. Participants interacted with triads of learning objects that the researcher identified as elements in the repertory grid. Participants spent $1 \frac{1}{2}$ to $2 \frac{1}{2}$ hours to complete the interview. The testing situation consisted of two computers set up, side-by-side, on a table. This facilitated easy interaction with three learning objects at a time. It was found that using three computers at a time was cumbersome. By using two computers and having the learning objects in separate browser tabs on each computer, it was possible to pull up two learning objects at the same time and flip to the third for comparison. Participants interacted with three learning objects at a time during the construct elicitation stage of the interview. The interviewer elicited constructs from each participant and responses were recorded on paper. Participant responses to all interview questions were recorded in writing then typed up, coded, and stored in a database. All electronic data and hard copies of data were kept at the researcher's home with backups of 
electronic data kept separately on a flash drive. A copy of the informed consent letter may be found in Appendix A.

\section{INSTRUMENTATION}

The data collection instruments used in this study included the repertory grid, the interview questions, and the Learning Object Review Instrument (LORI). The elements or learning objects used for the repertory grid analysis were selected by the researcher using a purposive strategy to ensure a representative sample of readily available online learning objects.

The repertory grid technique was used to examine the characteristics of learning objects that teachers determined met their instructional purposes. Each participant's responses were recorded on a repertory grid. Each element was coded, A to I, and as constructs emerged, they were recorded in the grid. For example, if elements A, E, and $\mathrm{H}$ were compared for similarity and dissimilarity, a slash mark (/) was recorded in their corresponding grid boxes. If, for example, a participant stated that $\mathrm{A}$ and $\mathrm{H}$ are interactive (similar) and $\mathrm{E}$ is not interactive (dissimilar), the constructs interactive - not interactive, were written in the grid and an $x$ was placed in the $\mathrm{E}$ box. This would indicate that the elements $\mathrm{A}$ and $\mathrm{H}$ are interactive and $\mathrm{E}$ is not. The construct, interactive, would be recorded on the left side of the grid under the emergent pole while its polar opposite, not interactive, would be recorded under the implicit pole. Constructs were elicited through a series of triadic comparisons of the elements (learning objects). Constructs, the characteristics of learning objects, and elements, the different learning objects, were then rated on a five-point Likert scale. This was done by asking the participant to rate each construct and the elements in 
terms of instructional purpose on the five-point Likert item. For example, if the participant elicited the construct interactivity, then the participant rated the elements on the five-point Likert item with five representing the element as most like the construct (emergent pole) and one representing the element as least like the construct (implicit pole). If a participant rated element $\mathrm{D}$ as a four on the interactive construct, a four would be recorded where interactive and element $\mathrm{D}$ intersect. Once participants rated the constructs for each learning object, the researcher used a question clarifying technique called laddering. By laddering, the researcher focused the questions more specifically on each construct using the following qualifiers: in terms of specific students in your classroom; in terms of student groupings in your classroom; and in terms of your instructional purpose. For example, one focused question was, "Using the construct interactive, in terms of specific students in your classroom, how important is interactive on a scale of 1 to 5 ? Responses were recorded for each construct and each qualifier.

The purpose of this last part of the RGT was to focus on the constructs or characteristics of learning objects, not the learning objects themselves, as they apply to all learning objects. For example, how important is it to your instructional purpose if a learning object is interactive? Does that importance change if you are using it with a specific student [perhaps an ELL student or one who needs further practice with a specific concept]? Or if you want to use the learning object with a student group [perhaps one group for review and another for challenge]? Or if you, the instructor, use it for demonstration, does it matter if the learning object is interactive or not? These are all questions whose purpose is to get at what makes a learning object useful to teachers in their classrooms.

The structured interview followed the construct elicitation and laddering. It consisted 
of open-ended questions designed to allow each teacher an opportunity to discuss the decision making and planning process that he uses when determining, which learning objects to use, as well as how it is used in his instruction. In addition, descriptive information such as gender, grade level, years of teaching, teaching situation (self-contained, team, support staff), and years of experience in using learning objects were collected. The Quick Reference Sheet and website links of the elements or learning objects are found in Appendix B. The Quick Reference Sheet was a visual tool for participants to refer to as they rated the elements. The RGT instrument and Structured Interview Questions are available in Appendix C.

The final instrument used, the Learning Object Review Instrument (LORI, was used to rate learning objects using learning object designer criteria. The LORI specifies nine dimensions of learning object quality: Content Quality (accuracy, presentation, and appropriateness of content); Learning Goal Alignment (goals, activities, and assessments) ; Feedback and Adaptation (feedback to learner and adaptive content); Motivation (ability to motivate and interest learners); Presentation Design (visual and auditory features); Interaction Usability (ease of navigation and user interface); Accessibility (features to accommodate the learning disabled); Reusability (use in varying contexts); and Standards Compliance (international standard) (Nesbit, Belfer, \& Leacock, 2003). The learning objects were rated using the LORI five point scale, with one indicating low relevancy and five indicating high relevancy on each of nine dimensions. A not applicable (NA) rating would indicate that for a particular learning object, a dimension may not be relevant or the reviewer of the learning object may not feel qualified to judge that criterion (Nesbit, et al., 2003, p. 2). The LORI was used in this study to verify the quality of the learning objects selected as elements in the repertory grid, to compare how their rating correlates with that of teachers, 
and to determine if any of the dimensions described in the LORI are found as characteristics that teachers determine useful in their classrooms.

It is important to note that the LORI measures three of the six learning object characteristics: reusability, adaptability, and accessibility. The three remaining learning object design characteristics, granularity, interoperability, and discoverability, were not measured as the learning objects were online and selected by the researcher which negated their measurement on these characteristics. However, the LORI measures reusability in such a way as to implicitly include granularity. A five rating on reusability would mean the learning object is a "stand alone that can be readily transferred to different courses, learning designs and contexts without modification." In addition, each of the learning objects were online resources whose context is embedded in specific mathematics content. They are not downloadable or part of a larger learning object; therefore they were innately less granular. Furthermore, the interactive online capability has built in interoperability characteristics because the software used is free and readily available for any computer, Macintosh or Windows operating systems, to download as needed. The characteristic, discoverability - that is being able to be located or found by users, could not be measured as the learning objects were selected by the researcher and provided for the participants and learning object design experts. While the LORI did not allow for the rating of these three characteristics, granularity, interoperability, and discoverability, it did measure additional characteristics deemed by the researcher as comparable to teacher criteria, i.e. content quality, learning goal alignment, feedback, and motivation. 


\section{Data Analysis}

The mixed methods approach provided multiple opportunities to analyze the characteristics of learning objects and may provide some insight into the instructional planning that teachers use when using learning objects in their instruction. Lastly, analyses was used to determine if K-12 teachers identify the characteristics of learning objects and their importance in a similar manner as learning object designers - those design experts in the field who are not practitioners (teachers). Quantitative analyses included descriptive statistics and hierarchical cluster analysis. Content analysis, a qualitative method, was used to develop categories of learning object characteristics which were then used to analyze themes across categories.

Quantitative and qualitative methods were used to analyze the repertory grids. Quantitative methods included descriptive statistics and hierarchical cluster analysis using WebGrid III, a computer program designed by Shaw and Thomas at Brunel University. WebGrid III has a number of interactive components to implement and analyze repertory grids. For the purposes of this study, the analysis features of WebGrid III Display, which displays the construct ratings in terms of the elements and FOCUS, a hierarchical cluster analysis program, were used. The hierarchical cluster analysis of the elements and constructs was used in order to evaluate the clustering of elements and constructs that participants used (Fransella, Bell, \& Bannister, 2004; Hewitt, 2005). The resulting dendrogram was analyzed for cluster patterns within- and between-relationships to determine if participants view and rate elements (LOs) and constructs (LO characteristics) in a similar manner. Frequency counts within the content analysis helped to determine the frequency of constructs across teachers. This added yet another dimension to the analyses. 
This study also used content analysis, a qualitative method, to generate categories of the characteristics of learning objects. An analysis of the teachers' repertory grids was used to determine the ways in which the categories reflect K-12 teachers' instructional purpose when using learning objects in their instruction. The structured interview, which followed the grid interview, was analyzed to determine how teachers' plan and the decisions they make when using learning objects in their instruction. In addition, it provided teachers an opportunity to mention any other information they feel is pertinent about the way they select learning objects and their usefulness in the classroom. The written transcripts of each teacher's interview were coded to determine if teachers provided any additional information pertinent to the study about learning objects. The data analyses were triangulated to see what relationships could be seen across constructs, elements, and instructional use.

Three expert learning object designers rated the elements (learning objects) in the study using the LORI. The mean ratings were used as an additional verification of the quality of the learning objects selected for use in the study. An average rating between four and five would indicate that the learning object quality was rated highly as measured in the nine dimensions of the LORI. It is important to note that some LOs were specifically chosen not because they were deemed of high quality, but to provide contrast and variety in the characteristics commonly found in learning objects.

Once all data had been triangulated, a profile or checklist of learning object characteristics that teachers determine as meeting their instructional needs was created. Member checking, a method in which participants check the accuracy of their responses as documented in the research project, was used in the follow-up interviews. A content analysis was used to determine what characteristics teachers deem as useful for their instructional 
purposes and to see if any correlations could be made to traditional design characteristics of learning objects, i.e. reusability, granularity, adaptability, interoperability, accessibility, and discoverability. Even though the LORI did not measure granularity, interoperability, and discoverability, these characteristics were not left out of the possible content analysis correlation. If they came up, then they were analyzed. While much discussion has been conducted in the "designer expert" arena, little has been done in the teaching arena to see if the criteria deemed important by both groups is consistent.

The principal focus of this study was to determine the characteristics of learning objects that teachers deem useful in instructional planning. However, simply analyzing learning object characteristics would not have provided a complete picture as instructional planning is contextual. In addition, instructional planning with digital learning objects requires different procedures that teachers take into account in their planning and decision making. Lastly, it seemed incongruous to examine and discuss what teachers deem as useful learning object characteristics in their instructional planning if the vast majority of learning object designers, who are not teachers, use different criteria for determining instructional usefulness. The robust analyses in this study provide multiple opportunities to support resulting conclusions. 


\section{CHAPTER 4}

\section{RESULTS}

This study examined the characteristics of learning objects that teachers who regularly use learning objects in their classroom deem as useful in their instruction. The results of the study were then used to create a tool that teachers, experienced or not, could use to facilitate the selection of useful learning objects when searching online. Lastly, the study compared the criteria that learning object designers use to determine the quality of learning objects with that of teachers to see if there was a correlation between the two. The research questions examined in the study were:

RQ1. What are the important characteristics of learning objects that K-12 teachers determine to be useful for their instructional purposes?

RQ1a. Do teachers discern that the purpose of some characteristics of learning objects are more appropriate for:

- conceptual development;

- skill development; and/or

- content information?

RQ1b. Do K-12 teachers use specific characteristics of learning objects for specific learners?

$\boldsymbol{R Q 2}$. How well do the characteristics of learning objects that teachers determine useful relate to traditional design characteristics of learning objects, i.e. reusability, granularity, adaptability, interoperability, accessibility, and discoverability? 
What follows is a description of the participants, an explanation of the data analysis procedures, and a presentation of the findings.

\section{Participants}

The participants in this study were current teachers ranging from grade 3 to high school. As the content of the learning objects was related to mathematics, the high school teachers were mathematics teachers while the elementary teachers taught math as part of their daily curriculum. There were a total of eight participants, seven females and one male. Open-ended questions at the conclusion of the interview provided descriptive statistics about the participants, (gender, number of years teaching, grade level, number of years using learning objects) and the teaching situation of the participants. A summary of the demographics is shown in Table 1.

Table 1. Demographics of Participants

\begin{tabular}{cccccc}
\hline Participant & Gender & $\begin{array}{c}\text { Grade } \\
\text { Level }\end{array}$ & $\begin{array}{c}\text { Teaching } \\
\text { Situation }\end{array}$ & $\begin{array}{c}\text { \# of Yrs. } \\
\text { Teaching }\end{array}$ & $\begin{array}{c}\text { \# of Yrs. } \\
\text { Using Learning } \\
\text { Objects }\end{array}$ \\
\hline 001 & female & 3 & SC/T & $\mathbf{8}$ & $\mathbf{8}$ \\
002 & female & 4 & SC & 3 & 7 \\
003 & female & $9-12$ & SC & 13 & 10 \\
004 & female & 5 & SC & 5 & 3 \\
005 & female & 6 & SC & 7 & 5 \\
006 & female & 4 & SC & 6 & 3 \\
007 & female & $9-12$ & SC & 34 & $10-15$ \\
008 & male & 5 & SC & 14 & $3-4$ \\
\hline Mean & & & & $\mathbf{1 1 . 3}$ yrs. & $\mathbf{6 . 1 - 6 . 9}$ yrs. \\
\hline
\end{tabular}

Teaching Situation: Self-contained (SC); Team (T) 
All teachers are in a self-contained classroom while participant \#001 specifically mentioned teaming for science with her grade level team. It is unknown whether any of the other teachers do any additional teaming with their grade level or content specific teams. The average number of years teaching was 11.3 years. Eliminating one outlier ( 34 years), the average was 8 years. The average number of years using learning objects was $6.1-6.9$ years. Half of the participants began using learning objects in their classrooms a few years after they first began teaching. The other half began using learning objects at various times in their career: two began using them many years later; one the same year she started teaching; and the last one began using learning objects when teaching students in a computer lab setting, prior to teaching in a self-contained classroom.

\section{Data Analysis Procedures and Findings}

At the beginning of the first participant's interview, one website which contains two of the learning objects was not operating so the order of the learning objects was moved to start further down the list in the hopes that the website would be up and running by the time it was needed. As a result, the order of viewing the three learning objects was reordered and compared in this order: ACE, EFG, GHI, HIJ, IJB, ABD. Due to the length of time of the interview, the possibility of participant fatigue, and the fact that constructs were being repeated, the triadic comparisons were halted by the researcher after $\mathrm{ABD}$, and the rest of the interview (rating the elements with the constructs, rating the constructs for instructional purpose, and the structured interview) was concluded as scheduled. [The first participant generated 19 constructs, the second highest of the group.] This first interview set the order of construct elicitation for the rest of the interviews to provide consistency in data collection 
procedures. Interviews with participants took $1 \frac{1}{2}$ to $2 \frac{1}{2}$ hours to complete. The follow-up interviews took 10-20 minutes to complete.

Participants were instructed to "get to know" each element (learning object) by "playing with it" - that is interacting with it just as they would do when they find learning objects online. Then participants were instructed to look at three learning objects at a time and think of how two are similar, yet different from the third. At this point, teachers often asked clarifying questions such as "Do you want me to tell you that these two are about fractions and the other one is about volume or do you want me to tell you that this one is more visual than the other two?" There was a sense of the "I want to make sure you get the data that you want from this interview" from all of the participants which underlined the seriousness with which each participant took the study. In response to these kinds of questions, the original question was repeated with the codicil, "It's what you think, no right or wrong answers." Each of the teachers interviewed initially struggled to think of how two of the learning objects were similar yet different from the third. Some of the interviews began with the teacher initially focusing on the specific learning object's content, but as the interview went on, all of the participants focused on the LO for its characteristics as well as its content.

Recording constructs became challenging at times as participants switched their focus from how two were similar, yet different from the third to talking about what they inferred as the positive characteristic in one element that was absent in the two elements. For example, participants would mention this one is interactive where those two are not. This would mean the emergent pole is "not interactive" and the implicit pole is "interactive". Verbalizing constructs in this way at times seemed to make sense to teachers because they were looking 
at the characteristics that stood out to them. Teachers made comments such as, "...this one you can see everything on one screen but those two you have to scroll down a lot... This would be engaging to my students but those two would not hold their attention at all." In addition, teachers often further clarified their ideas, eliminated constructs, or combined constructs when laddering and rating the constructs with the qualifiers towards the end of the RGT interview.

The intention of the laddering was to narrow down constructs so that they could be generalized across elements and more closely answer the research questions. This was done by framing the constructs within three situations, then asking the participant's preference which polar construct, and rating it on the Likert item. The three situations or qualifiers were: How important is [construct] in terms of specific students in your class; in terms of student groupings in your classroom; and in terms of your instructional purpose. For example, one construct was $3 \mathrm{D}$ - not $3 \mathrm{D}$ so the question becomes, "How important is $3 \mathrm{D}$ or not $3 \mathrm{D}$ on a scale of one to five, with 5 being ?" [left open for the teacher to place her preference first as a 5]. At this point the participant would state 5 is $3 \mathrm{D}$ and 1 is not $3 \mathrm{D}$. The question continued, "...in terms of specific students in your class? ...in terms of student groupings? ...in terms of your instructional purpose?" Each construct would be framed in the same way and its rating recorded. In this way, some constructs such as "too much reading" became a 1 while "just right reading" became a 5, but it was left up to the participant as to the frame of what was a 5, important, and what was a 1 , not as important. Constructs were stated according to how they were recorded with the emergent pole first and the implicit pole second. One construct, multicultural, was elicited during the triadic comparisons, but the teacher changed her mind about rating it as only one learning object had a picture featuring children of different 
ethnicities. This construct later resurfaced when rating the constructs, not the elements, as a 4 for specific students but in other situations a 2, not very important. Some constructs were combined (by the participant) during the laddering as having the same meaning. For example, kid friendly and user friendly were determined as having the same meaning as was moving around and manipulate it. The data accumulated were recorded on grids designed by the researcher according to grid research procedures.

During the structured interview portion of the interview, teachers readily responded to each of the questions with specific responses. One teacher outlined the criteria of what a learning object must have and what it should not be. The responses to each question were categorized into common themes and recorded in tables. The structured interview was designed to answer the research questions, so tables are presented as they relate to each of the research questions. All data collected from the RGT and the structured interview were then transcribed for analysis.

The final phase of the interviews was a follow-up interview with each participant for member checking and to clarify a finding in the data. Each participant was asked to review the learning object constructs (characteristics) generated, their ratings in terms of importance in each situation, and the responses from the structured interview. Some additional clarification was added to the structured interview portion for one participant. This concluded the member checking portion of the interview and participants were then asked to clarify one of the findings relating to specific students in your classroom. Initially, the researcher did not want to clarify who specific students were because it was hoped that in construct elicitation, this would be clarified by each teacher. That is, it was hoped that each teacher would specify who these specific students were in his classroom. This did not occur with any kind of 
consistency and to prevent observer bias the researcher did not specify. However, as a result of the analyses, it became clear that this group needed clarification because the mean rating for this group was uniformly the highest of all groups, indicating its importance to each teacher. Therefore, the researcher generated groups that she had had in mind as it relates to her own instruction and classroom experiences, i.e. English Language Learner (ELL) students, low performing students, students with learning disabilities, and Gifted And Talented Education (GATE) students. In the follow-up interview, each participant was asked to rate the constructs he'd generated in the RGT interview in terms of each of these four groups of students.

\section{INSTRUMENT RELIABILITY}

Content analysis was used to determine the percentage of agreement on the categories generated by the researcher. The characteristics were sorted and then grouped into categories. Table 2 summarizes the percentage of agreement. Overall there was $84 \%$ agreement on the characteristics and their categories. One area in which there was a significant disagreement was in Thinking \& Learning: Purpose - Review, Practice, \& Connections. There was 60\% agreement. There were two characteristics, fractions and useful, that the other analyzer was unable to categorize which automatically resulted in a $0 \%$ agreement. In addition, algorithm and compares 3 sets characteristics were categorized as user experience; design by the other analyzer while the researcher determined that they belonged to the Thinking \& Learning: purpose category. There were four additional areas of disagreement. However, the number of constructs in each category ranged from 2 to 4 . Overall, the percentage of agreement was high in most characteristic categories. The main difference was the level of specificity that 
the researcher used in describing each characteristic. Whereas, the additional analyzer used the same characteristic terms in a more general manner, i.e. LO Design: Color versus LO Design.

Table 2. Content Analysis - Percentage of Agreement

\begin{tabular}{|c|c|c|c|c|}
\hline Characteristic & \# of Constructs & Category & Agreement & $\begin{array}{c}\text { Significant } \\
\text { Disagreement }\end{array}$ \\
\hline Conceptual & 14 & $\begin{array}{l}\text { Thinking \& } \\
\text { Learning }\end{array}$ & 93 & \\
\hline Creative Thinking, & 12 & $T \& L$ & 91 & \\
\hline \multicolumn{5}{|l|}{ Problem Solving, \& } \\
\hline \multicolumn{5}{|l|}{ Discovery Learning } \\
\hline Purpose - Review, & 11 & $T \& L$ & 60 & yes \\
\hline \multicolumn{5}{|l|}{ Practice, \& Connections } \\
\hline Feedback & 5 & $\mathrm{~T} \& \mathrm{~L}$ & 100 & \\
\hline Motivation & 5 & $T \& L$ & 100 & \\
\hline Appropriate for Use & 3 & $\begin{array}{c}\text { Learning Object } \\
\text { Design }\end{array}$ & 33 & yes \\
\hline Accessing Content - & 24 & LO Design & 100 & \\
\hline \multicolumn{5}{|l|}{ Kid Friendly, Readability } \\
\hline Dynamic/Interactive & 15 & LO Design & 85 & \\
\hline Color & 5 & LO Design & 100 & \\
\hline Graphics & 2 & Lo Design & 75 & yes/no \\
\hline 3 Dimensional, Model & 9 & LO Design & 100 & \\
\hline \multicolumn{5}{|l|}{ Situation } \\
\hline Options - \# of Participants & 4 & L O Design & 100 & \\
\hline Options - Format & 4 & LO Design & 50 & yes \\
\hline Options - Variation & 12 & L O Design & 92 & \\
\hline Sound & 4 & LO Design & 100 & \\
\hline Visual Appeal & 2 & LO Design & 100 & \\
\hline \multirow[t]{2}{*}{ Outliers } & 2 & LO Design & 50 & yes/no \\
\hline & 133 Constructs & 2 Categories & 84 & \\
\hline
\end{tabular}


The Learning Object Review Instrument (LORI) used a convergent participation model to determine inter-rater reliability. The convergent participation model has two stages of ratings. In the first stage, participants determine the ratings on learning objects individually and in the second phase, participants discuss the ratings and come to consensus through a moderator. Reliability ranged from .70 and .80 on presentation aesthetics and design; .80 and .90 on accuracy of content, support for learning goals, and reusability; and above .90 on motivation, usability, feedback and adaption; The final two items, metadata compliance and accessibility standards were not measured due to insufficient variation (Vargo, Nesbit, Belfer, \& Archambault, 2003). The researchers believed this was due to participants' lack of knowledge of metadata compliance and accessibility standards. As a result of the inter-rater reliability study, the LORI 1.5, was revised to improve reliability of all items and to simplify the rubric (E-Learning Research and Assessment Network, n.d.).

\section{Research Question One Results}

$\boldsymbol{R Q 1 .}$ What are the important characteristics of learning objects that K-12 teachers determine useful for their instructional purposes?

$\boldsymbol{R Q 1 a}$. Do teachers discern that the purpose of some characteristics of learning objects are more appropriate for:

- conceptual development;

- skill development; and/or

- content information?

$\boldsymbol{R} \boldsymbol{Q 1 b}$. Do K-12 teachers use specific characteristics of learning objects for specific learners? 
Research question one has subcomponents as each subcomponent comprises the whole. In other words, you can't find out what characteristics of learning objects (LOs) are important without determining if it matters with different audiences. Also, inherent in the question is that teachers seek LOs for specific instructional purposes, so what are these instructional purposes? Are some LOs more appropriate for conceptual development, others for skill development, and still others for delivery of content information? To sum up, do teachers' instructional purposes for using LOs vary for different audiences?

\section{Structured Interview}

A total of nine open-ended questions were asked in the structured interview. The purpose was to provide descriptive statistics about the participants, answer the research questions in a different format, and to provide participants with an opportunity to discuss: what they consider when they plan [using learning objects]; why they use LOs; and what characteristics of LOs they consider as the most useful. In addition, it gave participants an opportunity to add any other ideas or comments that they think might be helpful for the study. Participant responses were analyzed to determine themes or categories of learning object characteristics.

Open-ended question six sought to answer RQ1a as each teacher was asked what his purpose was for using, reusing, and/or creating digital media/ learning objects [for the classroom]. Four overarching themes were generated: practice, instructional tools, conceptual philosophy, and the medium (technology). Teachers discussed using learning objects in their classrooms to provide students with opportunities to practice skills they'd taught them. The theme instructional tools had more to do with how learning objects are used: as an 
instructional tool, in centers, or in various student groupings. Conceptual philosophy involves how teachers perceive learning objects and their value in the classroom, i.e. they [learning objects]: help students visualize concepts; are fun; can reach more of their students; can be used to scaffold content; and provide more context for students. The last theme was the medium itself - learning objects. This theme crosses some themes as it is hard to separate the medium from its instructional purpose. However, teachers specifically characterized the learning objects as being visual, dynamic (interactive), an alternative way in accessing content, ability to immediately use it in the classroom, and providing students with opportunities to use technology. Table 3 outlines each of the themes and the teachers' comments.

In question seven, teachers were asked what do they consider or think about when planning to use learning objects. This question answers $R Q 1$ as it has to do with the decision making that goes behind determining instructional purpose as well as the characteristics of learning objects. In planning, teachers bring their own beliefs and perceptions to the table. In addition, they use information about their content standards and frameworks as well as their students; they determine the nature of the task - what do they want their students to do with a learning object; and they make judgments about the content and their students, i.e. components of Shavelson and Sterns' Decision Making Model. There were six overarching themes: practice; instruction; conceptual; access/readability; motivation; and interactive. These themes fell into the same categories as in questions six. See Table 4. The comments generated provided more specificity to what teachers consider when planning to use learning objects. As can be seen, the responses fell into four general themes: Practice, Instruction, Conceptual, and Medium. The theme Instruction had the greatest number of responses which 
would make sense as the question pertains to planning. However, it also demonstrates the multifaceted thinking of teachers when planning for instruction.

Table 3. Open-Ended Question Six

\begin{tabular}{|c|c|}
\hline \multicolumn{2}{|c|}{$\begin{array}{l}\text { What is your purpose for using, reusing, and/or creating digital media/learning } \\
\text { objects? }\end{array}$} \\
\hline Themes & Participant Responses \\
\hline Practice & $\begin{array}{l}\text { - Add as an aid } \\
\text { - Extra tool for learning } \\
\text { - Review } \\
\text { - Gives students opportunities [for practice] } \\
\text { - Access }\end{array}$ \\
\hline $\begin{array}{l}\text { Instructional } \\
\text { tool }\end{array}$ & $\begin{array}{l}\text { - Teaching tool } \\
\text { - Centers } \\
\text { - Independent/pair practice/small group }\end{array}$ \\
\hline Conceptual & $\begin{array}{l}\text { - To make it more concrete } \\
\text { - Different ways of looking at different concepts, especially math } \\
\text { - Kids need extra context } \\
\text { - Conceptual } \\
\text { - Reach all learners } \\
\text { - Scaffold instruction; Give background knowledge; Support, scaffold } \\
\text { students who need visual model } \\
\text { - Fun } \\
\text { - I want students to do more math - even at home; AAA Math website }\end{array}$ \\
\hline Medium & $\begin{array}{l}\text { - Immediately see it } \\
\text { - Change [from what students usually do] } \\
\text { - Visual/Visual model of concept } \\
\text { - Different ways of looking at different concepts, especially math } \\
\text { - Another way to get their [students'] material } \\
\text { - I feel as a teacher, I need to give students access to technology } \\
\text { - A form of intelligence } \\
\text { - Dynamic }\end{array}$ \\
\hline
\end{tabular}

Open-ended question eight also addresses $\boldsymbol{R} Q 1$ and asks why which uses the laddering strategy of the RGT to help determine specific constructs after participants worked with the learning objects and generated constructs. The characteristics fell into six themes: instructional purpose and organization; conceptual ideas; visual; visually appealing; access 
and readability; and interactive as seen in Table 5. The first two themes: instructional purpose \& organization and conceptual ideas have more to do with instruction and instructional strategies whereas the last four: visual; visually appealing; access and reliability; and interactive, have to more to do with the medium or learning object itself.

Table 4. Open-Ended Question Seven

\begin{tabular}{|l|l|}
\hline \multicolumn{2}{|l|}{ What do you consider or think about when planning to use learning objects? } \\
\hline Themes & Participant Responses \\
\hline Practice & $\begin{array}{l}\text { - Extra aid - 2nd step; different practice } \\
\text { - Reinforce what they get in the classroom } \\
\text { - Lower ability kids that haven't quite gotten the concept }\end{array}$ \\
\hline Instruction & $\begin{array}{l}\text { - How I'll sequentially present it and which students need it. } \\
\text { - Different ways - methodology, perspectives of doing same thing } \\
\text { - Purpose - what, why, end result } \\
\text { - What students get out of it } \\
\text { - Don't want it as busy work } \\
\text { - Actually learn something } \\
\text { - Applicable to what I'm teaching in class } \\
\text { - Standards } \\
\text { - Current in world such as weather patterns, charting tools } \\
\text { - I design it to be internet based. Ex. What will life be like after I } \\
\text { graduate; at } 30 \text { years; pre/post; my apartment - rent; stocks; checks }\end{array}$ \\
\hline Conceptual & $\begin{array}{l}\text { - Something that makes it very concrete, breaks it down into kid } \\
\text { friendly chunks } \\
\text { - Good memory tool, like a song or memory trick } \\
\text { - Visualize } \\
\text { Motivation } \\
\text { - Upper ability kids for challenge } \\
\text { - Student interest } \\
\text { - Hold their [student] attention } \\
\text { - I want them [students] to like math }\end{array}$ \\
\hline $\begin{array}{l}\text { Access/Readability } \\
\text { - Easily accessible } \\
\text { - Can they do it by themselves } \\
\text { - Can you read it - text font is readable } \\
\text { Interactive } \\
\text { - How interactive it is }\end{array}$ \\
\hline Medium
\end{tabular}


Table 5. Open-Ended Question Eight

\begin{tabular}{|c|c|}
\hline \multicolumn{2}{|c|}{$\begin{array}{l}\text { What characteristics of learning objects do you find the most useful for your } \\
\text { instructional purposes? Why? }\end{array}$} \\
\hline Themes & Participant Responses \\
\hline $\begin{array}{l}\text { Instruction: } \\
\text { purpose \& } \\
\text { organization }\end{array}$ & $\begin{array}{l}\text { Purpose } \\
\text { - Having specific outcome - task; Purpose driven; Learning something } \\
\text { from it } \\
\text { - Real world - things they [students] might actually do, make them like } \\
\text { math; } \\
\text { - Challenging } \\
\text { Organization } \\
\text { - Time constraints - can be done in a short amount of time; get more kids } \\
\text { on a computer } \\
\text { - Something to do with a partner }\end{array}$ \\
\hline $\begin{array}{l}\text { Conceptual } \\
\text { ideas }\end{array}$ & $\begin{array}{l}\text { - Conceptual - think about it in a different way; Show things in a new } \\
\text { way; Not necessarily the normal stuff [textbook]; Multiple examples } \\
\text { - Talk through - learn more } \\
\text { - Can include more sensory - sound, visual, kinesthetic } \\
\text { - Creative/different } \\
\text { - Real world - things they [students] might actually do, make them like } \\
\text { math } \\
\text { - Resource is truly a tool rather than a computer-based presentation of } \\
\text { something in a book. } \\
\text { - Dynamic tool I can manipulate at will and accurately illustrates } \\
\text { concepts } \\
\text { - 3D if helpful for concept }\end{array}$ \\
\hline Visual & $\begin{array}{l}\text { - Most important - visuals } \\
\text { - Visual for buy in; } \\
\text { - 3D if helpful for concept } \\
\text { - Diagrams } \\
\text { - Visualize on computers, you're able to show things more visually }\end{array}$ \\
\hline $\begin{array}{l}\text { Visually } \\
\text { appealing }\end{array}$ & $\begin{array}{l}\text { - Visually appealing } \\
\text { - Color coding }\end{array}$ \\
\hline $\begin{array}{l}\text { Access/ } \\
\text { Readability }\end{array}$ & $\begin{array}{l}\text { - Easily accessible } \\
\text { - User friendly; Can they do it by themselves; If kids can navigate easily } \\
\text { on their own; Easy to manipulate } \\
\text { - Can include more sensory - sound, visual, kinesthetic } \\
\text { - Directions - not too complicated; Chunks - steps of instruction } \\
\text { - Can you read it - text font is readable }\end{array}$ \\
\hline Interactive & $\begin{array}{l}\text { - Hands-on } \\
\text { - Dynamic tool I can manipulate at will and accurately illustrates } \\
\text { concepts. }\end{array}$ \\
\hline
\end{tabular}


The last open-ended question adds any additional comments from the participant about the study. As the responses cross all questions and adds additional context to each participant's personal constructs, they are presented in their entirety in Table 6.

Table 6. Open-Ended Question Nine

\begin{tabular}{|c|c|}
\hline \multicolumn{2}{|c|}{ Anything else you'd like to add that you think might pertain to this study? } \\
\hline Participant & Additional Comments \\
\hline 001 & $\begin{array}{l}\text { - Visuals most important } \\
\text { - Something you would be able to bring into the classroom } \\
\text { - Geared toward tech children }\end{array}$ \\
\hline 002 & $\begin{array}{l}\text { - } \text { Access } \\
\text { - Time } \\
\text { - Consistent } \\
\text { - } \text { Some kids get right on it } \\
\end{array}$ \\
\hline 003 & - Enjoyed seeing the learning objects \\
\hline 004 & $\begin{array}{l}\text { - Keeping them [students] interested, challenged, not too easy } \\
\text { - Kids get the most involved in ones more like games - don't know } \\
\text { they're learning }\end{array}$ \\
\hline 005 & $\begin{array}{l}\text { - These are useful, but finding them take a lot of time } \\
\text { - Central website with grade, standard, and have a list - what could be } \\
\text { more useful } \\
\text { Comments Regarding Learning Objects: } \\
\begin{array}{ll}\text { - Not desirable } & \text { Desirable } \\
\text { - Doesn't teach conceptual } & \text { - Highly interactive } \\
\text { - Not interactive } & \text { Builds conceptual } \\
\text { - A lot of reading } & \text { Sustains attention }\end{array}\end{array}$ \\
\hline 006 & $\begin{array}{l}\text { Some things [learning objects] - where you find them; you need to have a } \\
\text { lot of time for it. }\end{array}$ \\
\hline 007 & $\begin{array}{l}\text { Nothing more [just reiterated] - if I don't use them [learning objects], I lose } \\
\text { them [students]. }\end{array}$ \\
\hline 008 & $\begin{array}{l}\text { That it [learning object] enables students to solve word problems by } \\
\text { utilizing the visual model as a tool }\end{array}$ \\
\hline
\end{tabular}

\section{Repertory Grid}

The repertory grid was analyzed with WebGrid III's Display and FOCUS cluster programs (Shaw \& Gaines, n.d.). In addition, the grids were analyzed using content analysis 
which follows the cluster analysis. These analyses address all parts of Research Question One.

\section{FOCUS (HiERARChical) Cluster Analysis}

Figure 3 is an example of participant 008 's data in Display, which simply organizes the ratings, elements, and constructs into a table. Constructs are displayed horizontally on both sides of the figure, with "not spatial thinking" on the left and its bipolar construct "spatial thinking" on the right. At the bottom of the figure, the elements are listed left to right as A-J. Element A was rated by participant 008 as a 3 for "spatial thinking/not spatial thinking" which means it was right in the middle of the 1 to 5 Likert item. Element $\mathrm{C}$ received a 5 which means it was rated the highest on the scale for "spatial thinking".

Cluster analysis is a quantitative method that examines raw data, in this case the construct ratings generated by teachers as qualified by three different situations, and seeks correlations between elements and between constructs. Elements or constructs that are highly correlated would be at $86 \%$ (Stewart, Stewart, \& Fonda, 1981). The FOCUS program produces a V-branch dendrogram as a result of the cluster analysis. The closer the correlation in the dendrogram, the flatter the connecting branches appear. Figure 3 shows the V-branch dendrogram from participant 008 . Ratings of 4 or 5 are shaded and grouped together, while ratings of 1 or 2 are not shaded and also grouped together. A middle rating would be 3 and it has a dotted background. These scores represent the ratings that each element (numbered from one to ten below the box) received on each construct (numbered and located on the left and right side of the box). Looking across the scores, it can be seen that the patterns that are very similar are clustered together with their constructs. Correlation scores then determine 
the closeness of the branch and their proximity to other branches. In the upper right hand of the figure, you see a scale of 100 to 60 , which means the highest correlation would be at the $100 \%$ level and closest to the box on the left, while the lowest rating at $60 \%$ would be furthest from the box. In Figure 3, "Immediate feedback" and "Information visible on one screen" had a $100 \%$ correlation.

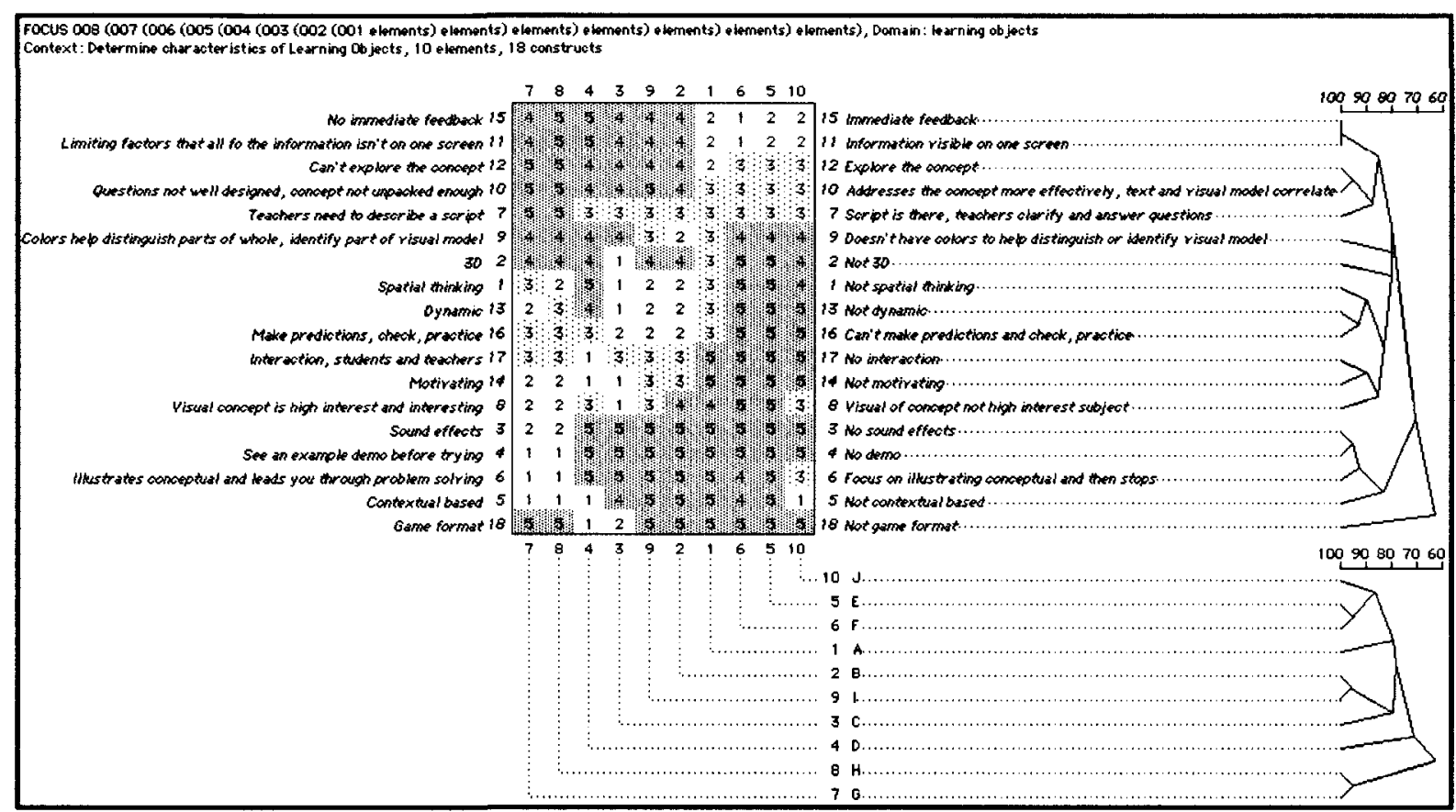

Figure 3. Display Data of Participant 8.

Now looking at Figure 4, one can see that participant 002 had a 95\% correlation between construct (C)5 "Less interactive/Interactive" and C19 "No strategies/Strategies". Another cluster pair of highly correlated constructs are C3 "Not thinking outside the box/Thinking outside the box" \& C5 "Less interactive/ Interactive" at $92.5 \%$. These constructs have a reverse or negative correlation as they appear reversed, that is if they had a positive correlation, you would see C3 "Thinking outside the box" and C5 "Interactive" on the right hand side of the box, not their polar constructs. Notice that C16 "Easy to access 
instructions" and C7 "Just right reading" have a positive correlation as they are located on the right side of the box. The cluster data indicates the correlation as positive or negative and as the researcher, you need to look at the data to see which correlations were rated as closer to which end of the 1-5 Likert rating. What this means is that some constructs have a negative correlation and some have a positive correlation. It is important to remember that in Personal Construct theory, you only know what a construct means when you see its polar opposite. However, in eliciting constructs, you can't assume that the opposite of a person's construct is the traditional "not", as is seen when you consider participant 008 's Construct 10 "Addresses the concept more effectively, text and visual model correlate." Its polar opposite as defined by the participant was "Questions not well designed, concept not unpacked enough." One of the advantages of the repertory grid method mentioned previously is that observer bias is eliminated when eliciting constructs; it is the participant who states the constructs and their polar opposites. So in the data, the relationships of $\mathrm{C} 16$ and $\mathrm{C} 7$ make sense, that is it makes sense that if a characteristic of a learning object is that it has "easy to read instructions", then it might also be described as having "just right reading". It is also possible that a learning object that is "less interactive" (C5), might also be "not thinking outside the box" (C3).

Some constructs are clustered together as in cluster group C16, C7, and C8 "Easy to access instruction/Less easy to access instructions", "Just right reading/Too much reading" and "More colorful/Less colorful", respectively. These constructs had an $87.5 \%$ correlation. Lastly, sometimes constructs are not branched with any other constructs, but instead are linked to clusters. For example, C13 "Teacher page/Not teacher page" is the only construct not branched with any other construct. Instead it connects at about a $60 \%$ correlation to the 
other construct clusters.

One of the benefits of using cluster analysis is that it doesn't throw out any of the details in the relationships between constructs and elements (Stewart, 2005). In addition, it is fairly easy to read the data displayed in the dendrogram.

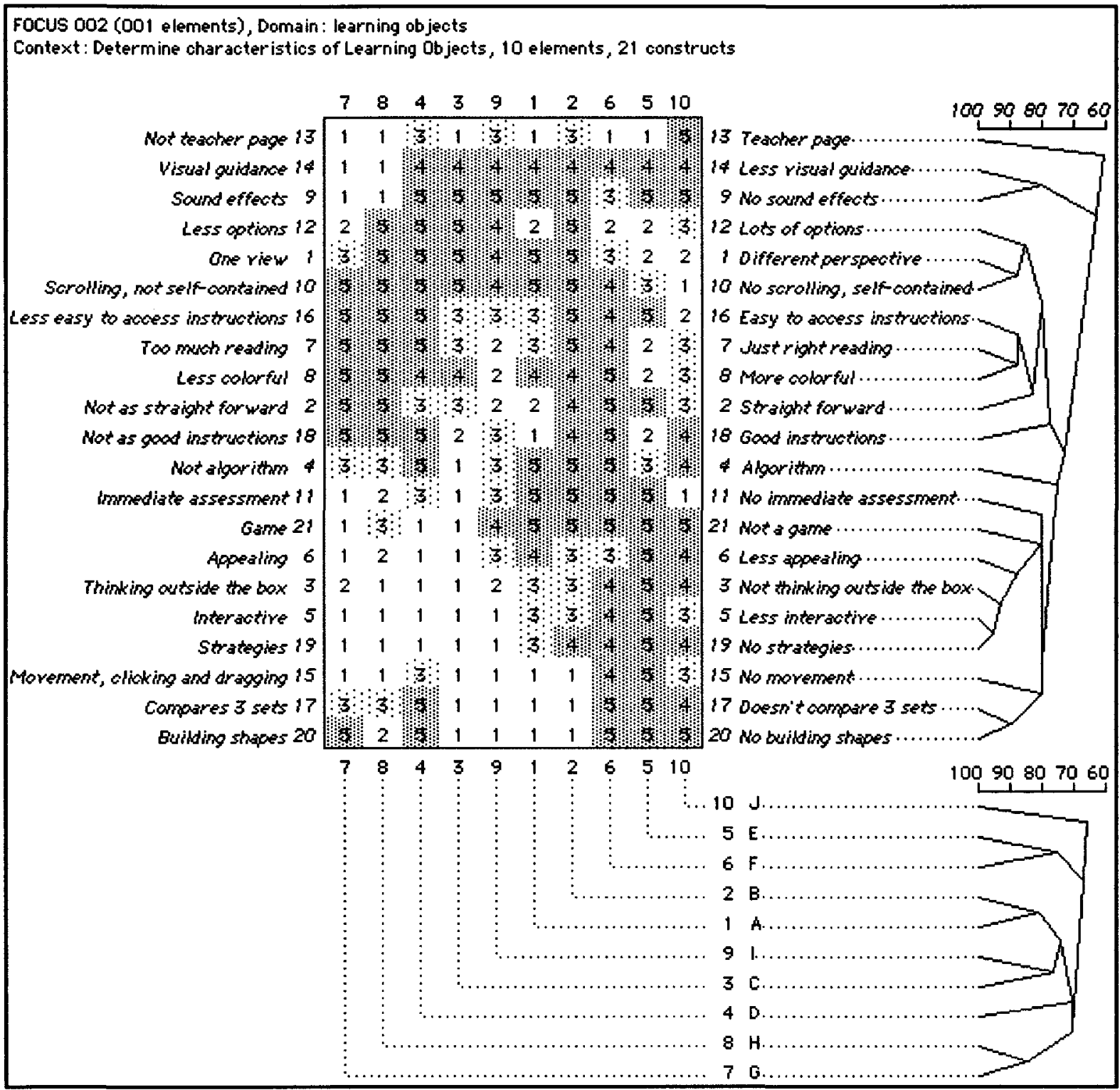

Figure 4. FOCUS V-branch Dendrogram of Participant 002.

Table 7 summarizes the correlations between constructs for each participant. Only the construct correlations above $86 \%$ were listed in the table as these have the highest 
correlations (Stewart, et al, 1981). As you look across the table, it is evident that each

teacher's constructs were highly correlated and there were many correlations above $86 \%$.

The only exception is participant 004 , who had two construct pairs at $87.5 \%$ correlation. This participant elicited 16 constructs, the mean for all construct elicitation was 16.25. However, there were four cluster pairs at the $85 \%$ level that had to do with problem solving, changing the format (not repetitious), situational (not a model), and being able to manipulate the learning object. A complete summary with specific percentage correlations is found in Appendix D.

Table 7. Summary of FOCUS Cluster Construct Correlations of All Participants

\begin{tabular}{|c|c|c|}
\hline Participant & Correlation \% & Constructs \\
\hline 001 & $87.5-100 \%$ & $\begin{array}{l}\text { Summary: The LO's characteristics are: More than one person; Game; } \\
\text { Engaging; More activities; Kinesthetic; Dynamic- building concep- } \\
\text { tual knowledge; the Technology enhances the conceptual learning; } \\
\text { Hands-on practice; Concrete; Kid friendly; Visuals enhance; Real } \\
\text { life Comparisons; Compares; Construction; and More fun. }\end{array}$ \\
\hline 002 & $87.5-95 \%$ & $\begin{array}{l}\text { Summary: Interactive; Strategies; Thinking outside the box; } \\
\text { Compares } 3 \text { sets; Building shapes; No scrolling, self contained; } \\
\text { Appealing; Just right reading; More colorful; and Easy access to } \\
\text { information. }\end{array}$ \\
\hline 003 & $87.5-97.5 \%$ & $\begin{array}{l}\text { Summary: Visualize; Practical; Making into parts; Interactive; } \\
\text { Conceptual; Teach something first; Easily accessible; Reading } \\
\text { doesn't hinder; User friendly; and Organized in an easier way. }\end{array}$ \\
\hline 004 & 87.5 & $\begin{array}{l}\text { Summary: Analytical thinking and problem solving; Problems to } \\
\text { solve; Like a game, a goal to reach; and has a Purpose. }\end{array}$ \\
\hline 005 & $87.5-97.5 \%$ & $\begin{array}{l}\text { Summary: Interactive; Holds attention; Challenging; Useful; Can't } \\
\text { help but learn; Discovery learning; Conceptual development; } \\
\text { Multiple ways, and } 2 \text { students more beneficial. }\end{array}$ \\
\hline 006 & $90-97.5 \%$ & $\begin{array}{l}\text { Summary: Engaging; Students responsible for doing something; } \\
\text { Interacting, in control; Challenging; Lends itself to partner work; } \\
\text { Multiple learning opportunities Directions clear; Kid friendly, easy } \\
\text { to access, gets to the point; Visually appealing; Conceptual } \\
\text { development; and Samples, models. }\end{array}$ \\
\hline 007 & $87.5-97.5 \%$ & $\begin{array}{l}\text { Summary: Adjust it and make changes; More than one answer; } \\
\text { Animation; Easier to understand, prompts; Area \& volume } \\
\text { relationships; Not verbose; Makes you think harder; Variation, } \\
\text { choices; 3D; and Visual. }\end{array}$ \\
\hline 008 & $87.5-100 \%$ & $\begin{array}{l}\text { Summary: Information is visible on one screen; Immediate feedback; } \\
\text { Sound effects; See an example, demo before trying; Addresses the } \\
\text { concept more effectively, text and visual correlate; Illustrates } \\
\text { conceptual and leads you through problem solving; Dynamic; Make } \\
\text { predictions, check, practice; Spatial thinking; Motivating; } \\
\text { Interaction, students and teachers; and Script is there, teachers }\end{array}$ \\
\hline
\end{tabular}




\begin{tabular}{|l|l|l|}
\hline Participant & Correlation \% & Constructs \\
\hline & & clarify and answer questions. \\
\hline
\end{tabular}

Note: Correlations for each construct pair are listed in the order of their relationship, positive or negative.

Four participants' construct correlations were negative (reversed), one was positive, and three were mixed. Participant 004 was the only one to have mixed correlations, that is one construct was positive and its correlation was negative, i.e $\mathrm{C}^{-1} 14$ and $\mathrm{C} 13$ (85\%); $\mathrm{C}^{-1} 14$ and C 7 (75\%); C ${ }^{-16}$ and C 11 (70\%). Construct ${ }^{-14}$ was "don't manipulate" and its pair was "situation (not a model)". It is also apparent that there is a language that is common to all teachers as they generated characteristics of learning objects. For example, engaging, visuals, interactive, conceptual, and kid friendly were a few of the common characteristics participants used.

\section{Content Analysis}

In order to conclude if teachers used similar characteristics of learning objects to determine their usefulness in the classroom, content analysis - a qualitative method, was used. First, the repertory grids of each teacher were compiled and the mean of each construct was calculated to include the three different situations for "how important is this [construct] in terms of": specific students in your classroom; student groupings in your classroom; and your instructional purpose. In addition, the mean of the "students", i.e. specific students and student groupings were calculated to see if it made a difference being separated from instructional use, which it did. If there were differences in the ratings for each construct, then the highest rating went to "specific students" and the lowest went to "your instructional purpose" with the exception of one construct and its related construct. This is discussed below. Not all ratings were the same across situations, nor were they all different. However, 
the mean for student purposes as compared to teacher purposes was always higher. In order to gain some idea of the correlation between construct terms, one of the features of WebGrid III was used as it generates construct matches and the percentage of those matches. This provided very visible evidence of how many constructs relationships there were and as well as patterns of common terms.

Next, a table which included each teacher's grid was compiled and terms were sorted. First, all the terms with exact pairs, then common idea pairs, next common themes, and finally, categories were generated. Table 8 illustrates how each teacher's constructs were sorted and then put into a category. The top row of the table sets the context for the table, i.e. the constructs are on each side of the table with the three situations or qualifiers between. The mean of the three situations had already been calculated and inserted as each construct was sorted. As there were only three ratings with each construct, the fact that the teacher's instructional purpose situation rating was always lower, if it was different, did not interfere with the sorting of the constructs or characteristics. In fact, it helped to point out that in all cases, that if there was a difference in the ratings, then the first situation, in terms of specific students in your class, always had the highest rating and total mean with the exception of the construct "games" and "number of participants" which are related. These two constructs fell into the "Options" category as you will later see in Table 10.

This result addresses: Research Question 1b. Do K-12 teachers use specific characteristics of learning objects for specific learners? The simple answer to the question is yes. When asked, "How important is [construct] in terms of specific students in your class?" teachers rated it the highest and often added additional comments.. A recurring comment went something like this: "Oh, that's really important, especially if I have a kid that doesn't 
get it or if he's an ELL - he needs the visuals." As a point of clarification, this particular result required a follow-up interview in order to clarify who these specific learners were. During construct elicitation and laddering, teachers did not identify who these learners were but clearly had specific learners in mind when planning. Additional comments that teachers made during construct elicitation were regarding some learning objects lending themselves to partner work even if that wasn't its purpose.

The themes that emerged fell into two basic categories: Thinking $\&$ Learning and Learning Object Design. Thinking and Learning had to do with teacher planning and decision making while the Learning Object Design category had to do with the learning objects themselves - their different features or characteristics. However, it is readily evident that the two cannot be separated as the thinking and learning is dependent upon the learning objects and how they are designed. Two constructs were "outliers," as they really didn't fall into a category and their ratings were the lowest - indicating least preference. These two were: teacher page/not teacher page and multicultural/not multicultural. Each construct was only mentioned once. The teacher page was rated $1 / 1 / 4$ and the multicultural ratings were $4 / 2 / 2-$ not surprising as one teacher mentioned that it would be important for "specific students" in the case of multicultural while the other mentioned that only teachers would be interested in the case of the teacher page.

One characteristic, dynamic; building conceptual knowledge, fell into two categories as it is describes the conceptual development as well as the design aspect of being interactive. Therefore, this characteristic is in both the Thinking \& Learning and the Learning Object Design categories. The number of constructs for both categories is listed as 133 total constructs, if you add 47 and 86 . However, since the construct, dynamic: building conceptual 
knowledge, is listed in both categories, there were actually 132 constructs. A complete list of the categories of constructs or learning object characteristics is found in Appendix E.

Table 8. Thinking \& Learning Category Sort

\begin{tabular}{|c|c|c|c|c|c|c|c|}
\hline \multicolumn{8}{|c|}{ Laddering Toward Purpose with Qualifiers - Importance } \\
\hline Constructs & \multicolumn{2}{|l|}{$\mathbf{S}$} & Ss & \multicolumn{2}{|c|}{$\mathbf{T}$} & Mean & Constructs \\
\hline Emergent Pole & \multicolumn{2}{|c|}{$\begin{array}{c}\begin{array}{c}\text { In terms of } \\
\text { specific } \\
\text { students in } \\
\text { your class }\end{array} \\
\end{array}$} & $\begin{array}{c}\text { In terms of } \\
\text { student } \\
\text { groupings in } \\
\text { your } \\
\text { classroom }\end{array}$ & \multicolumn{2}{|c|}{$\begin{array}{c}\begin{array}{l}\text { In terms of } \\
\text { your } \\
\text { instructional } \\
\text { purpose }\end{array} \\
\end{array}$} & $\begin{array}{c}\text { Mean of } \\
\text { Constructs } \\
\text { across } \\
\text { purposes }\end{array}$ & Implicit Pole \\
\hline \multicolumn{8}{|c|}{ Thinking \& Learning: Conceptual } \\
\hline \multicolumn{2}{|l|}{ Constructs } & $\mathbf{S}$ & Ss & $\mathbf{T}$ & Mean & \multicolumn{2}{|r|}{ Constructs } \\
\hline \multicolumn{2}{|l|}{$\begin{array}{l}\text { Addresses concept more } \\
\text { effectively }\end{array}$} & 5 & 5 & 5 & 5.00 & \multicolumn{2}{|c|}{$\begin{array}{l}\text { Questions not well } \\
\text { designed; concept not } \\
\text { unpacked enough }\end{array}$} \\
\hline \multicolumn{2}{|l|}{ Conceptual development } & 5 & 5 & 5 & 5.00 & \multicolumn{2}{|c|}{ No conceptual development } \\
\hline \multicolumn{2}{|l|}{ Conceptual development } & 5 & 5 & 5 & 5.00 & \multicolumn{2}{|r|}{ Not conceptual } \\
\hline \multicolumn{2}{|l|}{$\begin{array}{l}\text { *Dynamic; building } \\
\text { conceptual knowledge }\end{array}$} & 5 & 5 & 5 & 5.00 & \multicolumn{2}{|r|}{ Static; rote learning } \\
\hline \multicolumn{2}{|l|}{$\begin{array}{c}\text { Illustrates concept \& leads } \\
\text { you through sequential } \\
\text { problem solving process; } \\
\text { sequential routine }\end{array}$} & 5 & 5 & 5 & 5.00 & \multicolumn{2}{|c|}{$\begin{array}{l}\text { Not sequential problem } \\
\text { solving process }\end{array}$} \\
\hline \multicolumn{2}{|l|}{$\begin{array}{l}\text { Potential for interpreting } \\
\text { numbers \& concept is } \\
\text { higher because of the } \\
\text { dynamic nature; make } \\
\text { predictions \& check; } \\
\text { practicing }\end{array}$} & 5 & 5 & 5 & 5.00 & \multicolumn{2}{|c|}{$\begin{array}{l}\text { Can't make predictions \& } \\
\text { check; practice }\end{array}$} \\
\hline \multicolumn{2}{|l|}{$\begin{array}{l}\text { Visually enhanced; } \\
\text { conceptual understanding }\end{array}$} & 5 & 4 & 5 & 4.67 & \multicolumn{2}{|c|}{$\begin{array}{l}\text { Visuals didn't lend to } \\
\text { further understanding }\end{array}$} \\
\hline \multicolumn{2}{|l|}{$\begin{array}{l}\text { Not like pen \& paper; tech } \\
\text { enhances concepts, concrete }\end{array}$} & 5 & 3 & 5 & 4.33 & \multicolumn{2}{|c|}{$\begin{array}{l}\text { Paper \& pencil; no need for } \\
\text { tech }\end{array}$} \\
\hline \multicolumn{2}{|l|}{$\begin{array}{l}\text { Conceptual; explain } \\
\text { visually why }\end{array}$} & 5 & 4 & 1 & 3.33 & \multicolumn{2}{|c|}{$\begin{array}{l}\text { Not conceptual; doesn't } \\
\text { visualize why }\end{array}$} \\
\hline \multicolumn{2}{|l|}{$\begin{array}{l}\text { Visual of concept is high } \\
\text { interest subject \& } \\
\text { interesting }\end{array}$} & 5 & 5 & 5 & 5.00 & \multicolumn{2}{|c|}{$\begin{array}{l}\text { Visual of concept not high } \\
\text { interest subject or } \\
\text { interesting }\end{array}$} \\
\hline \multicolumn{2}{|l|}{ Visualize } & 5 & 5 & 5 & 5.00 & \multicolumn{2}{|r|}{ Not visualize } \\
\hline \multicolumn{2}{|l|}{ Spatial thinking } & 5 & 5 & 5 & 5.00 & \multicolumn{2}{|r|}{ Not spatial thinking } \\
\hline \multicolumn{2}{|l|}{ Visual } & 4 & 4 & 4 & 4.00 & & Concrete \\
\hline
\end{tabular}




\begin{tabular}{|c|c|c|c|c|c|}
\hline Concrete & 5 & 5 & 5 & 5.00 & Abstract \\
\hline Mean of Constructs & $\mathbf{4 . 9 3}$ & $\mathbf{4 . 6 4}$ & $\mathbf{4 . 6 4}$ & $\mathbf{4 . 7 4}$ & Ind. Student, Gps, Instr. \\
\hline
\end{tabular}

The results of all constructs in the Thinking and Learning category and their means are found in Table 9. Constructs or characteristics are listed in the first column of the table. The total number of constructs for each category is represented by $n$. Then the three situation qualifiers are represented as follows: specific students in your class $(S)$, student groupings $(S s)$, and instructional purpose (T). The total mean of all groups is in the final column. The themes for Thinking \& Learning were: Conceptual (14 constructs); Creative Thinking, Problem Solving, \& Discovery Learning (12); Purpose - Review, Practice, \& Connections (11); Feedback (5), and Motivation (5). Conceptual was often entwined with visual as teachers discussed kids being able to visualize a concept or that it [a learning object] made a concept visual for a student. Since that occurred so often during the interviews and teachers made "visual" distinct from perspective of 3D, it was included in the Thinking \& Learning: Conceptual category and not the Learning Object Design category. It had a mean of 4.93 and the third highest number of constructs which illustrates the importance teachers placed on this characteristic.

Creative Thinking, Problem Solving, and Discovery Learning are instructional strategies, but as there were no other distinctions made, this collectively became a characteristic. This characteristic also had a high mean at 4.92 and 12 constructs. PurposeReview, Practice, \& Connections are all related to instructional purpose. Feedback and Motivation are often used in context with one another as having a codependent relationship, but they are uniquely different so they each became a separate characteristic. While Feedback and Motivation were each mentioned only five times, they represent five out of eight 
participants, which is more than half of the total. In addition, their mean ratings were 4.80 and 5.00, respectively, demonstrating the high priority that teachers put on these characteristics. Lastly, both were mentioned again in the structured interviews.

Table 9. Thinking \& Learning Category

\begin{tabular}{|c|c|c|c|c|c|}
\hline \multicolumn{7}{|c|}{ THINKING \& LEARNING } \\
\hline Constructs & $\mathbf{n}$ & $\mathbf{S}$ & $\mathbf{S s}$ & $\mathbf{T}$ & Mean \\
\hline Characteristics & $\begin{array}{c}\text { \# of } \\
\text { construct } \\
\text { comments } \\
\text { in this } \\
\text { category }\end{array}$ & $\begin{array}{c}\text { In terms } \\
\text { of specific } \\
\text { students in } \\
\text { your class }\end{array}$ & $\begin{array}{c}\text { In terms } \\
\text { of student } \\
\text { groupings } \\
\text { in your } \\
\text { classroom }\end{array}$ & $\begin{array}{c}\text { In terms } \\
\text { of your } \\
\text { instruction } \\
\text { al purpose }\end{array}$ & $\begin{array}{c}\text { Mean of } \\
\text { Constructs } \\
\text { across } \\
\text { purposes }\end{array}$ \\
\hline Conceptual & 14 & 4.93 & 4.64 & 4.64 & 4.74 \\
\hline $\begin{array}{c}\text { Creative Thinking, } \\
\text { Problem Solving, \& } \\
\text { Discovery Learning }\end{array}$ & 12 & 4.92 & 4.75 & 4.42 & 4.69 \\
\hline $\begin{array}{c}\text { Purpose - Review, } \\
\text { Practice, \& } \\
\text { Connections }\end{array}$ & 11 & 4.73 & 3.64 & 3.09 & 3.82 \\
\hline Feedback & 5 & 4.80 & 4.80 & 4.40 & 4.67 \\
\hline Motivation & 5 & 5.00 & 4.60 & 4.20 & 4.60 \\
\hline \multicolumn{7}{|c|}{ Total \# of Constructs = 47 } & & \\
\hline
\end{tabular}

There were a total of 47 constructs in the Thinking and Learning category and almost twice as many constructs in the Learning Object Design category, 84 , not including the 2 outliers. As seen in Table 10, the Learning Object Design Category, the common characteristic that 3 teachers mentioned had to do with the learning object being an appropriate tool that it was not just "a paper and pencil activity" on the computer. This 
characteristic received the highest rating (5) in each of the three teachers' grids, for use with specific students in your class. While accessibility is a term identified with learning object design, as teachers used it, it had more to do with students accessing the content rather than accessing the tool such as is the case with accessibility, i.e. learning disabled or mobile learners. Accessing Content had the most constructs at 24 with a mean of 4.58 for in terms of specific students in your class, which is high considering the large number of constructs in this characteristic. The mean across situations (specific students, student groups, and instructional purpose) was 4.33 or $87 \%$. Learning objects with this characteristic are described as: straightforward; kid friendly; easy to understand; just right reading; and visible on one screen.

Dynamic and Interactive were used interchangeably by two participants. When queried about what dynamic meant, the descriptions were the same: it meant the learner was interacting with the learning object that was involved or meaningful. There were 15 constructs for this characteristic and the mean was 4.80 (for specific students), which is very high - rating the same as Feedback which had only 1/3 the number of constructs. The mean rating for in terms of your Instructional Purpose for Dynamic/Interactive was 1.00 less than that for specific students. Overall, the in terms of your Instructional Purpose tended to have the lowest ratings for every participant. One characteristic, Teacher Page, would only be pertinent to a teacher. It is located in the Outlier characteristic. Options - Number of Participants was rated higher for student groupings than specific students or instructional purpose. Color was mentioned in some capacity five times and had a 5.00 rating (for specific students). Graphics were only mentioned two times. The last characteristics and their number of constructs (\# of constructs) for the Learning Object Design category are: 3 Dimensional, 
Model, Situation (9); Options - Number of Participants (4); Options - Format (4); Options -

Variation (12); Sound (4), Visual Appeal (2); and Odds \& Ends-Outliers (2).

Table 10. Learning Object Design Category

\begin{tabular}{|c|c|c|c|c|c|}
\hline \multicolumn{7}{|c|}{ LEARNING OBJECT DESIGN } \\
\hline Constructs & $\mathbf{n}$ & $\mathbf{S}$ & Ss & T & Mean \\
\hline Characteristics & $\begin{array}{c}\text { \# of } \\
\text { construct } \\
\text { comments } \\
\text { in this } \\
\text { category }\end{array}$ & $\begin{array}{c}\text { In terms } \\
\text { of specific } \\
\text { students in } \\
\text { your class }\end{array}$ & $\begin{array}{c}\text { In terms } \\
\text { of student } \\
\text { groupings } \\
\text { in your } \\
\text { classroom }\end{array}$ & $\begin{array}{c}\text { In terms } \\
\text { of your } \\
\text { instruction } \\
\text { al purpose }\end{array}$ & $\begin{array}{c}\text { Mean of } \\
\text { Constructs } \\
\text { across } \\
\text { purposes }\end{array}$ \\
\hline Appropriate for Use & 3 & 5.00 & 4.00 & 5.00 & 4.67 \\
\hline $\begin{array}{c}\text { Accessing Content- Kid } \\
\text { Friendly, Readability }\end{array}$ & 24 & 4.58 & 4.38 & 4.04 & 4.33 \\
\hline Dynamic/Interactive & 15 & 4.80 & 4.27 & 3.80 & 4.29 \\
\hline Color & 5 & 5.00 & 4.20 & 4.00 & 4.40 \\
\hline Graphics & 2 & 4.50 & 3.50 & 4.00 & 4.00 \\
\hline 3 D, Model, Situation & 9 & 3.56 & 3.56 & 3.44 & 3.52 \\
\hline $\begin{array}{c}\text { Options - \# of } \\
\text { Participants }\end{array}$ & 4 & 2.50 & 4.00 & 1.50 & 2.67 \\
\hline Options - Format & 4 & 3.00 & 4.00 & 3.00 & 3.33 \\
\hline Options - Variation & 12 & 3.75 & 3.25 & 3.25 & 3.42 \\
\hline Sound & 4 & 4.00 & 3.00 & 2.00 & 3.00 \\
\hline Visual Appeal & 2 & 4.50 & 4.50 & 4.00 & 4.34 \\
\hline Odds \& Ends - outliers & 2 & 2.50 & 1.50 & 3.00 & 2.34 \\
\hline
\end{tabular}

\section{SUMmARY OF RESEARCH QUESTION ONE RESULTS}

$\boldsymbol{R} \boldsymbol{Q 1}$. What are the important characteristics of learning objects that K-12 teachers determine useful for their instructional purposes?

To summarize the results of the study for Research Question One, the researcher 
compared the data collected across tables, i.e. structured interviews, cluster analysis, and content analysis and found the important characteristics of learning objects fall into the two categories summarized in the content analysis. There are common themes and categories of characteristics that teachers determine the most useful for their instructional purposes. First, these have to do with the decision making and planning that teachers do when determining to use learning objects and then utilizing these characteristics as well as those found in the design of learning objects. The Thinking \& Learning and Learning Object Design categories encompass learning object characteristics found in the repertory grid interviews, structured interviews, and cluster analysis. Thinking \& Learning characteristics comprised $1 / 3$ of the total characteristics and had high mean ratings, $92 \%+$, across all situations except for Purpose - Review, Practice, \& Connections, which had a 76\% mean rating across situations and a $94 \%$ mean rating for specific students.

RQ1a. Do teachers discern that the purpose of some characteristics of learning objects are more appropriate for:

- conceptual development;

- skill development; and/or

- content information?

As indicated above, teachers discern that some learning objects are more appropriate for conceptual development; skill development - review, practice; and for content - learning objects used to teach mathematics. All of the teachers use math learning objects in their classrooms and their instructional purposes guide their selection of learning objects as shown in their structured interviews, especially the last open-ended question where teachers supplied additional comments for the study. Teachers look for effective uses of learning 
objects and frequently commented on liking a particular learning object as it was useful. A couple of teachers specifically mentioned time constraints, both in finding useful learning objects and in making the time in the classroom schedule, yet both made the time to use them in their classrooms. As one teacher stated, "If I don't use them [learning objects], I lose them [students]."

$\boldsymbol{R} \boldsymbol{Q 1 b}$. Do K-12 teachers use specific characteristics of learning objects for specific learners?

The results indicate that teachers use specific characteristics of learning objects for specific learners as found in the content analysis. To answer this question, the constructs were rated using the qualifier: in terms of specific students in your class, how important is [construct]. This situation prompted the most "thinking out loud" comments from teachers and the mean was the highest across all learning object characteristics, with the exception of learning object design: "options - format" (games or not) and its related construct "\# of participants". However, in order to answer the underlying question more specifically, that is, what are these specific characteristics of learning objects that teachers use for specific learners or is there a finite set of characteristics deemed critical, further questioning of participants would be needed. In order to avoid influencing the participants in how they responded to learning object characteristics and their uses, this underlying question was omitted but warrants further study. Therefore, the originally intended follow-up interview for member checking was expanded to include questions about these specific characteristics.

Teachers were asked to rate the constructs that they'd generated in terms of four groups of specific student groups: English Language Learners (ELL), Low Performing (LP), Students with Learning Disabilities (LD), and Gifted And Talented Educational students 
(GATE). The results were organized in terms of mean comparisons, just as it had been previously. The mean of the four groups were compared to the previous mean of "specific students in your class" and as relevant, comparisons were made within these four groups. In other words, if the data had significant rating differences between one or more groups, then it was compared. This was useful as it was easier to identify some significant differences between GATE students and the other three groups.

In the Thinking \& Learning Category, as seen in Table 11, the mean of all groups for this category was 4.45 and the previous rating of "specific students in your classroom" was 4.88. The "Conceptual" and "Motivation" characteristics had a mean of 4.84 and 4.75 , respectively, across all. This suggests the importance of learning objects having these characteristics for all groups. The GATE students group had the lowest ratings for all of the characteristics except "Creative Thinking, Problem Solving, \& Discovery Learning." This characteristic had the highest rating at 4.83 for GATE students, which was $1.08-1.25$ points more than all of the other groups, a significant difference. This rating difference indicates the importance of this characteristic in learning objects for GATE students and somewhat important but not as important as the other characteristics for the other groups. This characteristic had the lowest ratings, $3.58-3.75$, for the three other student groups. The three student groups: ELL, LP, and LD had very similar scores in all of the characteristics. Their mean rating for characteristics, "Feedback" and "Purpose-Review, Practice, \& Connections", was $0.8-1.19$ more than the GATE group. The standout rating for these three groups was the "Conceptual" characteristic, as teachers rated this 5.00 (the highest possible rating) for students with learning disabilities. To highlight the significance of this rating, it is important to note that there are 14 different responses identified for this characteristic. Low 
performing students also rated highly with a 4.93 and 13 of those 14 responses were 5.00 , which is also significant. The mean rating for ELLS was 4.79 and GATE 4.64.

In summary, conceptual and motivational characteristics rated highly for all groups. "Creative thinking, problem solving, and discovery learning" was rated significantly higher for GATE students while the purpose (review, practice, and connections) and feedback was significantly higher for ELL, LP, and LD student groups. In all characteristics, the original mean for specific students in your class was higher than the groups in the followup interview.

The results for the Learning Object Design Category for all groups, as seen in Table 12, were more consistent with the original mean, 4.29 compared to 4.11 . However, in this category, there were more characteristics that had means which were more than the original mean rating for specific students. Overall, "Appropriate for Use", "Dynamic/Interactive", and "3 Dimensional, Model, Situation" had consistent ratings across all groups. "Accessing Content (Kid Friendly, Readability), "Color", "Options - Format", "Graphics", and "Sound" were rated from $0.75-1.59$ higher than the GATE group with the "Accessing Content" having the greatest difference. The ELL, LP, and LD groups rated 5.00 for "Appropriate for Use" and "Graphics". As with the Thinking \& Learning Category, the three groups: ELL, LP, and LD students had similar ratings for the characteristics except for "Visual Appeal". In this characteristic, the students with learning disabilities were rated 1.00 less than ELL, LP, and GATE students. This is also the only characteristic in which these three groups had the same mean. In the interviews, comments for this characteristic, visual appeal, included the rationale that too many distracting components would interfere with student focus for students with learning disabilities. 
In summary, this Learning Object Design Category had the greatest differences between the original mean and the four defined groups: ELL, LP, LD, and GATE. 
The mean rating for GATE students overall was less than that of all groups with the exception of "Visual Appeal", "3 Dimensional, Model, Situation", and "Options-Variation". Finally, "Visual Appeal" was the only characteristic in which GATE students had the same mean rating as ELL and LP students which was 1.00 more than students with Learning Disabilities.

In summary, the characteristics that teachers find useful for specific students vary, as determined by the group. In general, teachers select learning objects with similar characteristics for English Language Learners, Low Performing students, and students with Learning Disabilities. Learning objects that have "Creative Thinking, Problem Solving, \& Discovery Learning" characteristics were rated the highest for GATE students and was the highest rated characteristic for GATE students. Learning objects whose characteristics include: Conceptual; Motivational; Graphics; Dynamic/Interactive; 3 Dimensional, Model, and Situational; and Appropriate for Use, are useful for all student groups. With the exception of 3 Dimensional, Model, and Situational (mean: 3.72), these characteristics also had the highest means at $4.70-4.92$ which are significantly high on a 5.00 scale.

Comparing the initial means with those of the follow-up interview means, highlighted some differences. The overall mean for the initial situations: specific students, student groupings, and instructional purpose was 4.5 or $90 \%$. For the follow-up interview, the mean was 4.45 or $89 \%$ which doesn't differ greatly across purposes. However, for specific students, the mean was 4.87 or $97 \%$ which is what prompted the researcher to conduct follow-up interview. As stated above, that mean was 4.45 or $89 \%$, lower than the initial means. However, the means for the Learning Object Design category went up from 4.11 or $82 \%$ initially to 4.29 or $86 \%$ for the follow-up interview. 
Table 11. Thinking \& Learning Category with Specific Students: ELL, LP, LD, \& GATE

\begin{tabular}{|c|c|c|c|c|c|c|c|c|c|c|c|}
\hline \multicolumn{12}{|c|}{ THINKING \& LEARNING } \\
\hline Constructs & & & & Mean & & Mean & $\mathbf{S}$ & Ss & $\mathbf{T}$ & Mean & Mean \\
\hline $\begin{array}{c}\text { Characterist } \\
\text { ics }\end{array}$ & \begin{tabular}{|c} 
In \\
terms \\
of \\
ELL \\
studen \\
ts \\
\end{tabular} & $\begin{array}{c}\text { In terms of } \\
\text { low } \\
\text { performing } \\
\text { students }\end{array}$ & $\begin{array}{l}\text { In terms of } \\
\text { students } \\
\text { w/learning } \\
\text { disabilities }\end{array}$ & $\begin{array}{l}\text { Mean } \\
\text { of All } \\
\text { BUT } \\
\text { GATE }\end{array}$ & $\begin{array}{c}\text { In terms } \\
\text { of } \\
\text { GATE } \\
\text { students }\end{array}$ & $\begin{array}{c}\text { Mean of } \\
\text { specific } \\
\text { students } \\
\text { ELL, LP, } \\
\text { LD, } \\
\text { GATE }\end{array}$ & $\begin{array}{c}\text { In terms } \\
\text { of } \\
\text { specific } \\
\text { students } \\
\text { in your } \\
\text { class }\end{array}$ & $\begin{array}{l}\text { In terms } \\
\text { of student } \\
\text { groupings } \\
\text { in your } \\
\text { classroom }\end{array}$ & $\begin{array}{l}\text { In terms } \\
\text { of your } \\
\text { instructi } \\
\text { onal } \\
\text { purpose }\end{array}$ & $\begin{array}{c}\text { Mean of } \\
\text { Construct } \\
\text { s across } \\
\text { purposes }\end{array}$ & $\begin{array}{c}\text { Mean of } \\
\text { specific } \\
\text { students } \\
\text { ELL, } \\
\text { LP, LD, } \\
\text { GATE }\end{array}$ \\
\hline Conceptual & 4.79 & 4.93 & 5.00 & 4.91 & 4.64 & 4.84 & 4.93 & 4.64 & 4.64 & 4.74 & 4.84 \\
\hline $\begin{array}{c}\text { Creative } \\
\text { Thinking, } \\
\text { Problem } \\
\text { Solving, \& } \\
\text { Discovery } \\
\text { Learning }\end{array}$ & 3.67 & 3.75 & 3.58 & 3.67 & 4.83 & 3.96 & 4.92 & 4.75 & 4.42 & 4.69 & 3.96 \\
\hline $\begin{array}{c}\text { Purpose - } \\
\text { Review, } \\
\text { Practice, \& } \\
\text { Connections } \\
\end{array}$ & 4.55 & 4.36 & 4.64 & 4.52 & 3.36 & 4.23 & 4.73 & 3.64 & 3.09 & 3.82 & 4.23 \\
\hline Feedback & 4.60 & 4.80 & 4.60 & 4.67 & 3.80 & 4.45 & 4.80 & 4.80 & 4.40 & 4.67 & 4.45 \\
\hline Motivation & 4.80 & 4.80 & 4.80 & 4.80 & 4.60 & 4.75 & 5.00 & 4.60 & 4.20 & 4.60 & 4.75 \\
\hline $\begin{array}{l}\text { Total \# of } \\
\text { Constructs } \\
=47\end{array}$ & 4.48 & 4.53 & 4.52 & 4.51 & 4.25 & 4.45 & 4.88 & 4.49 & 4.15 & 4.50 & 4.45 \\
\hline
\end{tabular}


Table 12. Learning Object Design Category with Specific Students: ELL, LP, LD, \& GATE

\begin{tabular}{|c|c|c|c|c|c|c|c|c|c|c|c|}
\hline \multicolumn{12}{|c|}{ LEARNING OBJECT DESIGN } \\
\hline Constructs & ELL & LP & LD & $\begin{array}{c}\text { Mean no } \\
\text { GATE }\end{array}$ & GATE & $\begin{array}{c}\text { Mean } \\
\text { ELL, } \\
\text { LP, LD, } \\
\text { GATE }\end{array}$ & $\mathrm{S}$ & Ss & $\mathrm{T}$ & $\begin{array}{c}\text { Mean S, } \\
\text { Ss, T }\end{array}$ & $\begin{array}{c}\text { Mean } \\
\text { ELL, } \\
\text { LP, LD, } \\
\text { GATE }\end{array}$ \\
\hline $\begin{array}{l}\text { Appropriate } \\
\text { for Use }\end{array}$ & 5.00 & 5.00 & 5.00 & 5.00 & 4.67 & 4.92 & 5.00 & 4.00 & 5.00 & 4.67 & 4.92 \\
\hline $\begin{array}{l}\text { Accessing } \\
\text { Content - Kid } \\
\text { Friendly, } \\
\text { Readability }\end{array}$ & 4.67 & 4.83 & 4.88 & 4.79 & 3.29 & 4.42 & 4.58 & 4.38 & 4.04 & 4.33 & 4.42 \\
\hline $\begin{array}{l}\text { Dynamic/Inter } \\
\text { active }\end{array}$ & 4.67 & 4.93 & 4.73 & 4.78 & 4.47 & 4.70 & 4.80 & 4.27 & 3.80 & 4.29 & 4.70 \\
\hline Color & 4.80 & 4.60 & 4.60 & 4.67 & 3.40 & 4.35 & 5.00 & 4.20 & 4.00 & 4.40 & 4.35 \\
\hline Graphics & 5.00 & 5.00 & 5.00 & 5.00 & 4.00 & 4.75 & 4.50 & 3.50 & 4.00 & 4.00 & 4.75 \\
\hline $\begin{array}{l}3 \text { Dimensional, } \\
\text { Model, } \\
\text { Situation }\end{array}$ & 3.56 & 3.56 & 3.89 & 3.67 & 3.89 & 3.72 & 3.56 & 3.56 & 3.44 & 3.52 & 3.72 \\
\hline $\begin{array}{l}\text { Options - } \\
\text { Number of } \\
\text { Participants }\end{array}$ & 3.75 & 4.00 & 3.75 & 3.83 & 3.50 & 3.75 & 2.50 & 4.00 & 1.50 & 2.67 & 3.75 \\
\hline $\begin{array}{l}\text { Options - } \\
\text { Format }\end{array}$ & 4.00 & 4.75 & 4.75 & 4.50 & 3.25 & 4.19 & 3.00 & 4.00 & 3.00 & 3.33 & 4.19 \\
\hline $\begin{array}{l}\text { Options - } \\
\text { Variation } \\
\end{array}$ & 4.08 & 4.17 & 4.50 & 4.25 & 4.25 & 4.25 & 3.75 & 3.25 & 3.25 & 3.42 & 4.25 \\
\hline Sound & 3.75 & 4.50 & 4.50 & 4.25 & 3.00 & 3.94 & 4.00 & 3.00 & 2.00 & 3.00 & 3.94 \\
\hline
\end{tabular}


Table 12. Learning Object Design Category with Specific Students: ELL, LP, LD, \& GATE (continued)

\begin{tabular}{|c|c|c|c|c|c|c|c|c|c|c|c|}
\hline \multicolumn{12}{|c|}{ LEARNING OBJECT DESIGN } \\
\hline Constructs & ELL & LP & $\mathrm{LD}$ & $\begin{array}{c}\text { Mean no } \\
\text { GATE }\end{array}$ & GATE & $\begin{array}{l}\text { Mean } \\
\text { ELL, } \\
\text { LP, LD, } \\
\text { GATE }\end{array}$ & $\mathrm{S}$ & Ss & $\mathrm{T}$ & $\begin{array}{c}\text { Mean S, } \\
\text { Ss, T }\end{array}$ & $\begin{array}{c}\text { Mean } \\
\text { ELL, } \\
\text { LP, LD, } \\
\text { GATE }\end{array}$ \\
\hline Visual Appeal & 4.50 & 4.50 & 3.50 & 4.17 & 4.50 & 4.25 & 4.50 & 4.50 & 4.00 & 4.34 & 4.25 \\
\hline $\begin{array}{l}\text { Overall w/out } \\
\text { Odds \& Ends } \\
\text { - outliers }\end{array}$ & 4.34 & 4.53 & 4.46 & 4.45 & 3.84 & 4.29 & 4.11 & 3.88 & 3.46 & 3.82 & 4.29 \\
\hline $\begin{array}{c}\text { Odds \& Ends - } \\
\text { outliers }\end{array}$ & 5.00 & 5.00 & 5.00 & 5.00 & 3.50 & 4.63 & 2.50 & 1.50 & 3.00 & 2.34 & 4.63 \\
\hline $\begin{array}{c}\text { Overall } \\
\text { w/Outliers }\end{array}$ & 4.40 & 4.57 & 4.51 & 4.49 & 3.81 & 4.32 & 3.97 & 3.68 & 3.42 & 3.69 & 4.32 \\
\hline $\begin{array}{c}\text { Total \# of } \\
\text { Constructs }= \\
86\end{array}$ & 4.34 & 4.53 & 4.46 & 4.45 & 3.84 & 4.29 & 4.11 & 3.88 & 3.46 & 3.82 & 4.29 \\
\hline
\end{tabular}




\section{RESEARCH QUESTION Two RESULTS}

$\boldsymbol{R Q 2}$. How well do the characteristics of learning objects that teachers determine useful relate to traditional design characteristics of learning objects, i.e. reusability, granularity, adaptability, interoperability, accessibility, and discoverability?

To analyze whether there was a relationship between teachers and learning object designers descriptions, it first had to be determined if both parties viewed the learning objects in a similar manner. In other words, when each element (learning object) was rated across each participant's constructs (characteristics), would the mean of these ratings be similar to the mean ratings that the elements received from the learning object experts? Since each of the teachers had different constructs upon which they rated each element on, you can't really compare each rating as the same nor were the ratings from the LORI the same as those of the teachers. However, to could get a sense of how each learning object was viewed through each party's lens and see if there were some general relationships, a mean of means was calculated. In Table 13, the mean ratings of first the teachers and then the experts are shown with the difference of the two means. Across each row, the total ratings for each element are listed for each participant and below that for each expert. The elements are listed in the columns. The final column lists the total number of constructs that each teacher generated as well as the total number of dimensions for each expert. There are nine dimensions on the LORI, but the ninth dimension measure is used to rate the learning object according to international standards and the experts did not use that rating so the total number of dimensions actually used was 8 . A mean of means was then calculated for each element by adding the sum total for each element and dividing that by the total number of constructs, 130 for participants and 24 for experts. You can see that element $G$ had the highest mean, 
both 4.07 for participants and 4.25 for the experts. Element $\mathrm{C}$ also had a 4.07 high rating for participants, but 3.67 for the experts. Clear favorites for teachers were elements $\mathrm{C}$ and $\mathrm{G}$ as they mentioned how much their students would enjoy these learning objects as well as how each LO taught their respective topics effectively.

Table 13. Element Ratings

\begin{tabular}{|c|c|c|c|c|c|c|c|c|c|c|c|}
\hline & & & er & ing & den & $(1$ & ing & ects) & & & \\
\hline \multirow[b]{2}{*}{ Participant } & \multicolumn{10}{|c|}{ Elements } & \multirow[b]{2}{*}{$\#$ of } \\
\hline & A & B & $\mathrm{C}$ & $\mathrm{D}$ & $\mathrm{E}$ & $\mathrm{F}$ & $\mathrm{G}$ & $\mathrm{H}$ & I & $\mathrm{J}$ & \\
\hline 001 & 57 & 80 & 73 & 44 & 29 & 25 & 65 & 81 & 27 & 58 & 19 \\
\hline 002 & 62 & 76 & 80 & 81 & 39 & 58 & 87 & 92 & 70 & 54 & 21 \\
\hline 003 & 47 & 76 & 74 & 28 & 40 & 25 & 80 & 43 & 75 & 25 & 16 \\
\hline 004 & 32 & 30 & 51 & 41 & 31 & 44 & 51 & 41 & 41 & 53 & 16 \\
\hline 005 & 18 & 33 & 74 & 52 & 39 & 23 & 68 & 53 & 60 & 39 & 16 \\
\hline 006 & 25 & 24 & 61 & 56 & 24 & 13 & 63 & 61 & 47 & 42 & 13 \\
\hline 007 & 50 & 52 & 54 & 41 & 12 & 11 & 47 & 40 & 43 & 14 & 11 \\
\hline 008 & 36 & 50 & 62 & 57 & 27 & 27 & 68 & 70 & 51 & 37 & 18 \\
\hline $\begin{array}{l}\text { Mean of } \\
\text { Means }\end{array}$ & 2.52 & 3.24 & 4.07 & 3.08 & 1.85 & 1.74 & 4.07 & 3.70 & 3.18 & 2.48 & 130 \\
\hline 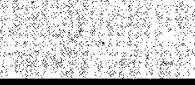 & & & & & 4 & & & & & & \\
\hline Expert 1 & 21 & 29 & 30 & 32 & 22 & 16 & 37 & 36 & 28 & 28 & 8 \\
\hline Expert 2 & 27 & 32 & 27 & 30 & 20 & 22 & 32 & 23 & 20 & 33 & 8 \\
\hline Expert 3 & 24 & 28 & 31 & 27 & NA & 26 & 33 & 33 & 32 & 29 & 8 \\
\hline $\begin{array}{l}\text { Mean of } \\
\text { Means }\end{array}$ & 3.00 & 3.71 & 3.67 & 3.71 & 1.75 & 2.67 & 4.25 & 3.83 & 3.33 & 3.75 & 24 \\
\hline $\begin{array}{c}\text { Mean } \\
\text { Difference }\end{array}$ & 0.48 & 0.47 & 0.4 & 0.63 & 0.1 & 0.93 & 0.18 & 0.13 & 0.15 & 1.27 & \\
\hline
\end{tabular}


As you can see the ratings of teachers and the experts were not substantially different except for elements $\mathrm{F}$ and $\mathrm{J}$. In these two elements, there were large differences: 0.93 for element $\mathrm{F}$ and 1.27 for element $\mathrm{J}$. The experts rated these two elements higher than the teachers. Elements E, F, and $\mathbf{J}$ were the lowest rated for teachers and elements $\mathrm{E}, \mathrm{F}$, and $\mathrm{A}$ were the lowest for the experts. While there is agreement that elements $\mathrm{E}$ and $\mathrm{F}$ are the lowest rating elements of the ten elements, the difference in the ratings for $\mathrm{F}$ and $\mathrm{J}$ may be indicative of the different criteria that teachers and LO designers use in determining important characteristics in learning objects. Elements E, F, and J, according to teachers, had too much reading/text and were not interactive or interactive enough. Also, elements $\mathrm{E}$ and $\mathrm{J}$ were not contained on one screen.

Next, each of the characteristics that teachers used was compared to the LORI which features criteria that rate three of the design characteristics central to learning objects: reusability, adaptability, and accessibility. The other three characteristics, interoperability, discoverability and granularity, were compared separately. Table 14 shows the comparison of learning object characteristics between the two parties, teachers and learning object designers using the LORI instrument for eight learning object characteristics. On the left hand side of the table is a description of each dimension in the LORI, with the exception of the ninth dimension which is for international standards and as stated previously, this was not assessed. On the right hand side of the table are the learning object characteristics as defined by the teachers. Within each dimension, \#1-8, you will see which learning object characteristics/constructs generated by the teachers correlate to the LORI definitions of learning object characteristics. The teachers had the greatest number of construct comparisons in the LORI Learning Goal Alignment. 
Table 14. Comparison of LORI and Teacher Defined Learning Object Characteristics

\begin{tabular}{|c|c|c|}
\hline & $\begin{array}{l}\text { Learning Object Review Instrument } \\
\text { (LORI): } \\
\text { Dimension of Quality }\end{array}$ & $\begin{array}{c}\text { Learning Object } \\
\text { Constructs/Characteristics as defined } \\
\text { by teachers }\end{array}$ \\
\hline 1 & $\begin{array}{l}\text { Content Quality: Veracity accuracy, balanced } \\
\text { presentation of ideas, and appropriate level of } \\
\text { detail } \\
5 \text { rating description: The content is free of error } \\
\text { and presented without bias or omissions that } \\
\text { could mislead learners. Claims are supported by } \\
\text { evidence or logical argument. Presentations } \\
\text { emphasize key points and significant ideas with } \\
\text { an appropriate level of detail. Differences among } \\
\text { cultural and ethnic groups are represented in a } \\
\text { balanced and sensitive manner. }\end{array}$ & $\begin{array}{l}\text { This was addressed when teachers were in the } \\
\text { "play and learn" part of the interview as they } \\
\text { played with each learning object to learn each of } \\
\text { its facets. Teachers found an omission in one of } \\
\text { the learning objects that could mislead learners - } \\
\text { all participants noticed this, i.e. the LO that had a } \\
\text { 3D box does not have a top/lid. It is purposed for } \\
\text { volume, but mentions surface area which it } \\
\text { correctly computes. However, this topic is taught } \\
\text { using all sides of an object, in this case a } \\
\text { rectangular prism which by definition has } 6 \text { sides. } \\
\text { Not mentioning that it doesn't have a top and that } \\
\text { it is not computed in the surface area computation } \\
\text { was an omission that might mislead learners. In } \\
\text { addition, one of the teachers noticed that a } \\
\text { learning object had ethnically diverse children } \\
\text { and that it was multicultural. No other teacher } \\
\text { commented on it and it was not addressed in any } \\
\text { other manner. } \\
\text { As the care of learning objects was given great } \\
\text { consideration, it is not surprising that this did not } \\
\text { come up. The researcher was very careful to } \\
\text { include learning objects that were accurate with } \\
\text { the exception of the one omission above. } \\
\text { However, the LO had characteristics that met } \\
\text { criteria to include it as one of the elements. }\end{array}$ \\
\hline
\end{tabular}


Table 14. Comparison of LORI and Teacher Defined LO Characteristics (continued)

\begin{tabular}{|c|c|c|}
\hline 2. & $\begin{array}{l}\text { Learning Goal Alignment: Alignment among } \\
\text { learning goals, activities, assessments, and learner } \\
\text { characteristics } \\
5 \text { rating description: Learning goals are } \\
\text { declared, either within content accessed by the } \\
\text { learner or in available metadata. The learning } \\
\text { goals are appropriate for the intended learners. } \\
\text { The learning activities, content and assessments } \\
\text { provided by the object align with the declared } \\
\text { goals. The learning object is sufficient in and of } \\
\text { itself to enable learners to achieve the learning } \\
\text { goals. }\end{array}$ & $\begin{array}{l}\text { This was addressed when teachers were in the } \\
\text { "play and learn" part of the interview as they } \\
\text { played with each learning object to learn each of } \\
\text { its facets. Teachers looked for teacher adjuncts } \\
\text { that described this but did not comment on them } \\
\text { specifically as being aligned to learner goals, but } \\
\text { as you can see below, the content of what } \\
\text { teachers mentioned demonstrates their focus on } \\
\text { alignment of LOs to their students and } \\
\text { instructional goals/purposes } \\
\text { Conceptual - addresses concept more } \\
\text { effectively; conceptual development; builds } \\
\text { conceptual knowledge } \\
\text { Creative Thinking, Problem Solving, \& } \\
\text { Discovery Learning - thinking outside the box; } \\
\text { more creative; analytical thinking and problem } \\
\text { solving; thinking logically; makes you think } \\
\text { harder; contextual based; challenging; think more } \\
\text { deeply } \\
\text { Purpose - Review, Practice, \& Connections - } \\
\text { good review of concepts; real life connection; } \\
\text { algorithm; comparing; more practical; useful; } \\
\text { students responsible for doing something } \\
\text { Instruction - standards; current in world such as } \\
\text { weather patterns, charting tools; internet based - } \\
\text { what would life be like after I graduate, at } 30 \text { yrs } \\
\text { - pre/post; purpose - what, why, end result; how } \\
\text { I'll sequentially present it and which students } \\
\text { need it; what students get out of it; don't want } \\
\text { busy work; applicable to what I'm teaching in } \\
\text { class; having a specific outcome - task, purpose } \\
\text { driven, learning something from it } \\
\text { Practice - reinforce what they get int the } \\
\text { classroom; extra tool for learning add as an aid; } \\
\text { review; give students opportunities [for practice] } \\
\text { Assessments are addressed in Feedback. } \\
\text { Open-ended comment at the end - a central } \\
\text { website with grade, standard, and have a list - } \\
\text { what could be more useful? }\end{array}$ \\
\hline
\end{tabular}


Table 14. Comparison of LORI and Teacher Defined LO Characteristics (continued)

\begin{tabular}{|c|c|c|}
\hline 3. & $\begin{array}{l}\text { Feedback and Adaptation: adaptive content or } \\
\text { feedback driven by differential learner input or } \\
\text { learner modeling } \\
5 \text { rating description: The learning object has the } \\
\text { ability (a) to tailor instructional messages or } \\
\text { activities according to the specific needs or } \\
\text { characteristics of the learner or (b) to simulate or } \\
\text { construct phenomena under study in response to } \\
\text { differential input from the learner. A model or } \\
\text { profile of the learner is maintained that influences } \\
\text { the behavior of the learning object. }\end{array}$ & $\begin{array}{l}\text { Feedback - immediate feedback; } \\
\text { encouragement; tells you when you're wrong and } \\
\text { gives you an opportunity to correct it; immediate } \\
\text { visual component to access the reason for the } \\
\text { mistake, in a dynamic way you can access the } \\
\text { visual model to illustrate correct/incorrect } \\
\text { answer. } \\
\text { Adaptation - adaptive content driven by the } \\
\text { learner was not mention by teachers in any of the } \\
\text { conversations or when constructs were elicited. }\end{array}$ \\
\hline 4. & $\begin{array}{l}\text { Motivation: Ability to motivate and interest an } \\
\text { identified population of learners } \\
5 \text { rating description: The learning object is } \\
\text { highly motivating. Its content is relevant to the } \\
\text { personal goals and interests of the intended } \\
\text { learners. The object offers choice, true-to-life } \\
\text { learning activities, multimedia, interactivity, } \\
\text { humor, drama, or game-like challenges. It } \\
\text { provides realistic expectations and criteria for } \\
\text { success. Feedback compares learner } \\
\text { performance to the criteria, shows natural } \\
\text { consequences of the performance, and explains } \\
\text { how the performance can be improved. Learners } \\
\text { are likely to report an increased interest in the } \\
\text { topic after working with the learning object. }\end{array}$ & $\begin{array}{l}\text { Motivation-motivating; more fun; engaging; } \\
\text { holds attention; sustains attention; keeps them } \\
\text { interested, challenged, not too easy } \\
\text { Not addressed in relation to ability to motivate } \\
\text { but these constructs would fall in this category } \\
\text { based on the LORI definition: } \\
\text { Real world - things they might actually do, make } \\
\text { them like math; } \\
\text { Kids get the most involved in ones more like } \\
\text { games - don't know they're learning } \\
\text { Dynamic/Interactive } \\
\text { Options - Format - game, interaction Ss to Ss; } \\
\text { Ss to T } \\
\text { Options - Variation - more activities; lots of } \\
\text { options; variation, choices }\end{array}$ \\
\hline 5. & $\begin{array}{l}\text { Presentation Design: design of visual and } \\
\text { auditory information for enhanced learning and } \\
\text { efficient mental processing } \\
5 \text { rating description: The production values and } \\
\text { information design enable the user to learn } \\
\text { efficiently. The presentations minimize visual } \\
\text { search. Text is legible. Graphs and charts are } \\
\text { labeled and free of clutter. Animated or video } \\
\text { recorded events are described by audio narration. } \\
\text { Meaningful headings signal the content of text } \\
\text { passages. Writing is clear, concise and free of } \\
\text { errors. Color, music, and decorative features are } \\
\text { aesthetically pleasing and do not interfere with } \\
\text { learning goals. }\end{array}$ & $\begin{array}{l}\text { Appropriate for Use - visually enhanced } \\
\text { conceptual understanding; not like pen \& paper - } \\
\text { tech enhances concepts concrete; appropriate for } \\
\text { the computer; visualize on computers, you're able } \\
\text { to show things more visually; resource is truly a } \\
\text { tool rather than a computer-based presentation of } \\
\text { something in a book } \\
\text { Access Content - Kid Friendly, Readability - } \\
\text { just right reading; not verbose; not too much } \\
\text { writing; reading doesn't hinder } \\
\text { Color - colors help distinguish part of the whole; } \\
\text { more colorful; color } \\
\text { Graphics - visually enhanced conceptual } \\
\text { understanding; graphics } \\
\text { Sound - sound effects; auditory } \\
\text { Visual Appeal - visually appealing; appealing }\end{array}$ \\
\hline
\end{tabular}


Table 14. Comparison of LORI and Teacher Defined LO Characteristics (continued)

\begin{tabular}{|c|c|c|}
\hline 6. & $\begin{array}{l}\text { Interaction Usability: Ease of navigation, } \\
\text { predictability of user interface, and quality of the } \\
\text { interface help features } \\
5 \text { rating description: The user interface design } \\
\text { implicitly informs learners how to interact with } \\
\text { the object, or there are clear instructions guiding } \\
\text { use. Navigation through the object is easy, } \\
\text { intuitive and free from excessive delay. The } \\
\text { behavior of the user interface is consistent and } \\
\text { predictable. }\end{array}$ & $\begin{array}{l}\text { Dynamic/Interactive } \\
\text { Access Content - Kid Friendly, Readability - } \\
\text { easy access instructions; directions clear; straight } \\
\text { forward; visual guidance; organized, no } \\
\text { scrolling, self-contained; If kids can navigate } \\
\text { easily on their own; samples; demo }\end{array}$ \\
\hline 7. & $\begin{array}{l}\text { Accessibility: Design of controls and } \\
\text { presentation formats to accommodate disabled } \\
\text { and mobile learners } \\
5 \text { rating description: The learning object } \\
\text { provides a high degree of accommodation for } \\
\text { learners with sensory and motor disabilities, and } \\
\text { can be accessed through assistive and highly } \\
\text { portable devices. It follows the IMS Guidelines } \\
\text { for Accessible Learning Applications and } \\
\text { conforms to W3C Web Content Accessibility } \\
\text { Guidelines at level 'AAA'. }\end{array}$ & $\begin{array}{l}\text { This was not addressed. This might be due to fact } \\
\text { that the teachers work with students not having } \\
\text { sensory or motor disabilities that require assistive } \\
\text { or adaptive devices. It is typical in this } \\
\text { researcher's experience that students needing } \\
\text { specific devices are clustered in schools that } \\
\text { specialize in assistive technologies for students. }\end{array}$ \\
\hline 8. & $\begin{array}{l}\text { Reusability: Ability to use in varying learning } \\
\text { contexts and with learners from differing } \\
\text { backgrounds } \\
5 \text { rating description: The learning object is a } \\
\text { stand-alone resource that can be readily } \\
\text { transferred to different courses, learning designs } \\
\text { and contexts without modification. It operates } \\
\text { effectively with a broad range of learners by } \\
\text { adapting content or providing adjunctive content } \\
\text { such as glossaries and summaries of prerequisite } \\
\text { concepts. }\end{array}$ & $\begin{array}{l}\text { This was addressed in a minor way by one } \\
\text { teacher when she stated, "I could adapt this for } \\
\text { my kids." This in reference to the content not at } \\
\text { her students' grade level but needing to address } \\
\text { the content with her students. } \\
\text { Reusability might not be addressed more } \\
\text { specifically perhaps for two reasons: } \\
\text { 1. The content was specifically math } \\
\text { related teaching specific content } \\
\text { 2. In this researcher's experience teachers } \\
\text { adapt their materials all the time and do } \\
\text { not consider the material they use as } \\
\text { being reusable or not - they just make } \\
\text { adaptations to it as part of the decision } \\
\text { making process. }\end{array}$ \\
\hline
\end{tabular}

Note: When characteristics in the LORI are not seen or addressed by teachers, they are italicized.

The remaining learning object characteristics discussed in the literature by learning object designers are interoperability, discoverability and granularity. Interoperability is the "plug and play" capability of learning objects. As these were online learning objects, this characteristic of learning objects was not discussed or measured. In addition, online learning objects traditionally have browser add-on links or the website itself assesses the participant's computer to see if it needs any software installed and if it does, then it provides a link for the 
free software. Discoverability is the ability of the learning object to be found which relies heavily on embedded metadata, which are the data that the designer uses to describe the learning object. Two teachers mentioned in the structured interview that finding learning objects was a time consuming task. Granularity refers to the size of a learning object. These learning objects had low granularity, that is they are stand alone, online learning objects. This was not addressed by the teachers.

\section{SumMARY OF RESEARCH QUESTION TWo RESULTS}

To summarize, there is clear evidence that the characteristics of learning objects that teacher determine useful are related to traditional design characteristics of learning objects. The way that the LORI rates learning objects broadens the traditional scope of learning object design characteristics to include: content quality, learning goal alignment, feedback and adaptation, and motivation. Accessibility, adaptability, and reusability are addressed in its ratings. While the characteristics of learning objects found in the LORI are generally aligned with those of teachers, the results of the content analysis demonstrate that teachers spend one-third of their focus on the decision making and planning characteristics of learning objects ( 46 constructs -1 overlap). The LORI does not adequately define this focus allotting $1 / 9$ of the ratings for this category of characteristics. However, comparing the ratings of the LORI are not intended to be taken out of context nor is that its purpose. It serves only as a guide with which to determine what is important in a learning object. The research on learning object design does not focus on the thinking and learning characteristics of learning objects as well, although it might be inherent in learning object design. The LORI focuses 3 out of 9 of its ratings on traditional learning object design: accessibility, adaptability, and reusability. It also has a dimension that is specific to presentation design: the aspect of LOs 
that determine whether someone will explore the LO further or not. This dimension addressed 6 characteristics that teachers had identified. Teachers spent two-thirds of their focus on learning object design ( 84 constructs). This may be a key difference between a practitioner and designer: that one third of the time is spent on the content features - learning and thinking aspect while learning object designers may devote more time to design characteristics. The focus of this study was not to determine alignment between the LORI and the characteristics that teachers determine are useful. However, the LORI was a practical tool that crossed the boundaries between learning object designers and instructional practitioners. It provided a means to account for commonalities and differences.

\section{VALIDATING FINDINGS}

The Repertory Grid Technique provides one way of validating each participant's responses as they are recorded with the participant present. In addition, member-checking is later used to determine the accuracy of the descriptions of each participant's decision making and planning process as well as a summary of the learning object characteristics that he identified as meeting his instructional needs. The profile or checklist of learning object characteristics that was generated was shared and discussed with each participant for accuracy and resonance. See Appendix F for a copy of the learning object profile/checklist. The Repertory Grid Technique is a research method which enables the interviewer to capture the interviewee's constructs without observer bias. While the repertory grid is an excellent vehicle to eliminate observer bias, there may be some bias in the selection or variety of learning objects or elements used in the study.

The researcher purposely selected learning objects to depict a range of digital media. Bias may come into play as the researcher determines that the participants have had an 
opportunity to interact with a representative sample of learning objects. However, to alleviate potential bias in the quality of the learning objects, the expert group's rating of the learning objects was analyzed. The ratings of the learning objects indicated that a representative sample was used in the study. Researcher bias may influence the correlations of the characteristics of learning object as determined by teachers and learning object designers. However, overall validity is enhanced due to the variety of instruments used as well as the triangulation of the data and member checking. 


\section{CHAPTER 5}

\section{DISCUSSION}

The purpose of this study was to determine the important characteristics of learning objects that teachers deem useful for their instructional purposes. In addition, this study examined whether teachers discern if some characteristics of learning objects are more appropriate for certain instructional purposes and for specific students. Lastly, this study examined if the characteristics that teachers use to determine useful learning objects align to those of learning object designers, as there is little research in the literature. This chapter will discuss the findings related to each research question. In addition, the implications for teachers and learning object designers will be discussed as well as the limitations of this study and recommendations for future research.

\section{LeARning ObJect Characteristics}

Research question one asked: What are the important characteristics of learning objects that K-12 teachers determine useful for their instructional purposes? Personal construct theory underlies the study. It provided a means to think about the constructs that teachers have developed about learning objects and their usefulness in the classroom as well as how teachers may have common constructs. In personal construct theory, you cannot understand a person's constructs unless the person bounds it with a polar opposite. If a person says a learning object is great, you have no context for what great is unless it is further clarified with ideas or constructs that the individual defines. Using the repertory grid as a framework to interview teachers allowed the researcher to gain access to the personal 
constructs of each teacher without observer bias. This was critical in the interview process and it placed no restrictions on what were acceptable responses from teachers and instead allowed the researcher insight into the thinking processes of teachers as they struggled to verbalize their personal constructs. It was almost like being a fly on the wall watching the planning and decisions that teachers regularly make. Each teacher's personal constructs are developed through his experiences in using learning objects and in seeking out useful ones for his students. While teachers might not have actually verbalized their constructs before this study, their constructs are firmly established. For example, during the course of the interviews, teachers put emphasis on what some elements' characteristics were and how they could see using it [learning object] in their classroom. The characteristics of other elements were clearly disliked as stated with comments like this learning object had "too much reading" or "my kids would get bored with this". In addition, it became evident that at the core of each individual in the study, what made them uniquely qualified to discuss learning object characteristics besides the fact that they use them in their instruction, is that using learning objects:

- is intentional; must make sense - that is it is only useful, if it is purposeful and adds to the learners' perception or understanding of a concept;

- isn't a replication of what can be done in the classroom - the tool must be appropriate;

- helps to model concepts that are hard to visualize, such as 3-D models;

This was evidenced by the comments found in the structured interviews and the constructs generated in the repertory grids. In addition, to understand what teachers might determine as useful for their instructional purposes, one must first understand what it is to be a teacher making instructional decisions. This brings us to Shavelson and Sterns' Decision Model, Figure 1, which was adapted by the researcher (Figure 2) to include current 
instructional planning and decision making ideas which include curriculum frameworks and standards as well as a broader scope of data about students' instructional history. Using the Decision Model as an overlay to the Thinking \& Learning Categories, one can see that teachers make decisions about their instructional purpose; their students' abilities, motivation, behavior, and groupings; and the content they teach. Underlying this are the differences among teachers in their beliefs (using learning objects and how); conceptions of subject matter; and conceptual complexity (how to teach with learning objects - the conceptual development of students in this medium). As teachers plan, they seek specific characteristics of learning objects such as those found in Table 15 for use in their instruction. Lastly, depending on instructional purpose, the need for 3 dimensional, models $\&$ situations; number of participants; format - as in games; and variations to the learning objects, may be called for as part of the plan.

\section{Table 15. Categories of Learning Object Characteristics}

\begin{tabular}{|l|l|}
\hline Thinking \& Learning & Learning Object Design \\
\hline - Conceptual & - Appropriate for use \\
- Creative Thinking, Problem & - Accessing Content - Kid Friendly, \\
Solving, \& Discovery Learning & Readability \\
- Purpose - Review, Practice, \& & - Dynamic/Interactive \\
Connections & $\begin{array}{l}\text { - Color } \\
\text { - Feedback }\end{array}$ \\
Motivation & - Graphics \\
& - Sound \\
\hline
\end{tabular}

\section{Learning Object Purpose}

Research questions 1a asked: Do teachers discern that the purpose of some characteristics of learning objects are more appropriate for: conceptual development; skill 
development; or content information? The results indicated that teachers are intentional when determining which characteristics might be more useful for each of these instructional purposes. In the structured interview, when asked what the purpose was for using learning objects, their characteristics fell into four themes: practice, instructional tool, conceptual, and medium. In addition, in the content analysis of the repertory grid, the constructs or characteristics that teachers generated fell into each of these themes: conceptual; creative thinking, problem solving, \& discovery learning; and purpose - review, practice, \& connections as well as feedback and motivation. In addition, data from structured interview questions seven, eight, and nine provide evidence of the instructional planning used to determine how the learning objects would be used and for what. Content information was a little harder to discern as the content was mathematics. However, teachers made comments such as: standards; applicable to what I'm teaching in class; real world - things they [students] might actually do, make them like math; current in the world such as weather patterns, charting tools; how I'll sequentially present it and which students need it.

\section{LeARNIng ObJects For SPECIFIC STUdents}

Research question $1 \mathrm{~b}$ asked: Do K-12 teachers use specific characteristics of learning objects for specific learners? Teacher judgment, part of the Shavelson and Sterns' Decision Model, was inherent in each participant as indicated by their teaching philosophy - how they use technology; content knowledge - accuracy and/or correct representation of mathematical concepts; an understanding of what their children need to be successful and what they need to provide for their students' success; and an understanding of children - what motivates them and what doesn't. There was clear evidence that teachers make judgments about using specific characteristics of learning objects for specific learners. The results from the content 
analysis of the repertory grids demonstrates that across all constructs, whether it was in the Thinking \& Learning category or the Learning Object Design category, teachers weighed the importance of each characteristic more heavily for in terms of specific students in your classroom than any other situation, with the exception of the game format and number of participants which would clearly eliminate it from this consideration as it falls into the in terms of student grouping situation. In the Teaching \& Learning category, it account for a mean of $94 \%+$ of the 47 constructs (characteristics) that teachers generated. This was a startling finding. As mentioned in the results chapter, underlying this question is: what are the specific characteristics of learning objects that teachers use for specific students. This question was answered in the data, but it was fleshed out further in the follow-up interviews.

Teachers were asked to rate the constructs they'd previously generated in terms of four specific student groups: English Language Learners (ELLs); Low Performing students (LP); students with Learning Disabilities (LD); and Gifted And Talented Education students (GATE). For all four groups, conceptual and motivational were highly rated characteristics in the Thinking and Learning category. The mean for conceptual was 5.00 for students with learning disabilities and 4.93 for low performing students which suggests that this characteristic is critical for these populations. In the Learning Object Design category, dynamic/interactive; 3 dimensional, model, situation; and appropriate for use were highly rated characteristics. Van de Walle and Lovin (2006) recommend developing conceptual knowledge; constructing appropriate, problem-based tasks; engaging students in interactive activities; learning with and from others; and using models when teaching mathematics to children. These same characteristics or constructs teachers determined useful in learning objects by participants. Some characteristics were not rated very high for GATE students but 
were for ELLs, LPs, and LDs. For example, teachers rated feedback, 4.67; and purpose review, practice, $\&$ connections, 4.52 ; as well as accessing content - kid friendly, readability, 4.79; color, 4.67; graphics, 5.00; and options - format, 4.50. Teacher judgment plays a large part in how teachers determine which learning objects for which students. It makes sense that as a teacher, you would seek certain characteristics of learning objects for certain students because your instructional practice probably doesn't change - using learning objects is a different medium, not a different instructional practice. It was interesting that the expectation of what GATE students need, differed from those of the other three populations in many instances. A standout was that of "Creative Thinking, Problem Solving, \& Discovery Learning". Perhaps this is because teachers use a variety of other strategies with the ELL, LP, \& LD populations and do not consider using learning objects in this way when it comes to deep thinking and problem solving. Or perhaps the general thinking is these three populations need more scaffolding than might be provided with learning objects which require creative thinking and problem solving. Or perhaps this is a perception or construct of teachers that GATE students need deep thinking and problem solving more than the other three populations. This finding warrants further study. It was interesting to note that in the Visual Appeal characteristic, teachers overall paused and stated that too many screen distractions prohibited students with learning disabilities from focusing on the learning object and its purpose. This construct aligns with instructional practice to limit distractions for LD students. It is clear, however, that teachers determine that some characteristics of learning objects are more appropriate or useful for some populations of learners.

\section{Learning OBJeCt Design ChaRACTeristics}

Research question two asked: How well do the characteristics of learning objects that 
teachers determine useful relate to traditional design characteristics of learning objects, i.e. reusability, granularity, adaptability, interoperability, accessibility, and discoverability? The results of the study show there is a relationship between what teachers determine as useful characteristics of learning objects and what the literature of traditional design characteristics are. The specificity with which teachers describe as important characteristics of learning objects demonstrate that teachers have a construct system not unlike learning object designers. However, the decision making process that teachers use when determining the useful characteristics of learning objects differs than that of learning object designers. It may be that traditional learning object design characteristics are transparent to teachers, as they are meant to be from a learning object designer's perspective, so teachers don't look for them. They may unconsciously use them, i.e. can I find this learning object; is this learning object too bulky and hard to manage, etc. Two teachers specifically mentioned that finding learning objects was very time consuming - both characteristic of discoverability and an institutional constraint (part of Shavelson and Sterns' Decision Model) - time during a teacher's instructional day is not allotted to discover learning objects. Instead teachers use their own time to do this. Finally, it may be that in the field of learning object design, the criteria that designers use needs to advance as technologies advance. If a design element becomes the "norm", do you still need to measure its usage? For example, reusability is an important characteristic for designers but most teachers will probably consider this somewhere down the list in their priorities. Online resources will surely be used first as it is already available in an easy to use format. Interoperability, while once a major concern for all computer users, is not as important as designers consider which tools will allow all users to access the LO. Flash and Java are two platforms that provide designers a means to create learning objects for 
all operating systems. Therefore, is interoperability really a consideration when the technology has advanced to the level where it no longer matters which operating system you use?

\section{DELIMITATIONS AND LIMITATIONS}

This study was confined to Southern California teachers who volunteered to participate. In addition, each of the participants taught at different schools in three different school districts. The student population that each works with was not analyzed so it is unknown if or how that may factor into each teacher's constructs. The limited number of participants, eight, as well as the limited scope of teaching levels $\left(3^{\text {rd }}, 4^{\text {th }}(2), 5^{\text {th }}(2)\right.$, $6^{\text {th }}$, and $9-12^{\text {th }}(2)$ grades) limits the generalizability of the study. As this study addressed only the personal constructs of these eight teachers and their perceptions of what characteristics of learning objects are useful for their instructional purposes. Personal constructs by their very nature, are personal. What one construes as important may not be important to another. As a result, unique constructs elicited may not reflect the entire picture of what a teacher means nor its application. The constructs generated in this study do not represent the views or constructs of all teachers who select learning objects for use in their classroom. In addition, the participants in the study were volunteers, and might have a higher interest in learning objects than a typical teacher. While it was the intention of the researcher to have a diverse representation of participants within the purposive sample in the study, these volunteers did not completely reflect diversity in gender, teaching experience, and technical skill. Only one participant was male. Lastly, due to time constraints - the extended time as one website containing two learning objects was "down" for a portion of the first interview and the resulting fatigue of the first participant, not all comparisons between elements were made, so 
there may be additional constructs that were not mentioned. The interview was quite intensive, lasting $1 \frac{1}{2}$ hours to $2 \frac{1}{2}$ hours, and participants may have tired which could limit the number of constructs generated. Additional constructs may surface if participants were interviewed again.

This study considered how teachers think and the judgments they make when planning instruction to provide background on the unique profession of teaching. However, investigating instructional planning was not the purpose of this study and other factors may account for the decisions that teachers make when determining which learning objects are useful for classroom instruction. For example, district/school mandates to use more technology or time constraints with too few computers in the classroom would have an impact. While time constraints and limited computers in the classroom came up in the structured interview, it was not discussed how this might influence what learning objects teachers seek for their students use. Lastly, this study used mathematical learning objects as a constant. The findings of this study may only apply to learning objects in that domain.

\section{FUtURE RESEARCH}

The study of what teachers deem as important characteristics warrants further study. If learning objects are to become the norm, then studying the decisions teachers make in their instructional planning is important. There are a number of efforts across the United States (Multimedia Educational Resource for Learning and Online Teaching (MERLOT) and Wisconsin Online Resource Center) and Internationally (Tasmanian School Education Division and The Learning Federation (TLF), an initiative of the federal governments of Australia and New Zealand) which are creating learning objects specifically for classroom usage. New textbook adoptions include various video, simulations, and online components. 
Are they being used in the classrooms? Are some learning objects used more frequently than others? Why?

Future studies could include content analysis of teacher blogs with a focus on learning object characteristics that teachers find useful in their classroom. This could be set up or may already be set up in school districts to promote more widespread use of learning objects as well as providing a forum to study the growth of usage. It would also provide a means to discover what characteristics teachers are finding the most useful and why. This information could then drive future textbook adoptions with their adjunct technologies. Lastly, these studies need to include both learning object designers and classroom teachers, not just teachers as is often the case. Student voices also need to be heard and studied as thay are our intended audience.

\section{Conclusions}

Technology changes rapidly and today's learners acquire and use various technologies at a pace that exceeds most teachers' knowledge and awareness. If we are to capture the attention of this audience, we need to entice learners with technology that is both engaging and pedagogically effective. Video games and social media compete for our students' attention in the realm of technology. Teachers can capitalize on their students' interest by using learning objects not just as an instructional tool to meet individual student's educational needs but turn over the desire to use technology in this way to students. What we learn from teachers experienced in using learning objects can provide some direction for schools to integrate the use of learning objects in their curriculum. The internet has provided school districts with an ongoing means of communication with students, parents, teachers, and the community at large. School districts have websites that house vast amounts of 
information and/or links to resources for all its constituents. Integrating learning objects into this framework would be simple to do, but requires the active participation of the district and experienced teachers to incorporate it into school culture. The tools and expertise are present, but they need to be organized.

The findings of this study demonstrate that teachers are intentional in their selection of learning objects and the characteristics they find useful for their instructional purpose. Teachers seek learning objects that develop their students' conceptual knowledge, are dynamic, motivating, and appropriate to use on the computer. In addition, teachers determine certain characteristics of learning objects are more useful for specific students in their classrooms. Classrooms of today are an amalgam of learners requiring different instructional strategies to successfully access and understand the content. Kid friendly and graphic-rich learning objects as well as feedback on correct and incorrect responses are characteristics sought by teachers for their English Language Learners, low performing students, and students with learning disabilities. With today's technology, learning objects readily emulate some of the same characteristics of effective instruction that teachers use in the classroom. Providing immediate feedback for a student is sometimes challenging in a classroom where there are $20-35$ more learners. Supporting students by providing additional opportunities to practice strategies taught in the class is possible with learning objects especially if they provide immediate feedback and it is motivating for students.

As technology advances, the criteria for quality learning objects need to change. It is critical for learning object designers and teachers in the classroom to collaborate on the characteristics of learning objects that will best facilitate learning opportunities for students. Just as the studies of children's programming provided insight into the thinking of children, 
e.g., transparency of a button that shows an open door for "exit", studies of children using learning objects needs to be conducted to gain insight into the thinking of the technologyminded children of today. With collaboration among designers, teachers, and students, learning objects can be motivating, interactive, and easy to locate for specific purposes, for students and teachers alike. 


\section{REFERENCES}

Allert, H., Richter, C., \& Nejdl, W. (2004). Lifelong learning and second-order learning objects. British Journal of Educational Technology, 35(6), 701-715.

Anderson, B. L. (1977). Differences in teachers' judgment policies for varying numbers of verbal and numerical cues. Organizational Behavior and Human Performance, 19(1), 68-88.

Boeree, C. G. (2006). George Kelly. Retrieved October 11, 2007, from http://webspace.ship.edu/cgboer/kelly.html

Borko, H. \& Cadwell, J. (1982). Individual differences in teachers' decision strategies: An investigation of classroom organization and management decisions. Journal of Educational Psychology, 74, 598-610.

Borko, H, Shavelson, R. J., \& Stern, P. (1981). Teachers' decisions in the planning of reading instruction. Reading Research Quarterly, 16(3), 449-466.

Brown, D.S. (1990). A survey of experienced teachers' planning practices. Journal of Education for Teaching, 16(1), 57-79.

Calvert, S. L. \& Kotler, J. A. (2003) Lessons from children's television: The impact of the Children's Television Act on children's learning. Applied Developmental Psychology, 24, 275-335.

Chen, H. L. (2000). Teacher planning: Social studies teachers in Taiwan. (Doctoral dissertation, University of Texas, 2000.) Retrieved August 19, 2007, from ProQuest Digital Dissertations database. (Publication No. AAT9983164).

Chen, M. (1984). Formative evaluation of Season III of 3-2-1 Contact: Segment and cast appeal for ten shows. New York: Children's TelevisionWorkshop.

Clark, C. M. \& Yinger, R. J. (1977). Research on teacher thinking. Curriculum Inquiry, 7(4), 279-304.

Clark, C., Wildfong, S., \& Yinger, R. J. (1978). Identification of salient features of language arts activities. Unpublished Mimeographed, Michigan State University, East Lansing.

Creswell, J. W. (1998). Qualitative inquiry and research design: Choosing among five traditions. Thousand Oaks: Sage Publications.

E-Learning Research and Assessment Network (eLera). (n.d.). About LORI. Retrieved September 16, 2009, from http://www.elera.net/eLera/Home/About\%20\%20LORI/ 
Fitzharris, L. H. (2005). Making all the right connections. Journal of Staff Development, 26(1), 24-28.

Fransella, F., Bell, R. \& Bannister, D. (2004). A manual for repertory grid technique, (2nd ed.). West Sussex: Wiley \& Sons.

Glatthorn, A. A. (1993, March). How principals can help - teacher planning: A foundation for effective instruction. NASSP Bulletin, 77, 1-7.

Gronn, D., Clarke, O., \& Lewis, G. (2006). Using The Learning Federation's learning objects in the classroom. Australian Primary Mathematics Classroom, 11(2), 4-7.

Hewitt, A. (2005). Teachers' personal construct models of pupil individuality and their influence in the music classroom. Music Education Research, 7(3), 305-330.

Hunter, M. (1985). What's wrong with Madeline Hunter? Educational Leadership, 42(5), 57 60.

Institute of Electrical and Electronics Engineers (IEEE) Learning Technology Standards Committee (LTSC). The learning object metadata standard. Retrieved March 29, 2006, from http://www.ieeeltsc.org/working-groups/wg12LOM/ lomDescription/

Kelly, G. A. (1955). The psychology of personal constructs, Vols. 1-2. New York: Norton \& Company.

Kleiner, A., \& Lewis, L. (2003). Internet access in U.S. public schools and classrooms: 1994-2002 (NCES 2004-011). U.S. Department of Education. Washington, DC: National Center for Education Statistics. Retrieved March 30, 2006, from http://nces.ed.gov/pubs2004/2004011.pdf

Marland, P. (1986). Models of teachers' interactive thinking. The Elementary School Journal, 87(2), 209-226.

McAlpine, L., Weston, C., Berthiaume, D., \& Fairbank-Roch, G. (2006). How do instructors explain their thinking when planning and teaching? Higher Education, 51(1), 125 155.

McCutcheon, G. (1980). How do elementary school teachers plan? The nature of planning and influences on it. The Elementary School Journal, 81(1), 4-23.

Mielke, K.W. (1983). The educational use of production variables and formative research in programming. In M. Meyer (Ed.), Children and the formal features of television. Munchen, Germany: Saur.

Nesbit, J. C., Belfer, K. \& Leacock, T. (2003). Learning object review instrument (LORI). ELearning Research and Assessment Network. Retrieved November 27, 2007, from http://www.elera.net/eLera/Home/Articles/LORI\%201.5.pdf 
Nugent, G. C. (2005). Use and delivery of learning objects in K-12: The public television experience. Tech Trends, 49(4), 61-66.

Oblinger, D. G. \& Oblinger, J. L. (Eds.). (2005). Educating the net generation. Educause Center for Applied Research. Retrieved April 9, 2006, from http://www.educause.edu/ir/library/pdf/pub7101.pdf

Parker, W. C. \& Gehrke, N. J. (1986). Learning activities and teachers' decisionmaking: Some grounded hypotheses. American Educational Research Journal, 23(2), 227-242.

Peterson, P. L., Marx, R. W., \& Clark, C. M. (1978). Teacher planning, teacher behavior, and student achievement. American Educational Research Journal, 15(3), 417-432.

Reeves, B. F. (1970). The first year of Sesame Street: The formative research. Final report, volume II of V volumes. New York, NY: Children's Television Workshop.

Reigeluth, C. M. (1999). Instructional-design theories home page. Retrieved April 9, 2006, from http://www.indiana.edu/ idtheory/home.html

Reusable Learning. (2007). Reusable learning. Retrieved May 5, 2007, from http://www.reusablelearning.org/index.asp?id=30

Roberts, D. F., Foehr, U. G., \& Rideout, V. (2005). Generation M: Media in the lives of 8-18 year-olds. Retrieved October 27, 2007, from http://www.kff.org/entmedia/7251.cfm

Sammur, G. B. (1990). Selected bibliography of research on programming at the Children's Television Workshop. Educational Technology, Research and Development, 38(4), 81-92.

Shavelson, R. J. \& Stern, P. (1981). Research on teachers' pedagogical thoughts, judgments, decisions, and behavior. Review of Educational Research, 51(4), 455-498.

Shaw, M. \& Gaines, B. (n.d.).WebGrid III online software program. Retrieved March 15, 2009, from http://wallace.cpsc.ucalgary.ca: 1500 .

Stewart, V, Stewart, A., \& Fonda, N. (1981). Business applications of the repertory grid. Maidenhead, England: McGraw-Hill Book Company.

Stewart, V. (2005) Business applications of repertory grid index. Retrieved August 16, 2007 , from http://www.enquirewithin.co.nz/BUS_APP/business.htm

Strommen, E. E. \& Revelle, G. L. (1990). Research in interactive technologies at the Children's Television Workshop. Educational Technology, Research and Development, 38(4), 65-80.

Tasmanian Department of Education. (2007). Planning. Retrieved October 25, 2007, from http://www.ltag.education.tas.gov.au/planning/learnseq/ict/objects.htm 
The British Library Board. (n.d.) Exchange Formats. Retrieved May 2, 2007, from http://www.bl.uk/services/bibliographic/exchange.html

Tyler, R. W. (1950). Basic principles of curriculum and instruction. Illinois: University of Chicago Press.

Van de Walle, John \& Lovin, LouAnn H. (2006). Teaching student-centered mathematics, grades 3-5, volume 2. Boston: Pearson Education, Inc.

Vargo, J., Nesbit, J. , Belfer, K., \& Archambault, A. (2003). Learning object evaluation: Computer-mediated collaboration and inter-rater reliability. International Journal of Computers and Applications, 25(3), 198-205.

Wiggins, G., \& McTighe, J. (1998). Understanding by design. Alexandria, VA: Association for Supervision and Curriculum Development.

Wiley, D. A. (2002). Connecting learning objects to instructional design theory: A definition, a metaphor, and a taxonomy. In D. Wiley (Ed.), The Instructional Use of Learning Objects. Bloomington: Association for Educational Communications and Technology. Retrieved March 30, 2006, from http://www.reusability.org/read/

Wiley, D. A., Recker, M. M., \& Gibbons, A. (2000). The reusability paradox. Retrieved July 23, 2006, from http://rclt.usu.edu/whitepapers/paradox.html

Yinger, R. J. (1980). A study of teacher planning. The Elementary School Journal, 80(3), 107-127.

Zahorik, J. A. (1975). Teachers' planning models. Educational Leaders, 33(2), 134-139. 
APPENDIX A

\section{INFORMED CONSENT}




\title{
San Diego State University and University of San Diego
}

\author{
Consent to Act as a Research Subject
}

\section{An Investigation into Digital Media: Characteristics of Learning Objects which Elementary Teachers Determine Meet Their Instructional Needs}

You are being asked to participate in a research study. Before you give your consent to volunteer, it is important that you read the following information and ask as many questions as necessary to be sure you understand what you will be asked to do.

Investigators: Patti Guthrie, M.S. of Educational Technology and Doctoral Student in SDSU-USD Doctoral Program in Education. Dr. Bernard Dodge, Ph.D., Professor of Educational Technology at San Diego State University is overseeing this study.

Purpose of the Study: The purpose of the study is to determine the characteristics of learning objects that teachers find most useful in their instruction. As a result of the study, a checklist for teachers to use when determining which learning objects to use in their instruction will be created. Teachers skilled or unskilled in using learning objects in their instruction will be able to use the checklist to help them in their instructional planning.

This study is seeking seven-to-ten participants who meet the following criteria.

\section{Participants must meet all three criteria:}

1. Elementary teacher, K-6;

2. Teaches math or has taught it in the last three years;

3. Uses, reuses, and/or creates learning objects for use in their instruction.

Description of the Study: The study will be completed in two phases.

\section{Participation Requirements:}

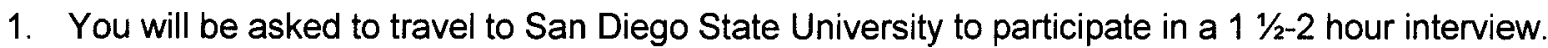
During the interview, you will explore or interact with different learning objects on computers and discuss their characteristics with the investigator. Other background questions will be asked including questions on gender, years of teaching, grade currently teaching, and instructional uses of learning objects in the classroom.

2. At the conclusion of the study, you will be asked to participate in a 45 minute-to-one hour online chat with other participants about the learning object checklist. You will discuss the accuracy and usefulness of the profile in determining the characteristics of learning objects for instructional use in the classroom.

Risks or Discomforts: You may feel physical discomfort from the extended sitting times, but you will be offered a 10 minute break and will be provided with snacks. In addition, if at any time, you are uncomfortable with any part of the interview, inform the investigator so the investigator can alleviate the problem or if requested, stop the interview. 
Benefits of the Study: Potential benefits of the study may be professional development for leaning object designers who may find it useful to view learning object characteristics from a teacher's perspective for better development of learning objects and professional development for teachers. I cannot guarantee, however, that you will receive any benefit from participating in this study.

Confidentiality: Confidentiality will be maintained to the extent allowed by law. During the interview, participants will be digitally audio taped then transcribed to ensure accuracy. All records are kept confidential and identifiable information will not be used. Study documents (interview and online discussion transcript) will be given a number code known only to the investigator. This code will be the only identifying marker on the study documents. If you agree to be a participant in this study, you will be asked for a username preference which will be how you are identified in the group chat at the end of the study. Upon completion of the study, the digital audiotapes will be erased and email correspondence will be permanently deleted from investigator's account. All study documents will be stored in a locked file cabinet and on a back-up flash drive in the investigator's office for a period of three years. At the end of three years, all study documents will be destroyed.

Incentives to Participate: The investigator is providing a $\$ 20.00$ gift certificates to a bookstore for all participants who complete both the interview at San Diego State University and the online chat. If you discontinue the study after the interview, you will not receive a gift certificate. If you are unable to participate in the online chat because of technical reasons on the day of the scheduled chat, then you will receive a $\$ 10.00$ gift certificate. If however, you evaluate the checklist on your own and submit feedback to the investigator, then you will receive the $\$ 20.00$ gift certificate. After completion of the online chat, the gift certificate will be mailed to all qualifying participants.

In addition, a parking pass will be provided to you for the interview at San Diego State University if you need it and will be paid for by the investigator.

All participants will receive a copy of the learning object checklist for their personal use.

Costs and/or Compensation for Participation: The only cost to you is your time and travel to San Diego State University. There are no other costs associated with this study.

Voluntary Nature of Participation: Participation in this study is voluntary. Your choice of whether or not to participate will not influence your future relations with San Diego State University or the University of San Diego. If you decide to participate, you are free to withdraw your consent and to stop your participation at any time without penalty or loss of benefits to which you are allowed.

Questions about the Study: If you have any questions about the research now, please ask. If you have questions later about the research, you may contact Patti Guthrie at or by email at

If you have any questions about your rights as a participant in this study, you may contact the Institutional Review Board at San Diego State University (telephone: 619-594-6622; email: irb@mail.sdsu.edu) or the Office of the Vice President and the Provost at the University of San Diego (telephone: 619-260-4553) 
Consent to Participate: The San Diego State University Institutional Review Board and the University of San Diego Institutional Review Board have approved this consent form, as signified by the Board's stamp. The consent form must be reviewed annually and expires on the date indicated on the stamp.

Your signature below indicates that you have read the information in this document and have had a chance to ask any questions you have about the study. Your signature also indicates that you agree to be in the study and have been told that you can change your mind and withdraw your consent to participate at any time. You have been given a copy of this consent form. You have been told that by signing this consent form you are not giving up any of your legal rights.

Name of Participant (please print)

Signature of Participant

Date

Signature of Investigator

Date 
APPENDIX B

\section{LEARNING OBJECT QUICK REFERENCE}



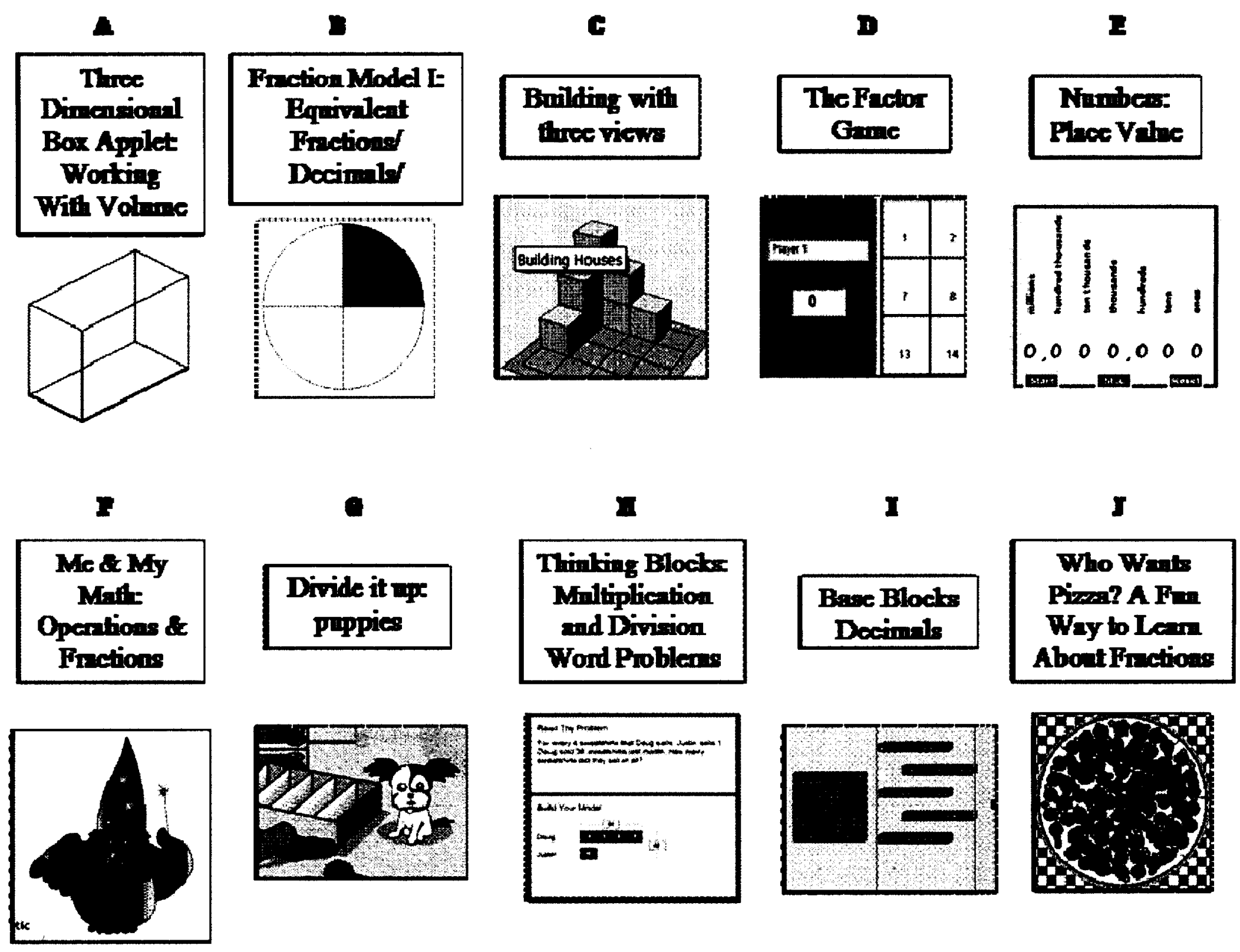


\section{LEARNING OBJECT WeBSITES}

A: Three Dimensional Box Applet Working with Volume. http://mste.illinois.edu/users/carvell/3dbox/

B: Fractional Model I: Equivalent Fractions/Decimals.

http://illuminations.nctm.org/ActivityDetail.aspx?ID=11

C: Building with Three Views

http://www.fi.uu.nl/wisweb/isdde/

D: The Factor Game

http://illuminations.nctm.org/ActivityDetail.aspx?ID=12

E: Numbers: Place Value

http://www.math.com/school/subject1/lessons/S1U1L1GL.html

F: Me \& My Math: Operations \& Fractions

http://www.kidsolr.com/math/math.html

G: Divide it up: puppies

http://www.thelearningfederation.edu.au/for teachers/sample learning materia Is/tm - maths.html

H: Thinking Blocks: Multiplicaiton and Division Word Problems

http://www.thinkingblocks.com/ThinkingBlocks MD/TB MD Main.html

I: Base Blocks Decimals

http://nlvm.usu.edu/en/nav/frames asid 264 g 2 t 1.html?from=category g 2

$\underline{\text { t 1.html }}$

J: Who Wants Pizza? A Fun Way to Learn About Fractions

http://www.math.rice.edu/ lanius/fractions/index.html 
APPENDIX C

REPERTORY GRID INSTRUMENT AND STRUCTURED INTERVIEW 
$\begin{array}{llllllllllll}\text { Participant: } & 001 & 002 & 003 & 004 & 005 & 006 & 007 & 008 & 009 & 010 & \text { Date: }\end{array}$

Table A1. Initial Repertory Grid to Determine Constructs

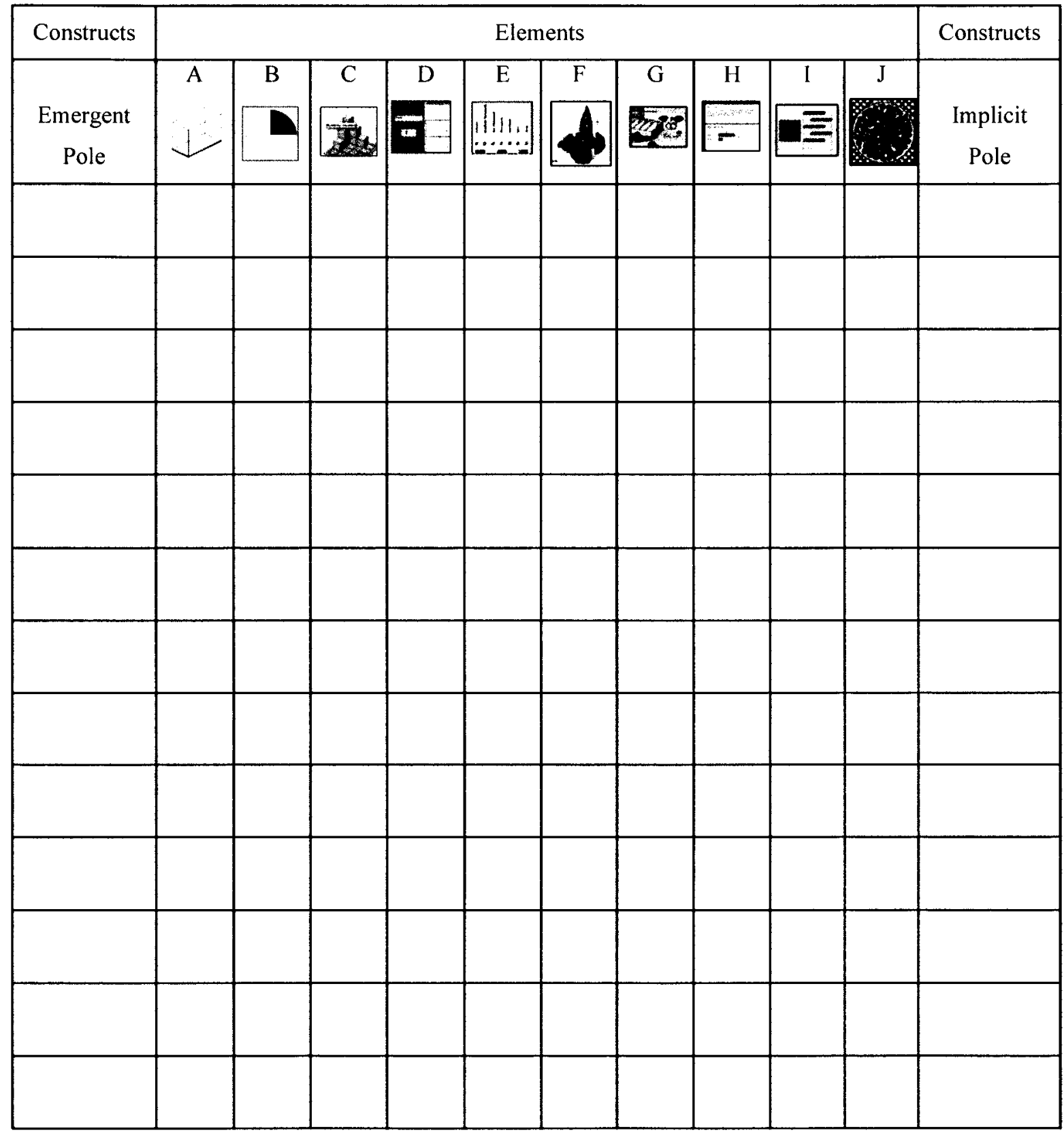

Key: $\quad$ Constructs compared $=$

Construct closer to Implicit Pole $=\mathrm{X}$ 
$\begin{array}{llllllllllll}\text { Participant: } & 001 & 002 & 003 & 004 & 005 & 006 & 007 & 008 & 009 & 010 & \text { Date }\end{array}$

Table A2. Repertory Grid with Ratings from Likert Scale

\begin{tabular}{|c|c|c|c|c|c|c|c|c|c|c|c|}
\hline Constructs & & & & & Elem & & & & & & Constructs \\
\hline & $\mathrm{A}$ & B & $\mathrm{C}$ & $\mathrm{D}$ & $E$ & $\bar{F}$ & $\mathrm{G}$ & $\overline{\mathrm{H}}$ & $\bar{I}$ & $\mathrm{~J}$ & \\
\hline Emergent & & $\mathbf{D}$ & \% & $=$ & Inta. & $A$ & 㞔象 & $=$ & 国 & & Implicit \\
\hline & & & & & & & & & & 2 & Pole \\
\hline & & & & & & & & & & & \\
\hline & & & & & & & & & & & \\
\hline & & & & & & & & & & & \\
\hline & & & & & & & & & & & \\
\hline & & & & & & & & & & & \\
\hline & & & & & & & & & & & \\
\hline & & & & & & & & & & & \\
\hline & & & & & & & & & & & \\
\hline & & & & & & & & & & & \\
\hline & & & & & & & & & & & \\
\hline & & & & & & & & & & & \\
\hline & & & & & & & & & & & \\
\hline & & & & & & & & & & & \\
\hline
\end{tabular}

Likert Scale

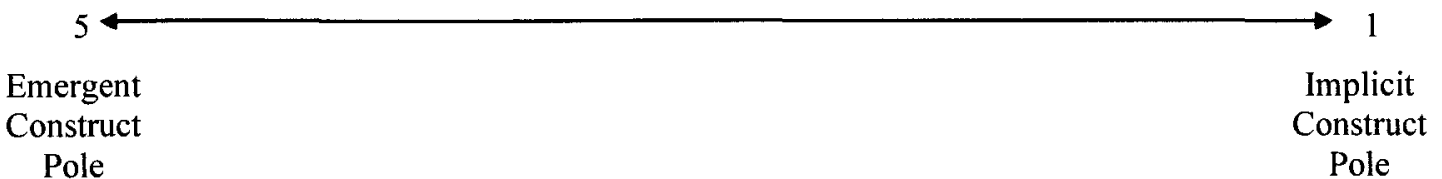


$\begin{array}{llllllllllll}\text { Participant: } & 001 & 002 & 003 & 004 & 005 & 006 & 007 & 008 & 009 & 010 & \text { Date: }\end{array}$

Table A3. Construct Elicitation - Laddering

\begin{tabular}{|c|c|c|c|c|c|c|}
\hline Constructs & & addering $T$ & vard Purpos & - Importance & & Constructs \\
\hline Emergent Pole & $\begin{array}{c}\text { In terms of } \\
\text { specific } \\
\text { students in } \\
\text { your class } \\
\end{array}$ & $\begin{array}{c}\text { In terms of } \\
\text { specific } \\
\text { students in } \\
\text { your class } \\
\end{array}$ & $\begin{array}{l}\text { In terms of } \\
\text { specific } \\
\text { students in } \\
\text { your class }\end{array}$ & $\begin{array}{l}\text { In terms of } \\
\text { student } \\
\text { groupings in } \\
\text { your } \\
\text { classroom }\end{array}$ & $\begin{array}{l}\text { In terms of } \\
\text { your } \\
\text { instructional } \\
\text { purpose }\end{array}$ & Implicit Pole \\
\hline & & & & & & \\
\hline & & & & & & \\
\hline & & & & & & \\
\hline & & & & & & \\
\hline & & & & & & \\
\hline & & & & & & \\
\hline & & & & & & \\
\hline & & & & & & \\
\hline & & & & & & \\
\hline & & & & & & \\
\hline & & & & & & \\
\hline & & & & & & \\
\hline & & & & & & \\
\hline
\end{tabular}

\section{Likert Scale}

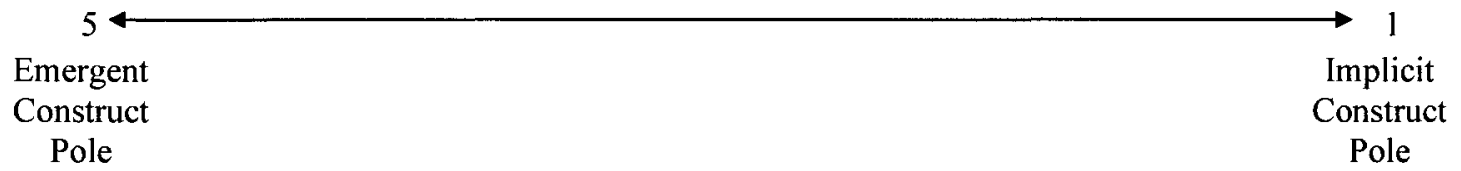


$\begin{array}{llllllllllll}\text { Participant: } & 001 & 002 & 003 & 004 & 005 & 006 & 007 & 008 & 009 & 010 & \text { Date: }\end{array}$

\section{Survey Questions:}

1. Gender: Male Female

2. Number of Years of Teaching:

3. Grade level:

4. Teaching situation: self-contained team support staff

5. Number of years of experience in using learning objects in the classroom

6. What is your purpose for using, reusing, and/or creating digital media/learning objects?

7. What do you consider or think about when planning to use learning objects?

8. What characteristics of learning objects do you find the most useful for your instructional purposes? Why?

9. Anything else you'd like to add that you think might be pertinent to this study? 


\section{APPENDIX D}

\section{SUMMARY OF FOCUS CLUSTER CONSTRUCT CORRELATIONS OF ALL PARTICIPANTS}




\section{Summary of FOCUS Cluster Construct Correlations of All Participants}

\begin{tabular}{|c|c|c|}
\hline Participant & Correlation \% & Constructs \\
\hline 001 & $\begin{array}{c}100 \\
97.5 \\
95 \\
92.5\end{array}$ & $\begin{array}{l}\text { One person/More than one person \& Not a game/Game; } \\
\text { Not engaging/Engaging \& Less activities/More activities; } \\
\text { Observation/Kinesthetic \& Static-rote learning/Dynamic-builds } \\
\text { conceptual knowledge; } \\
\text { Not engaging/Engaging \& No need for tech/Tech enhances concepts; } \\
\text { Learning how to but not how/Hands-on practice \& } \\
\text { Abstract/Concrete; Too much writing/More concrete \& Not kid } \\
\text { friendly/Kid friendly; Not engaging/Engaging \& Less } \\
\text { activities/More activities; } \\
\text { Visuals don't enhance/Visuals enhance \& No need for tech/Tech } \\
\text { enhances concepts; No connections/Real life connections \& Doesn't } \\
\text { compare/Compares } \\
\text { Not 3D/3D \& Not construction/Construction; Learning how to but not } \\
\text { how/Hands-on practice; Static-rote learning/Dynamic-builds } \\
\text { conceptual knowledge \& Visuals don't enhance/Visuals enhance; } \\
\text { Less activities/More activities \& Less fun/More fun } \\
\text { Summary: The LO's characteristics are: More than one person; } \\
\text { Game; Engaging; More activities; Kinesthetic; Dynamic - building } \\
\text { conceptual knowledge; the Technology enhances the conceptual } \\
\text { learning; Hands-on practice; Concrete; Kid friendly; Visuals } \\
\text { enhance; Real life Comparisons; Compares; Construction; and } \\
\text { More fun. }\end{array}$ \\
\hline 002 & $\begin{array}{c}95 \\
92.5 \\
90 \\
\\
87.5\end{array}$ & $\begin{array}{l}\text { Less interactive/Interactive \& No strategies/Strategies; } \\
\text { Not thinking outside the box/Thinking outside the box \& Less } \\
\text { interactive/Interactive; } \\
\text { Doesn't compares } 3 \text { sets/Compares } 3 \text { sets \& No building } \\
\text { shapes/Building shapes; } \\
\text { Different perspective/One view \& No scrolling, self } \\
\text { contained/Scrolling, not self contained; Less appealing/Appealing } \\
\text { \& Not thinking outside the box/Thinking outside the box; Just right } \\
\text { reading/Too much reading \& More colorful/Less colorful; Just right } \\
\text { reading/Too much reading \& Easy to access instruction/Less easy to } \\
\text { access instructions } \\
\text { Summary: Interactive; Strategies; Thinking outside the box; } \\
\text { Compares } 3 \text { sets; Building shapes; No scrolling, self contained; } \\
\text { Appealing; Just right reading; More colorful; and Easy access to } \\
\text { information. }\end{array}$ \\
\hline 003 & $\begin{array}{c}97.5 \\
95 \\
92.5\end{array}$ & $\begin{array}{l}\text { No visualize/Visualize \& Less practical/Practical } \\
\text { Not making into parts/Making into parts \& Not visualize/Visualize; } \\
\text { Not making into parts/Making into parts \& Less } \\
\text { interactive/Interactive; Less interactive/Interactive \& Not } \\
\text { conceptual/Conceptual; Expect prior knowledge/Teach something } \\
\text { first \& Not conceptual/Conceptual } \\
\text { Less practical/Practical \& Not as accessible/Easily accessible } \\
\text { Not as accessible/Easily accessible \& Reading hinders/Reading } \\
\text { doesn't hinder; Not user friendly/User friendly \& More } \\
\text { difficult/Organized in an easier way } \\
\text { Summary: Visualize; Practical; Making into parts; Interactive; } \\
\text { Conceptual; Teach something first; Easily accessible; Reading } \\
\text { doesn't hinder; User friendly; and Organized in an easier way. }\end{array}$ \\
\hline
\end{tabular}




\section{Summary of FOCUS Cluster Construct Correlations of All Participants (continued)}

\begin{tabular}{|c|c|c|}
\hline 004 & 87.5 & $\begin{array}{l}\text { Analytical thinking and problem solving/Don't have to think ahead of } \\
\text { time \& Problem to solve/Don't have problems; Like a game, goal to } \\
\text { reach/Not like a game, no goal \& Has a purpose/No purpose, } \\
\text { observe } \\
\text { Summary: Analytical thinking and problem solving; Problems to } \\
\text { solve; Like a game, a goal to reach; and has a Purpose. }\end{array}$ \\
\hline 005 & $\begin{array}{c}97.5 \\
95 \\
90 \\
\\
87.5\end{array}$ & $\begin{array}{l}\text { Interactive/Not interactive \& Holds attention/Doesn't hold attention; } \\
\text { Holds attention/Doesn't hold attention \& Challenging/Not as } \\
\text { challenging } \\
\text { Interactive/Not interactive \& Useful/Not as useful; Can't help but } \\
\text { learn/Not as much learning \& Discovering learning/Not discovery } \\
\text { learning } \\
\text { Conceptual development/not conceptual development \& Useful/Not } \\
\text { as useful; Can't help but learn/Not as much learning \& Multiple } \\
\text { ways/one way; Challenging/Not as challenging \& } 2 \text { Students more } \\
\text { beneficial/Not as beneficial } \\
\text { Summary: Interactive; Holds attention; Challenging; Useful; Can't } \\
\text { help but learn; Discovery learning; Conceptual development; } \\
\text { Multiple ways, and 2 students more beneficial. }\end{array}$ \\
\hline 006 & $\begin{array}{r}97.5 \\
97.5 \\
95\end{array}$ & $\begin{array}{l}\text { Not engaging/engaging \& Students not responsible for doing } \\
\text { something/Students responsible for doing something } \\
\text { Not engaging/engaging \& Note taking, not in control/Interacting, in } \\
\text { control; } \\
\text { Not challenging/challenging \& Doesn't lend itself to partner } \\
\text { work/Lends itself to partner work; Not multiple learning } \\
\text { opportunities/ Multiple learning opportunities \& Doesn't lend itself } \\
\text { to partner work/Lends itself to partner work; } \\
\text { Not challenging/challenging \& Students not responsible for doing } \\
\text { something/Students responsible for doing something; } \\
\text { Unclear/Directions clear \& Not as easy to access, kid friendly/Kid } \\
\text { friendly, easy to access, gets to the point } \\
\text { Not visually appealing/Visually appealing \&Not } \\
\text { conceptual/Conceptual development; Not multiple learning } \\
\text { opportunities/ Multiple learning opportunities \& No samples or } \\
\text { modeling/Samples, models } \\
\text { Summary: Engaging; Students responsible for doing something; } \\
\text { Interacting, in control; Challenging; Lends itself to partner work; } \\
\text { Multiple learning opportunities Directions clear; Kid friendly, easy } \\
\text { to access, gets to the point; Visually appealing; Conceptual } \\
\text { development; and Samples, models. }\end{array}$ \\
\hline
\end{tabular}




\section{Summary of FOCUS Cluster Construct Correlations of All Participants (continued)}

\begin{tabular}{|c|c|c|}
\hline 007 & $\begin{array}{c}97.5 \\
95 \\
92.5 \\
90 \\
87.5\end{array}$ & $\begin{array}{l}\text { Least adjustments and changes/Adjust it and make changes \& } \\
\text { Static/More than one answer } \\
\text { Least adjustments and changes/Adjust it and make changes \& Less } \\
\text { animation/Animation; Less animation/Animation \& No } \\
\text { prompting/Easier to understand, prompts } \\
\text { Not area and volume relationships/Area and volume relationships \& } \\
\text { Verbose/Not verbose; No prompting/Easier to understand, prompts } \\
\text { \& Provides everything for you/Makes you think harder } \\
\text { Static/More than one answer \& No variation/Variation, choices; No } \\
\text { variation/Variation, choices \& Not 3D/3D } \\
\text { Not area and volume relationships/Area and volume relationships \& } \\
\text { Not 3D/3D; Concrete/Visual \& Provides everything for you/Makes } \\
\text { you think harder } \\
\text { Summary: Adjust it and make changes; More than one answer; } \\
\text { Animation; Easier to understand, prompts; Area \& volume } \\
\text { relationships; Not verbose; Makes you think harder; Variation, } \\
\text { choices; 3D; and Visual. }\end{array}$ \\
\hline 008 & $\begin{array}{c}95 \\
92.5\end{array}$ & $\begin{array}{l}\text { Information visible on one screen/Limiting factor that all of the } \\
\text { information isn't on one screen \& Immediate feedback/No } \\
\text { immediate feedback; } \\
\text { No sound effects/Sound effects \& No demo/See an example demo } \\
\text { before trying; Addresses the concept more effectively, text and } \\
\text { visual model correlate/Questions not well designed, concept not } \\
\text { unpacked enough } \\
\text { No demo/See an example demo before trying \& Focus on illustrating } \\
\text { conceptual and then stops/Illustrates conceptual and leads you } \\
\text { through problems solving; Not dynamic/Dynamic \& Can't make } \\
\text { predictions or check, practice/Make predictions, check, practice } \\
\text { Not spatial thinking/Spatial thinking \& Not dynamic/Dynamic; Not } \\
\text { motivating/Motivating \& No interaction/Interaction, students and } \\
\text { teachers } \\
\text { Script is there, teachers clarify and answer questions/Teachers need to } \\
\text { describe a script \& Addresses the concept more effectively, text and } \\
\text { visual model correlate/Questions not well designed, concept not } \\
\text { unpacked enough } \\
\text { Summary: Information is visible on one screen; Immediate feedback; } \\
\text { Sound effects; See an example, demo before trying; Addresses the } \\
\text { concept more effectively, text and visual correlate; Illustrates } \\
\text { conceptual and leads you through problem solving; Dynamic; Make } \\
\text { predictions, check, practice; Spatial thinking; Motivating; } \\
\text { Interaction, students and teachers; and Script is there, teachers } \\
\text { clarify and answer questions. }\end{array}$ \\
\hline
\end{tabular}


APPENDIX E

\section{CATEGORIES OF CONSTRUCTS OR LEARNING OBJECT CHACTERISTICS}


THINKING \& LEARNING

\begin{tabular}{|l|c|c|c|c|c|}
\hline Emergent Pole & $\begin{array}{c}\text { In terms of } \\
\text { specific } \\
\text { sudents in } \\
\text { your class }\end{array}$ & $\begin{array}{c}\text { In terms of } \\
\text { student } \\
\text { groupings in } \\
\text { your } \\
\text { classroom }\end{array}$ & $\begin{array}{c}\text { In terms of } \\
\text { your } \\
\text { instructional } \\
\text { purpose }\end{array}$ & $\begin{array}{c}\text { Mean of } \\
\text { Constructs } \\
\text { across } \\
\text { purposes }\end{array}$ & Implicit Pole \\
\hline
\end{tabular}

Thinking \& Learning: Conceptual

\begin{tabular}{|c|c|c|c|c|c|}
\hline Constructs & $\mathbf{S}$ & Ss & $\mathbf{T}$ & Mean & Constructs \\
\hline $\begin{array}{l}\text { Addresses concept more } \\
\text { effectively }\end{array}$ & 5 & 5 & 5 & 5.00 & $\begin{array}{l}\text { Questions not well } \\
\text { designed; concept not } \\
\text { unpacked enough }\end{array}$ \\
\hline Conceptual development & 5 & 5 & 5 & 5.00 & No conceptual development \\
\hline Conceptual development & 5 & 5 & 5 & 5.00 & Not conceptual \\
\hline $\begin{array}{l}\text { *Dynamic; building } \\
\text { conceptual knowledge }\end{array}$ & 5 & 5 & 5 & 5.00 & Static; rote learning \\
\hline $\begin{array}{c}\text { Illustrates concept \& leads } \\
\text { you through sequential } \\
\text { problem solving process; } \\
\text { sequential routine }\end{array}$ & 5 & 5 & 5 & 5.00 & $\begin{array}{l}\text { Not sequential problem } \\
\text { solving process }\end{array}$ \\
\hline $\begin{array}{l}\text { Potential for interpreting } \\
\text { numbers \& concept is } \\
\text { higher because of the } \\
\text { dynamic nature; make } \\
\text { predictions \& check; } \\
\text { practicing }\end{array}$ & 5 & 5 & 5 & 5.00 & Can't \\
\hline $\begin{array}{c}\text { Visually enhanced; } \\
\text { conceptual understanding }\end{array}$ & 5 & 4 & 5 & 4.67 & $\begin{array}{l}\text { Visuals didn't lend to } \\
\text { further understanding }\end{array}$ \\
\hline $\begin{array}{l}\text { Not like pen \& paper; tech } \\
\text { enhances concepts, concrete }\end{array}$ & 5 & 3 & 5 & 4.33 & $\begin{array}{l}\text { Paper \& pencil; no need for } \\
\text { tech }\end{array}$ \\
\hline $\begin{array}{c}\text { Conceptual; explain } \\
\text { visually why }\end{array}$ & 5 & 4 & 1 & 3.33 & $\begin{array}{l}\text { Not conceptual; doesn't } \\
\text { visualize why }\end{array}$ \\
\hline $\begin{array}{c}\text { Visual of concept is high } \\
\text { interest subject \& } \\
\text { interesting }\end{array}$ & 5 & 5 & 5 & 5.00 & $\begin{array}{c}\text { Visual of concept not high } \\
\text { interest subject or } \\
\text { interesting }\end{array}$ \\
\hline Visualize & 5 & 5 & 5 & 5.00 & Not visualize \\
\hline Spatial thinking & 5 & 5 & 5 & 5.00 & Not spatial thinking \\
\hline Visual & 4 & 4 & 4 & 4.00 & Concrete \\
\hline Concrete & 5 & 5 & 5 & 5.00 & Abstract \\
\hline Mean of Constructs & 4.93 & 4.64 & 4.64 & 4.74 & Ind. Student, Gps, Instr. \\
\hline
\end{tabular}


Thinking \& Learning: Creative Thinking, Problem Solving, \& Discovery Learning

\begin{tabular}{|c|c|c|c|c|c|}
\hline Constructs & S & Ss & T & Mean & Constructs \\
\hline More creative & 5 & 5 & 5 & 5.00 & Less creative \\
\hline Thinking outside the box & 5 & 5 & 5 & 5.00 & $\begin{array}{c}\text { Not thinking outside the } \\
\text { box }\end{array}$ \\
\hline $\begin{array}{c}\text { Analytical thinking \& } \\
\text { problem solving }\end{array}$ & 5 & 5 & 5 & 5.00 & $\begin{array}{c}\text { Don't have to think ahead } \\
\text { of time }\end{array}$ \\
\hline Think more deeply & 5 & 5 & 5 & 5.00 & Not thinking more deeply \\
\hline Makes you think harder & 5 & 5 & 5 & 5.00 & Provides everything for you \\
\hline Think logically & 5 & 5 & 5 & 5.00 & Not as logical \\
\hline Strategies & 5 & 5 & 5 & 5.00 & No strategies \\
\hline Challenging & 5 & 4 & 4 & 4.33 & Not challenging \\
\hline Challenging & 5 & 4 & 1 & 3.33 & Not as challenging \\
\hline Contextual based & 5 & 5 & 5 & 5.00 & Not contextual based \\
\hline Discovery learning & 4 & 4 & 3 & 3.67 & Not discovery learning \\
\hline Can't help but learn & 5 & 5 & 5 & 5.00 & Not as much learning \\
\hline Mean of Constructs & $\mathbf{4 . 9 2}$ & $\mathbf{4 . 7 5}$ & $\mathbf{4 . 4 2}$ & $\mathbf{4 . 6 9}$ & Ind. Student, Gps, Instr. \\
\hline
\end{tabular}

Thinking \& Learning: Purpose - Review, Practice, \& Connections

\begin{tabular}{|c|c|c|c|c|c|}
\hline Constructs & S & Ss & T & Mean & Constructs \\
\hline More practical & 5 & 3 & 3 & 3.67 & Less practical \\
\hline Useful & 5 & 5 & 2 & 4.00 & Not as useful \\
\hline $\begin{array}{c}\text { Students responsible for } \\
\text { doing something }\end{array}$ & 5 & 4 & 4 & 4.33 & $\begin{array}{c}\text { Students not responsible for } \\
\text { doing something }\end{array}$ \\
\hline Good review of concepts & 5 & 5 & 1 & 3.67 & $\begin{array}{c}\text { Not a good review of } \\
\text { concepts }\end{array}$ \\
\hline Teach something first & 5 & 3 & 1 & 3.00 & Expect prior knowledge \\
\hline Real life connection & 5 & 3 & 5 & 4.33 & Not connections \\
\hline Algorithm & 5 & 4 & 4 & 4.33 & Not algorithm \\
\hline Fractions & 4 & 4 & 4 & 4.00 & Not fractions \\
\hline Compares to each other & 5 & 3 & 3 & 3.67 & Doesn't compare \\
\hline Compares 3 sets & 3 & 3 & 3 & 3.00 & Doesn't compare 3 sets \\
\hline Specific Purpose & 5 & 3 & 4 & 4.00 & Not a specific purpose \\
\hline Mean of Constructs & $\mathbf{4 . 7 3}$ & $\mathbf{3 . 6 4}$ & $\mathbf{3 . 0 9}$ & $\mathbf{3 . 8 2}$ & Ind. Student, Gps, Instr. \\
\hline
\end{tabular}


Thinking \& Learning: Feedback

\begin{tabular}{|c|c|c|c|c|c|}
\hline Constructs & S & Ss & T & Mean & Constructs \\
\hline $\begin{array}{c}\text { Immediate visual } \\
\text { component to access the } \\
\text { reason for the mistake; in a } \\
\text { dynamic way you can } \\
\text { access the visual model to } \\
\text { illustrate correct/ incorrect } \\
\text { answer; immediate } \\
\text { feedback }\end{array}$ & 5 & 5 & 5 & 5.00 & $\begin{array}{c}\text { No link to misconception; } \\
\text { static visual model not } \\
\text { linked and no feedback to } \\
\text { know why or even } \\
\text { prompted why; student not } \\
\text { motivated to find out reason } \\
\text { for error; no immediate } \\
\text { feedback }\end{array}$ \\
\hline $\begin{array}{c}\text { Tells you when you're } \\
\text { wrong; gives you } \\
\text { opportunity to correct it }\end{array}$ & 5 & 5 & 5 & 5.00 & $\begin{array}{c}\text { Doesn't tell you when } \\
\text { you're wrong or lets you } \\
\text { correct it }\end{array}$ \\
\hline Encouragement & 4 & 4 & 4 & 4.00 & No encouragement \\
\hline Immediate assessment & 5 & 5 & 5 & 5.00 & No immediate assessment \\
\hline Self correct & 5 & 5 & 3 & 4.33 & Not self correcting \\
\hline Mean of Constructs & $\mathbf{4 . 8 0}$ & $\mathbf{4 . 8 0}$ & $\mathbf{4 . 4 0}$ & $\mathbf{4 . 6 7}$ & Ind. Student, Gps, Instr. \\
\hline
\end{tabular}

Thinking \& Learning: Motivation

\begin{tabular}{|c|c|c|c|c|c|}
\hline Constructs & S & Ss & T & Mean & Constructs \\
\hline Motivating & 5 & 5 & 5 & 5.00 & Not motivating \\
\hline More fun & 5 & 3 & 1 & 3.00 & Less fun \\
\hline Holds attention & 5 & 5 & 5 & 5.00 & Doesn't hold attention \\
\hline Engaging & 5 & 5 & 5 & 5.00 & Not engaging \\
\hline Engaging & 5 & 5 & 5 & 5.00 & Not engaging \\
\hline Mean of Constructs & $\mathbf{5 . 0 0}$ & $\mathbf{4 . 6 0}$ & $\mathbf{4 . 2 0}$ & $\mathbf{4 . 6 0}$ & Ind. Student, Gps, Instr. \\
\hline
\end{tabular}




\section{LEARNING OBJECT DESIGN}

Learning Object Design: Appropriate for Use

\begin{tabular}{|c|c|c|c|c|c|}
\hline Constructs & S & Ss & T & Mean & Constructs \\
\hline $\begin{array}{c}\text { *Visually enhanced; } \\
\text { conceptual understanding }\end{array}$ & 5 & 4 & 5 & 4.67 & $\begin{array}{c}\text { Visuals didn't lend to } \\
\text { further understanding }\end{array}$ \\
\hline $\begin{array}{c}\text { *Not like pen \& paper; tech } \\
\text { enhances concepts, concrete }\end{array}$ & 5 & 3 & 5 & 4.33 & $\begin{array}{c}\text { Paper \& pencil; no need for } \\
\text { tech }\end{array}$ \\
\hline $\begin{array}{c}\text { *Appropriateness for } \\
\text { computer }\end{array}$ & 5 & 5 & 5 & 5.00 & $\begin{array}{c}\text { Not as appropriate for } \\
\text { computer }\end{array}$ \\
\hline Mean of Constructs & $\mathbf{5 . 0 0}$ & $\mathbf{4 . 0 0}$ & $\mathbf{5 . 0 0}$ & $\mathbf{4 . 6 7}$ & Ind. Student, Gps, Instr. \\
\hline
\end{tabular}

\section{Learning Object Design: Accessing Content - Kid Friendly, Readability}

\begin{tabular}{|c|c|c|c|c|c|}
\hline Constructs & S & Ss & T & Mean & Constructs \\
\hline Kid friendly; user friendly & 5 & 5 & 1 & 3.67 & Not kid friendly \\
\hline User friendly & 5 & 4 & 4 & 4.33 & Not user friendly \\
\hline $\begin{array}{c}\text { Easy access; gets to the } \\
\text { point; kid friendly }\end{array}$ & 4 & 4 & 4 & 4.00 & $\begin{array}{c}\text { Not easy to access or kid } \\
\text { friendly }\end{array}$ \\
\hline Easily accessible & 5 & 5 & 5 & 5.00 & Not as accessible \\
\hline Easy to access instructions & 5 & 5 & 5 & 5.00 & Less easy to access \\
\hline Good instructions & 5 & 5 & 5 & 5.00 & Not as good instructions \\
\hline Directions clear & 5 & 5 & 5 & 5.00 & Unclear \\
\hline Simple to understand & 5 & 5 & 5 & 5.00 & Not as simple to understand \\
\hline Easier to understand & 4 & 4 & 4 & 4.00 & Harder to understand \\
\hline $\begin{array}{c}\text { Script is there; teachers just } \\
\text { need to clarify \& answer }\end{array}$ & 4 & 4 & 4 & 4.00 & $\begin{array}{c}\text { Teachers need to design a } \\
\text { questions }\end{array}$ \\
\hline Straight forward & 4 & 5 & 5 & 4.67 & Not as straight forward \\
\hline Straight forward & 5 & 3 & 1 & 3.00 & Assumes a lot \\
\hline Visual guidance & 5 & 5 & 5 & 5.00 & Less visual guidance \\
\hline Prompts & 3 & 3 & 3 & 3.00 & Doesn't prompt \\
\hline Lessons explains & 3 & 2 & 2 & 2.33 & Lessons not explained \\
\hline Samples; modeling & 5 & 5 & 5 & 5.00 & No samples, modeling \\
\hline $\begin{array}{c}\text { See an example demo } \\
\text { before trying }\end{array}$ & 3 & 3 & 3 & 3.00 & No demo \\
\hline
\end{tabular}


Learning Object Design: Accessing Content - Kid Friendly, Readability (Continued)

\begin{tabular}{|c|c|c|c|c|c|}
\hline Constructs & S & Ss & T & Mean & Constructs \\
\hline More concrete & 5 & 5 & 5 & 5.00 & Too much writing \\
\hline Just right reading & 5 & 5 & 5 & 5.00 & Too much reading \\
\hline Not verbose & 5 & 5 & 5 & 5.00 & Verbose \\
\hline Reading doesn't hinder & 5 & 3 & 1 & 3.00 & Reading hinders \\
\hline Organized effectively & 5 & 5 & 5 & 5.00 & Not organized as effectively \\
\hline $\begin{array}{c}\text { Organized; no scrolling; } \\
\text { self-contained }\end{array}$ & 5 & 5 & 5 & 5.00 & Scrolling; not self-contained \\
\hline $\begin{array}{c}\text { Information is visible on } \\
\text { one screen }\end{array}$ & 5 & 5 & 5 & 5.00 & $\begin{array}{c}\text { Limiting factors not all of } \\
\text { the info. is visible on one } \\
\text { screen }\end{array}$ \\
\hline $\begin{array}{c}\text { Mean of Constructs } \\
\text { Outlier to Constructs of Kid Friendly and Readability }\end{array}$ \\
\hline $\begin{array}{c}\text { Don't have to have prior } \\
\text { understanding }\end{array}$ & 1 & 1 & 1 & 1.00 & $\begin{array}{c}\text { Have to have prior } \\
\text { understanding }\end{array}$ \\
\hline Mean of Constructs & $\mathbf{4 . 4 4}$ & $\mathbf{4 . 2 4}$ & $\mathbf{3 . 9 2}$ & $\mathbf{4 . 2 0}$ & Ind. Student, Gps, Instr. \\
\hline
\end{tabular}

Learning Object Design: Dynamic/Interactive

\begin{tabular}{|c|c|c|c|c|c|}
\hline Constructs & S & Ss & T & Mean & Constructs \\
\hline Dynamic & 5 & 5 & 5 & 5.00 & Not dynamic \\
\hline $\begin{array}{c}\text { *Dynamic; building } \\
\text { conceptual knowledge }\end{array}$ & 5 & 5 & 5 & 5.00 & Static; rote learning \\
\hline Interactive & 5 & 3 & 3 & 3.67 & Less interactive \\
\hline Interactive & 5 & 5 & 5 & 5.00 & Less interactive \\
\hline Interactive & 5 & 4 & 1 & 3.33 & Not interactive \\
\hline Interacting; in control & 5 & 4 & 4 & 4.33 & Note taking; not in control \\
\hline Explore the concept & 5 & 5 & 5 & 5.00 & Can't explore the concept \\
\hline Hands-on practice & 5 & 3 & 1 & 3.00 & Learning how to but not \\
\hline Kinesthetic & 5 & 5 & 1 & 3.67 & Observation \\
\hline Manipulate & 2 & 2 & 4 & 2.67 & Don't manipulate \\
\hline $\begin{array}{c}\text { Movement; clicking \& } \\
\text { dragging }\end{array}$ & 5 & 3 & 3 & 3.67 & No movement \\
\hline Building shapes & 5 & 5 & 5 & 5.00 & No building shapes \\
\hline Making into parts & 5 & 5 & 5 & 5.00 & Not making into parts \\
\hline Construction & 5 & 5 & 5 & 5.00 & Not construction \\
\hline Animation & 5 & 5 & 5 & 5.00 & Less animation \\
\hline Mean of Constructs & $\mathbf{4 . 8 0}$ & $\mathbf{4 . 2 7}$ & $\mathbf{3 . 8 0}$ & $\mathbf{4 . 2 9}$ & Ind. Student, Gps, Instr. \\
\hline
\end{tabular}


Learning Object Design: Color

\begin{tabular}{|c|c|c|c|c|c|}
\hline Constructs & S & Ss & T & Mean & Constructs \\
\hline Color & 5 & 5 & 5 & 5.00 & Not as colorful \\
\hline More colorful & 5 & 5 & 5 & 5.00 & Less colorful \\
\hline Color coded & 5 & 3 & 3 & 3.67 & Not color coded \\
\hline Color doesn't confuse & 5 & 3 & 3 & 3.67 & Color confuses \\
\hline $\begin{array}{c}\text { Colors help distinguish part } \\
\text { of a whole; identify part of } \\
\text { visual model }\end{array}$ & 5 & 5 & 4 & 4.67 & $\begin{array}{c}\text { Doesn't have colors to help } \\
\text { distinguish or identify part } \\
\text { of visual model }\end{array}$ \\
\hline Mean of Constructs & $\mathbf{5 . 0 0}$ & $\mathbf{4 . 2 0}$ & $\mathbf{4 . 0 0}$ & $\mathbf{4 . 4 0}$ & Ind. Student, Gps, Instr. \\
\hline
\end{tabular}

Learning Object Design: Graphics

\begin{tabular}{|c|c|c|c|c|c|}
\hline Constructs & S & Ss & T & Mean & Constructs \\
\hline $\begin{array}{c}\text { *Visually enhanced; } \\
\text { conceptual understanding }\end{array}$ & 5 & 4 & 5 & 4.67 & $\begin{array}{c}\text { Visuals didn't lend to } \\
\text { further understanding }\end{array}$ \\
\hline Graphics & 4 & 3 & 3 & 3.33 & No graphics \\
\hline Mean of Constructs & $\mathbf{4 . 5 0}$ & $\mathbf{3 . 5 0}$ & $\mathbf{4 . 0 0}$ & $\mathbf{4 . 0 0}$ & Ind. Student, Gps, Instr. \\
\hline
\end{tabular}

Learning Object Design: 3 Dimensional, Model, Situation

\begin{tabular}{|c|c|c|c|c|c|}
\hline Constructs & S & Ss & T & Mean & Constructs \\
\hline 3D & 5 & 5 & 5 & 5.00 & Not 3D \\
\hline 3D visual & 5 & 5 & 5 & 5.00 & Not 3D visual \\
\hline 3D & 3 & 4 & 2 & 3.00 & Not 3D \\
\hline 3D & 3 & 3 & 3 & 3.00 & Not 3D \\
\hline 3D & 3 & 3 & 3 & 3.00 & Not 3D \\
\hline Different perspective & 5 & 5 & 5 & 5.00 & One view \\
\hline Model & 3 & 3 & 4 & 3.33 & Not model \\
\hline Situations & 3 & 2 & 2 & 2.33 & Model \\
\hline Grid & 2 & 2 & 2 & 2.00 & Model \\
\hline Mean of Constructs & $\mathbf{3 . 5 6}$ & $\mathbf{3 . 5 6}$ & $\mathbf{3 . 4 4}$ & $\mathbf{3 . 5 2}$ & Ind. Student, Gps, Instr. \\
\hline
\end{tabular}


Learning Object Design: Options - Number of Participants

\begin{tabular}{|c|c|c|c|c|c|}
\hline Constructs & S & Ss & T & Mean & Constructs \\
\hline More independently & 5 & 3 & 1 & 3.00 & Teacher tool \\
\hline More than one person & 1 & 5 & 1 & 2.33 & One person \\
\hline Lends itself to partner work & 3 & 3 & 3 & 3.00 & $\begin{array}{c}\text { Doesn't lend itself to } \\
\text { partner work }\end{array}$ \\
\hline 2 students more beneficial & 1 & 5 & 1 & 2.33 & Not as beneficial \\
\hline Mean of Constructs & $\mathbf{2 . 5 0}$ & $\mathbf{4 . 0 0}$ & $\mathbf{1 . 5 0}$ & $\mathbf{2 . 6 7}$ & Ind. Student, Gps, Instr. \\
\hline
\end{tabular}

Learning Object Design: Options - Format

\begin{tabular}{|c|c|c|c|c|c|}
\hline Constructs & S & Ss & T & Mean & Constructs \\
\hline Interaction Ss to Ss; Ss to T & 5 & 5 & 3 & 4.33 & No interaction \\
\hline Game & 1 & 5 & 1 & 2.33 & Not a game \\
\hline Game & 3 & 3 & 3 & 3.00 & Not a game \\
\hline Game format & 3 & 3 & 5 & 3.67 & Not game format \\
\hline Mean of Constructs & $\mathbf{3 . 0 0}$ & $\mathbf{4 . 0 0}$ & $\mathbf{3 . 0 0}$ & $\mathbf{3 . 3 3}$ & Ind. Student, Gps, Instr. \\
\hline
\end{tabular}

\section{Learning Object Design: Options - Variation}

\begin{tabular}{|c|c|c|c|c|c|}
\hline Constructs & S & Ss & T & Mean & Constructs \\
\hline More activities & 5 & 3 & 1 & 3.00 & Less activities \\
\hline Lots of options & 3 & 1 & 2 & 2.00 & Less options \\
\hline Variation; choices & 3 & 3 & 3 & 3.00 & No variation \\
\hline $\begin{array}{c}\text { Multiple learning } \\
\text { opportunities }\end{array}$ & 4 & 4 & 4 & 4.00 & $\begin{array}{c}\text { Not multiple learning } \\
\text { opportunities }\end{array}$ \\
\hline Multiple ways & 5 & 5 & 5 & 5.00 & One way \\
\hline Repetition & 4 & 3 & 2 & 3.00 & Not repetitious \\
\hline More than one solution & 3 & 3 & 3 & 3.00 & Not more than one solution \\
\hline More than one answer & 4 & 4 & 4 & 4.00 & Static \\
\hline Different levels & 4 & 2 & 3 & 3.00 & Not different levels \\
\hline Changed format & 3 & 4 & 3 & 3.33 & Not changed \\
\hline Adjust it \& make changes & 5 & 5 & 5 & 5.00 & Least adjustments \& \\
\hline Alter sizes & 2 & 2 & 4 & 2.67 & Not alter sizes \\
\hline Mean of Constructs & $\mathbf{3 . 7 5}$ & $\mathbf{3 . 2 5}$ & $\mathbf{3 . 2 5}$ & $\mathbf{3 . 4 2}$ & Ind. Student, Gps, Instr. \\
\hline
\end{tabular}


Learning Object Design: Sound

\begin{tabular}{|c|c|c|c|c|c|}
\hline Constructs & S & Ss & T & Mean & Constructs \\
\hline Sound effects & 2 & 2 & 2 & 2.00 & No sound effects \\
\hline Auditory & 5 & 3 & 1 & 3.00 & Not auditory \\
\hline Sound effects & 5 & 4 & 3 & 4.00 & No sound effects \\
\hline Sound & 4 & 3 & 2 & 3.00 & No sound \\
\hline Mean of Constructs & $\mathbf{4 . 0 0}$ & $\mathbf{3 . 0 0}$ & $\mathbf{2 . 0 0}$ & $\mathbf{3 . 0 0}$ & Ind. Student, Gps, Instr. \\
\hline
\end{tabular}

\section{Learning Object Design: Visual Appeal}

\begin{tabular}{|c|c|c|c|c|c|}
\hline Constructs & S & Ss & T & Mean & Constructs \\
\hline Visually appealing & 4 & 4 & 3 & 3.67 & Not visually appealing \\
\hline Appealing & 5 & 5 & 5 & 5.00 & Less appealing \\
\hline Mean of Constructs & $\mathbf{4 . 5 0}$ & $\mathbf{4 . 5 0}$ & $\mathbf{4 . 0 0}$ & $\mathbf{4 . 3 4}$ & Ind. Student, Gps, Instr. \\
\hline
\end{tabular}

Learning Object Design: Odds \& Ends - outliers

\begin{tabular}{|c|c|c|c|c|c|}
\hline Constructs & S & Ss & T & Mean & Constructs \\
\hline $\begin{array}{c}\text { Teacher page [use for } \\
\text { instruction] }\end{array}$ & 1 & 1 & 4 & 2.00 & $\begin{array}{c}\text { Not teacher page [not use } \\
\text { for instruction] }\end{array}$ \\
\hline Multicultural & 4 & 2 & 2 & 2.67 & Not multicultural \\
\hline Mean of Constructs & $\mathbf{2 . 5 0}$ & $\mathbf{1 . 5 0}$ & $\mathbf{3 . 0 0}$ & $\mathbf{2 . 3 4}$ & Ind. Student, Gps, Instr. \\
\hline
\end{tabular}


APPENDIX F

LEARNING OBJECT PROFILE/CHECKLIST 


\section{Technology Enhances Concepts}

Conceptual Development

○ Visualize Concepts

- Concrete

o Spatial Thinking

- Accurate Content
2

Thinking/Problem Solving

o Think Deeply

- Problem Solving

- Challenging

- More than one solution
Purpose
Feedback
- Review
Immediate
Motivation
- Practice
- Able to Correct
Engaging
- High Interest
- Scaffold
- Encourages
o Fun

\section{Accessing Content \\ - Kid Friendly \\ - Easy to read instructions \\ - Straight forward \\ - Just right reading \\ - Organized effectively \\ - Visible on One Screen \\ - Demo or Sample}

\begin{tabular}{llll}
\multicolumn{1}{c}{ Groupings } & & \multicolumn{2}{c}{ Student Needs } \\
Individual & & $\circ$ ELL \\
$\circ$ Partner & & $\circ$ Low \\
$\circ$ Group & & $\circ$ High \\
$\circ$ Center & &
\end{tabular}

\section{Dynamic/Interactive}

- Dynamic interaction

- Interactive builds concept

- Hands-on practice

- Animated

\section{Color}

- Colorful

- Distinguish parts

- Helps visualize
Sound

- Sound effects

- Directions

o Prompting

\section{Options}

- Game

- Participants

- Lots of Activities

- Lots of Choices

- Different Levels

- Adjustable

\section{Student Needs}

Low

(1)

\begin{tabular}{ll} 
Subject \\
\hline H-SS \\
$\circ$ & LA \\
$\circ$ & Math \\
O & Science
\end{tabular}

Resource URL:

- Downloadable

- Reusable

- Online Only

Topic: 